\title{
A spatial analysis of the role of entrepreneurship in the economic development in Northeast region of the United States
}

\author{
Saima Bashir \\ West Virginia University
}

Follow this and additional works at: https://researchrepository.wvu.edu/etd

\section{Recommended Citation}

Bashir, Saima, "A spatial analysis of the role of entrepreneurship in the economic development in Northeast region of the United States" (2011). Graduate Theses, Dissertations, and Problem Reports. 4688.

https://researchrepository.wvu.edu/etd/4688

This Dissertation is protected by copyright and/or related rights. It has been brought to you by the The Research Repository @ WVU with permission from the rights-holder(s). You are free to use this Dissertation in any way that is permitted by the copyright and related rights legislation that applies to your use. For other uses you must obtain permission from the rights-holder(s) directly, unless additional rights are indicated by a Creative Commons license in the record and/ or on the work itself. This Dissertation has been accepted for inclusion in WVU Graduate Theses, Dissertations, and Problem Reports collection by an authorized administrator of The Research Repository @ WVU.

For more information, please contact researchrepository@mail.wvu.edu. 


\title{
A SPATIAL ANALYSIS OF THE ROLE OF ENTREPRENEURSHIP IN THE ECONOMIC DEVELOPMENT IN NORTHEAST REGIONOF THE UNITED STATES
}

\author{
Saima Bashir \\ Dissertation Submitted to the Davis College of Agriculture, Natural Resources and Design \\ at West Virginia University \\ in Partial Fulfillment of the Requirements \\ for the Degree of \\ Doctor of Philosophy \\ in \\ Natural Resource Economics
}

Tesfa Gebremedhin, Ph.D., Chair

Peter Schaeffer, Ph.D.

Donald Lacombe, Ph.D.

Dale Colyer, Ph.D.

Michael Dougherty, Ph.D.

Agricultural and Resource Economics Program

Division of Resource Management

West Virginia University

Morgantown, West Virginia

2011

Keywords: Entrepreneurship, Spatial Analysis, Economic Development, Northeast 


\begin{abstract}
A Spatial Analysis of the Role of Entrepreneurship in the Economic Development in the Northeast Region of the United States
\end{abstract}

\title{
Saima Bashir
}

Increasing population and very modest economic growth are major concerns in regional economic development. There have been many fluctuations and inconsistencies in regional economic growth since the Second World War. Policy makers started to pay attention to the possibility of increasing entrepreneurial activities in the Northeast region after realizing that manufacturing firms alone cannot meet the employment needs of local residents. The United States has focused on providing more support to entrepreneurs to have a competitive economy. Entrepreneurship is important for economic activities such as employed resources, labor and capital goods pricing, organizing production, and marketing goods. This study develops relationships among population density, employment, per capita income, and new firm formation and self-employment as measures of entrepreneurship, assuming that these variables can be determined jointly.

The main objective of the study is to identify and estimate the impacts of entrepreneurship in the economic development of the Northeast region. A theoretical model is developed using endogenous growth theory. This model's emphasis is on the role of entrepreneurship in economic growth. In a theoretical conclusion the relationship between entrepreneurship and economic growth can be seen in two ways: entrepreneurial effect and production effect. At a social optimum, the entrepreneurial effect is stronger than the production effect and shows an increase in economic growth as entrepreneurship increases. For empirical analysis, two methods are used: non-spatial model and spatial model. The non-spatial model of this study is derived from the three-equation simultaneous model of Deller et al. (2001). The spatial model is derived from a Spatial Durbin Model with four equations. The study used the non-spatial simultaneous equations model to estimate the relationship using Three-Stage Least Squares (3SLS).

The empirical results of this study on the relationship between entrepreneurship and economic development are an extension that incorporates the simultaneous relationship of new firm formation and self-employment in the economic development of the region. Another contribution of this study is using the spatial Durbin model technique. New firm formation as a measure of entrepreneurship plays a significant role in the economic development of the Northeast region of the Unites States. Although, self-employment also contributes in the process of economic development, new firm formation has stronger impact on economic development than self-employment. The results of self-employment growth are weak in the empirical models. Basically, it is possible that entrepreneurship can enhance regional economic development. 


\section{Dedication}

I would like to dedicate this work to my father Bashir Ahmad, my mother Safooran BiBi, my sister Farzana Naurin, my brother-in-law Muhammad Aslam and to my cute nephews; Umar Aslam, Abdullah Muhammad Aslam, and Ahmad Dawood Aslam for their love, support, encouragement, and inspiration. 


\section{Acknowledgement}

I would like to express my sincere gratitude to my advisor Dr. Tesfa G. Gebremedhin for his guidance, encouragement, and constructive comments throughout my studies. I would like to thank him for his devotion to my success and for giving me the freedom to accomplish my research. I am lucky to have him as my major advisor. I would also like to thank my dissertation committee members, Dr. Peter V. Schaeffer, Dr. Donald Lacombe, Dr. Dale Colyer, and Dr. Michael Dougherty for their constructive comments, suggestion, and contribution of their time. I would like specially thank my friend Davina Danielle Bird for editing and reviewing my dissertation and for her comments and suggestions.

I also express my gratitude to the Division of Resource Management, Davis College of Agriculture, Natural Resource, and Design for accepting me as graduate student and providing me an opportunity to work as research assistant for the first two years of my Ph.D. studies. I also like to give thanks to the faculty, colleagues, and friends in the Division of Resource Management.

I really appreciate the administrative assistance, care, and help of Mrs. Lisa Lewis, Mrs. Melanie Jimmie, and Mrs. Ellen Hartley-Smith. I am thankful to Dr. Jerry J. Fletcher and Dr. Mark Sperow for funding me for the first two years in the Division of Resource Management, for the opportunity to work with them, and for their valuable guidance and support. I also appreciate Mrs. Jacquelyn Strager for the help in compiling the GIS data. I am also thankful to Dr. Mulugeta Kahsai for his suggestions.

I am especially thankful to my sisters Farzana Naurin and Nyla Bashir and brother Adnan Bashir. Their love, financial, and moral support enabled me to complete my graduate studies, encouraged me to successfully complete my dissertation. Above all, I am really thankful to the Almighty Allah for giving me the opportunity and strength to pursuit my studies and to face challenges during my studies. 


\section{Table of Contents}

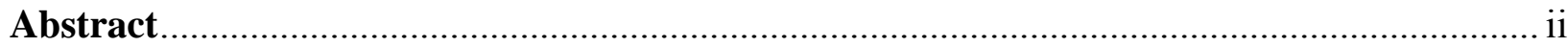

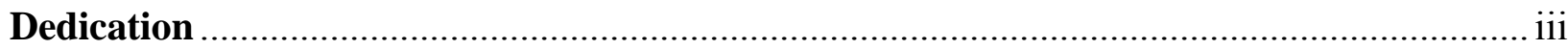

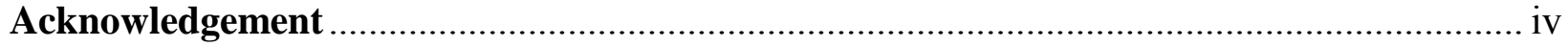

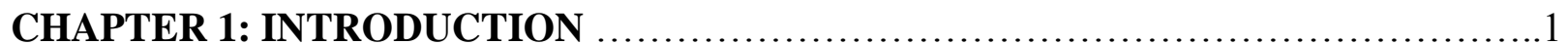

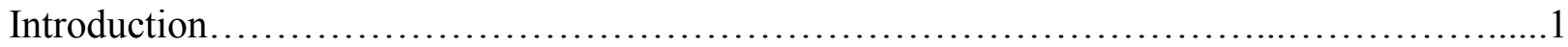

1.1. Overview of Study Area.........................................................

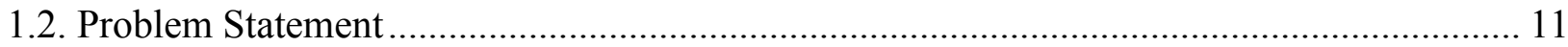

1.3. Research Motivation ....................................................................................................... 12

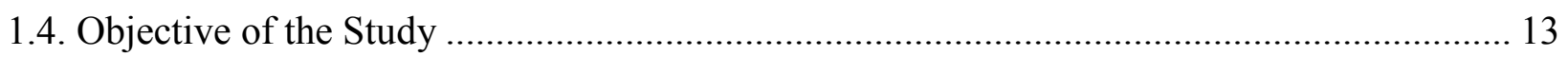

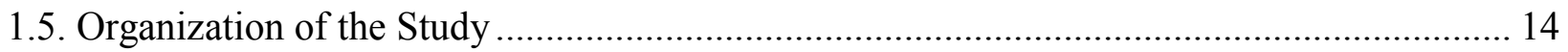

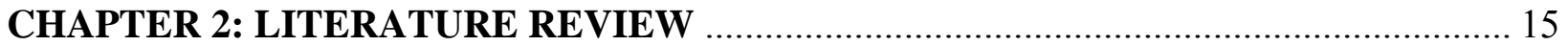

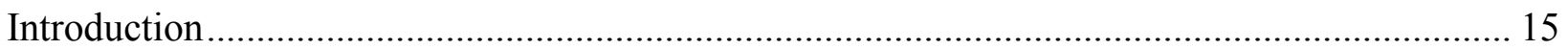

2.1. Concept and Type of Entrepreneurship ................................................................... 15

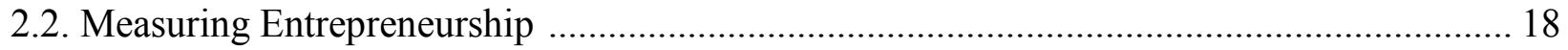

2.3. Entrepreneurship and Economic Growth................................................................ 22

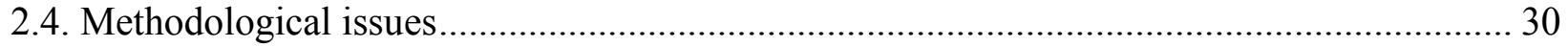

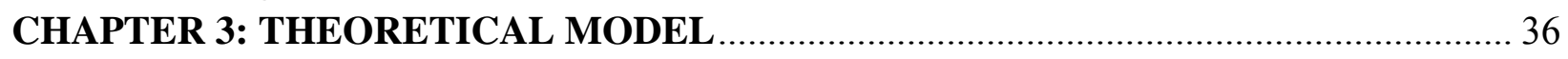

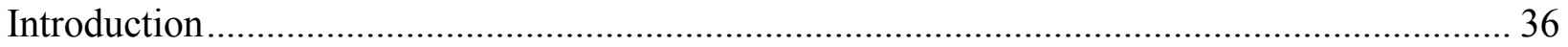

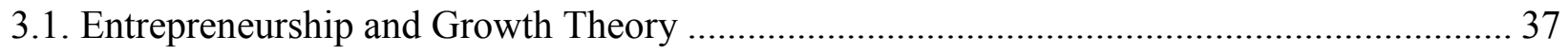

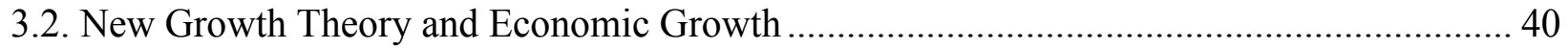

3.3. Entrepreneurship and Socially Optimum Growth..................................................... 42

CHAPTER 4: EMPIRICAL MODEL AND DATA ...................................45

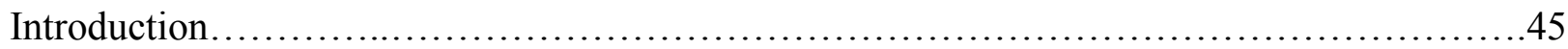

4.1. Non-Spatial Growth Model (Model 1) ............................................45

4.2. Non-Spatial Model.......................................................49

4.2.1. Population Density Growth Equation....................................49

4.2.2. Employment Growth Equation.......................................... 50

4.2.3. Per Capita Income Growth Equation...................................... 51

4.2.4. Entrepreneurship Growth Equation (Equation 1) ..........................52

4.2.5 Entrepreneurship Growth Equation (Equation 2)...........................54

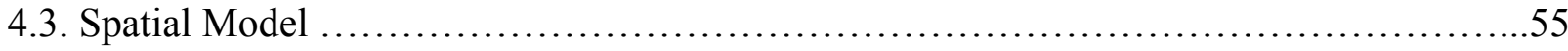

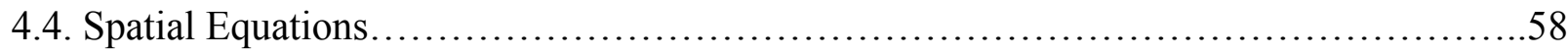

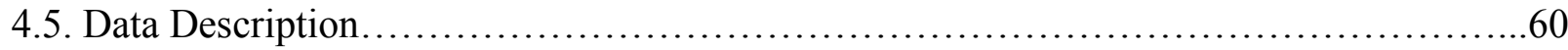

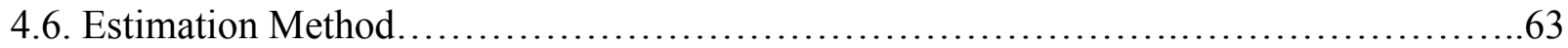

CHAPTER 5: EMPIRICAL RESULTS AND ANALYSIS ..........................66

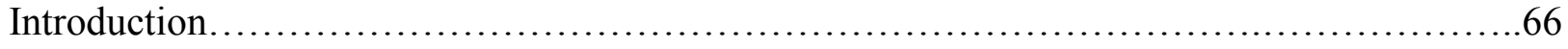

5.1 Non-spatial Growth Model Results.............................................66

The Results of Entrepreneurship Represented by New Firm Formation and its

Relationship with Economic Development....................................67 
The Results of Entrepreneurship Represented by self-employment and its Relationship with Economic Development..................................................... 75

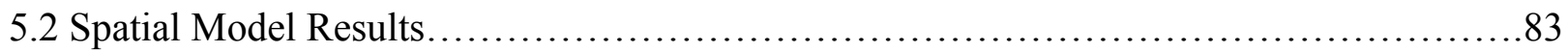

The Results of Entrepreneurship Represented by New Firm Formation and its

Relationship with Economic Development..........................................84

The Results of Entrepreneurship Represented by self-employment and its Relationship

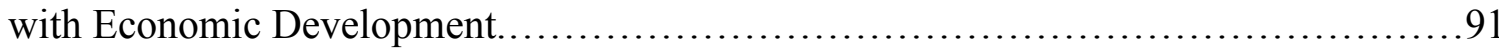

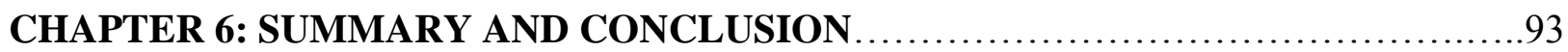

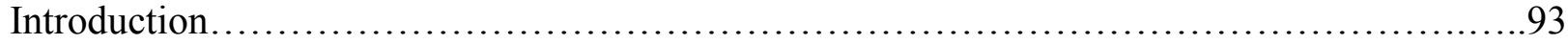

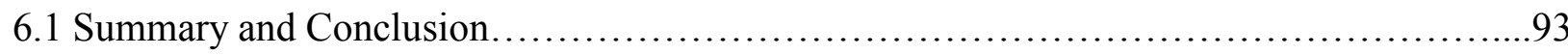

6.1.1 Non-spatial Models......................................................... 94

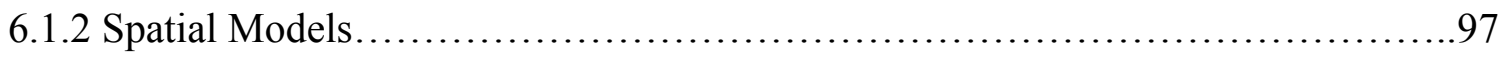

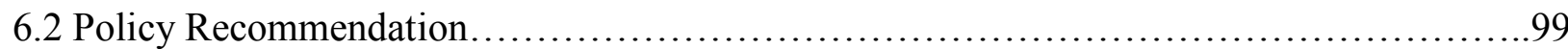

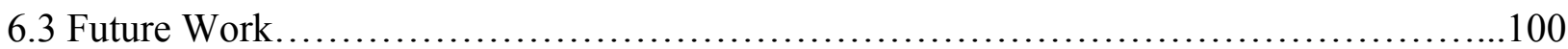

REFERENCES

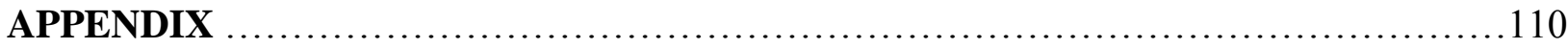




\section{List of Tables}

Table 1: Entrepreneurship in Economic development........................................ 3

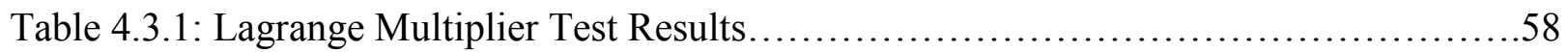

Table 4.5: Definition and Data Sources for the Endogenous and Initial Condition Variables ...61

Table 4.6.1: Definition and Data Sources for Exogenous Variables............................64

Table 4.6.2: Descriptive Statistics for the Counties of the Northeast Region 1993-2008.........65

Table 5.1.1 Three Staged Least Square Results of Growth in Population Density.................68

Table 5.1.2 Three Staged Least Square Results of Growth in employment........................70

Table 5.1.3 Three Staged Least Square Results of Growth in Per Capita Income.................72

Table 5.1.4 Three Staged Least Square Results of Growth in Entrepreneurship...................75

Table 5.1.5 Three Staged Least Square Results of Growth in Population Density.................77

Table 5.1.6 Three Staged Least Square Results of Growth in Employment.......................79

Table 5.1.7 Three Staged Least Square Results of Growth in Per Capita Income....................80

Table 5.1.8 Three Staged Least Square Results of Growth in Entrepreneurship...................82

Table 5.2 Estimated Value of Spatial Dependence Statistic, RHO ............................. 84

Table 5.2.1 The SDM Results of Growth in Population Density ............................. 85

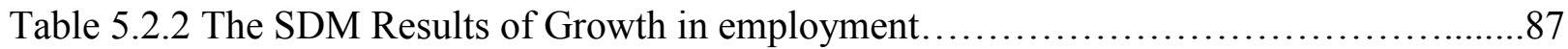

Table 5.2.3 The SDM Results of Growth in Per Capita Income..................................88

Table 5.2.4 The SDM Results of Growth in Entrepreneurship..................................90

Table 5.2.5 The SDM Results of Growth in Population Density..............................110

Table 5.2.6 The SDM Results of Growth in employment....................................111

Table 5.2.7 The SDM Results of Growth in Per Capita Income................................112

Table 5.2.8 The SDM Results of Growth in Entrepreneurship..............................91 


\section{List of Figures}

Figure 1.1: The Northeast Region (metro and non-metro counties)........................6

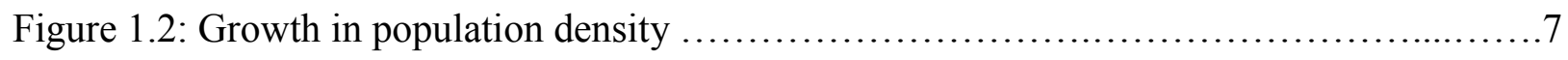

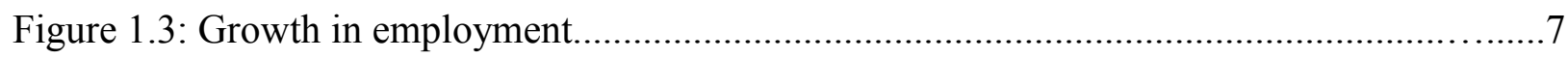

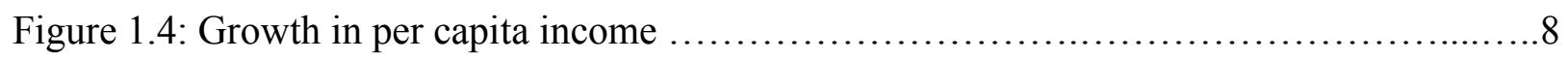

Figure 1.5: Growth in non-farm employees.......................................... 8

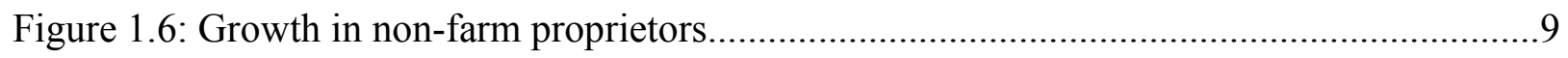

Figure 1.7: Rural population in the Northeast region................................. 


\section{CHAPTER 1: INTRODUCTION}

\section{Introduction}

A variety of transformations in development have been observed in the world over the last fifty years stemming from diverse and innovations. Although economists stressed that the theory of entrepreneurship is incompletely defined, it can be argued that many of transformations have gained momentum by broadening the understanding of entrepreneurship and economic development (Naudé, 2008).

Entrepreneurship as an economic engine is a substantial part of the economic system today. Entrepreneurs as economic agents are engaged in entrepreneurial activities in most capitalist economies. Aggregation of these activities leads to economic growth at the macro level (Minniti, 2008; Wennekers and Thurik, 1999; Shane, 2006). Entrepreneurial supply is different among countries but the main difference is whether entrepreneurship is productive or not. Entrepreneurial activities bring wealth when appropriate conditions exist and entrepreneurship itself can be shown to take different forms (Baumol, 1996).

Before we can explain the relationship between entrepreneurship and economic development, these two terms need to be defined. Schumpeter (1934) presents the entrepreneur as an agent who plays a role in the mechanism of change and economic development by creating new ideas and innovations. Kirzner (1973) argues that each firm which makes profits from its business is an entrepreneur. $\mathrm{Yu}$ (1998) stresses that Schumpeter"s entrepreneur is the creative destructor who tries to stop the economy from reaching a stagnant equilibrium, whereas Kirzner"s entrepreneur is the reason for an economy"s equilibrium.

Economic development is a process of changing the economy ${ }^{\text {ec }}$ s condition from simple and low income to modern and high income. This process assumes a population with sustained 
growth. Sometimes economic growth and economic development are used interchangeably in economic literature. Kindleberger (1965) explained that "Economic growth is an increase in output. While, economic development implies both an increase in output and changes in technical and institutional arrangements by which it is produced and distributed. Growth may involve greater efficiency."

In recent years, economists have paid special attention to see the conceptual relationship between entrepreneurship and economic development. New firms"e start-ups vitalize economic development and employment growth. Efforts for economic development at national and local levels have focused to increase entrepreneurship. Entrepreneurs play a dominant role in the growth, development and prosperity of the economy. They are a reliable source of technological innovations in production processes. Entrepreneurs form new firms and use different types of business methods. These newly established firms are important for economic activities such as employed resources, labor and capital goods pricing, organizing production, and marketing goods (Schmitz, 1989; Spulber, 2008).

Herrick and Kindleberger (1983) explained that entrepreneurs formulate the economic activities for a large group of people. Entrepreneurs, who use other inputs in the right proportion to produce, are considered to be scarce resources. This implies that as the number of entrepreneurs increase, development also increases. Jhingan (1988) mentioned Arthur Lewis"s suggestion which indicates that unemployment and income inequalities can be reduced by using unemployed labor from rural areas in urban industries. Goetz et al. (2009) explained entrepreneurship in economic development as shown in the Table 1 below: 
Table 1: Entrepreneurship in Economic Development

\begin{tabular}{|l|l|l|l|}
\hline \multicolumn{4}{|c|}{ Economic Development Base } \\
\hline Features & Factor-based & Efficiency-based & Innovation-based \\
\hline $\begin{array}{l}\text { Main organizational } \\
\text { form }\end{array}$ & $\begin{array}{l}\text { Self-employment/ } \\
\text { proprietorship }\end{array}$ & $\begin{array}{l}\text { Wage \& Salary } \\
\text { employment }\end{array}$ & $\begin{array}{l}\text { Opportunity/necessity } \\
\text { entrepreneurs }\end{array}$ \\
\hline Income level & Lower & Medium & Higher \\
\hline Dominant sector & Natural resources & Manufacturing & Services \\
\hline Sources of growth & $\begin{array}{l}\text { Abundance of } \\
\text { resources }\end{array}$ & Gap-filling/copy-cat & $\begin{array}{l}\text { New product, } \\
\text { services }\end{array}$ \\
\hline Firm size & Smaller & Medium & Larger \\
\hline
\end{tabular}

Source: Goetz et al. 2009

The importance of entrepreneurship as "the process of starting and continuing to expand new businesses" is widely recognized. Due to its importance, developed as well as developing countries are spending a considerable amount of their resources to increase the rate of entrepreneurship. Previous studies (Cabarcos and Rodríguez, 2006; Gries and Naudé, 2008; and Mojica et al., 2009) measured the rate of entrepreneurship by the rate of self-employment statistically, or the rate of start-up of firms dynamically. New firms create new jobs, promote new and flexible organizational forms, and improve the economy by providing strength to reforms. Some researchers agree that entrepreneurship is important in maintaining an economy and also necessary in initiating new business start-ups in low income areas for economic development.

New firm start-up is a vital component of economic development and one of the main indicators of entrepreneurship. It performs an important role in employment creation, innovation, economic development and unemployment reduction. Different surveys showed that the new firm formation rate varies across countries and regions. Therefore, it is important for each region to know the reasons for variations. These variations may have important implications in terms of entrepreneurship policy where it is essential to understand the way to increase new firm formation rates in regions (Choi and Phan, 2006; Venesaar, 2006). 
Entrepreneurs as self-employed individuals have positive impacts on economic growth in industrialized countries. Creative and qualified self-employed individuals contribute to economic growth by inventing new products, production processes, distribution methods, and employing other people. However, an increase in employment is uncertain because entrepreneurial skills are assumed to be risky and that self-employed workers can learn their skills gradually after starting their businesses (Jovanovic, 1982; Mandelman and Montes-Rojas, 2009; Bögenhold and Fachinger, 2009).

The growing importance of small businesses is making society reinvent entrepreneurship and innovation as one of its tools. According to Schumpeter (1934), setting up a new production function is innovation. Although Schumpeter's definition of innovation is criticized by other researchers, it helps to define innovations as an economic tool (McDaniel, 2000). According to Sweezy (1943) "Innovation is, therefore, the function of a sociological type of individual known as the entrepreneur." In this study, considerable attention will be paid to exploring the relationship between entrepreneurship and economic development. The main focus of the study is to determine the importance of entrepreneurship in economic development in the northeast region of the U.S.

The difference between this study and the existing literature can be described in two significant ways. First, this study focuses on the role of entrepreneurship in economic development by analyzing the interdependent relationships among growth in population, employment, per capita income, and entrepreneurship. Thus, the analysis is extended to a comparison between effects of entrepreneurship as new firm formation and entrepreneurship as self-employment. Using econometric techniques, the analysis discovers a system of relationships between the endogenous factors using a four-equation simultaneous regional growth model, 
derived from the Deller et al. (2001) growth model. Second, the study estimates spillover effects resulting from the spatial heterogeneity in economic incentives and entrepreneurial activities using the Spatial Durbin Model.

\subsection{Overview of Study Area}

The study area consists of 299 counties in Connecticut, Delaware, Massachusetts, Maine, Maryland, New York, New Jersey, New Hampshire, Pennsylvania, Rohde Island, Vermont, and West Virginia. United States Census 2000 data of population reveal that the Northeast region had a population of approximately 62 million which is equal to 22 percent of the U.S. population. The net change in the population between 1990 and 2000 for the Northeast region was 5.5 percent growth which is 45.8 percent of the U.S. net change of 13.2 percent. State population varies from the lowest population of approximately 60,000 in Vermont to the highest population of approximately 19 million in New York. Population change was unequal in the region due to differences in economic opportunities, infrastructure, services, etc. According to the USDAERS County Typology (2004), the region has more urban population with 55 percent of its 299 counties. In the region, 94 counties are non-metropolitan and are adjacent to a metropolitan area.

Figures 1.1 to 1.6 below describe the regional economic growth in the Northeast region of the United States for the period from 1993-2008. Figure 1.1 provides the description of metro and non-metro counties in the region. Figure 1.2 describes the spatial distribution of population in the region. This distribution shows that population growth in the region is not symmetrical. Overall increase in population in the region is 6.7 percent. Population growth in non-metro counties is 3.5 percent whereas in metro areas it is 7.0 percent. Figure 1.3 shows growth in employment in the region during 1993-2008. Employment growth declined in 25 counties, whereas it is below the average employment growth rate of the region in 81 counties. Figure 1.4 
explains growth in per capita income in the region. Figure1.5 describes growth in the number of nonfarm employees in the region which has an average growth rate of 13.7 percent. Thirty percent of the counties have employment growth of less than 10 percent and 11 percent of counties have a negative employment growth rate. Only 9 percent of counties in the region have more than 38 percent employment growth. Figure 1.6 shows growth in the number of proprietors in the region. Average growth of the number of proprietors is 63.1 percent with 44.8 percent growth in non-metro areas. However, almost 7.5 percent of counties show a decrease in the number of proprietors and 34.0 percent of counties have growth rates of less than 40.0 percent.

\section{Fig. 1.1: The Northeast region (Metro and Non-metro counties)}

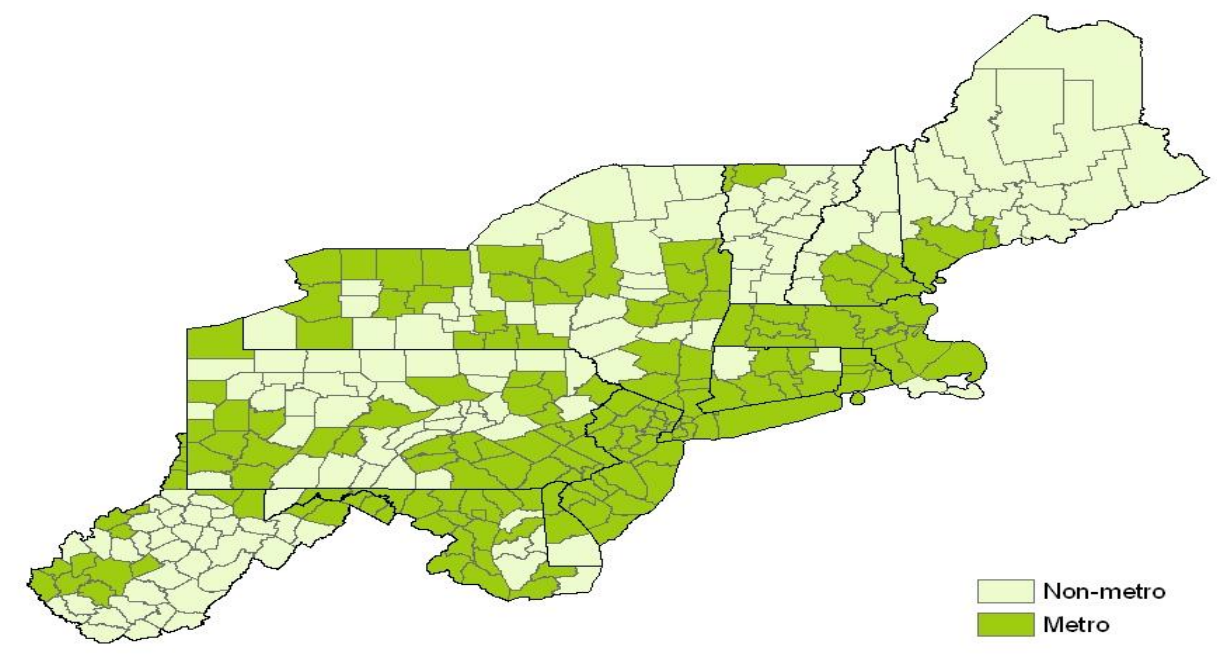

Source: USDA-ERS TOPOLOGY (2004) 
Fig. 1.2: Growth in Population Density

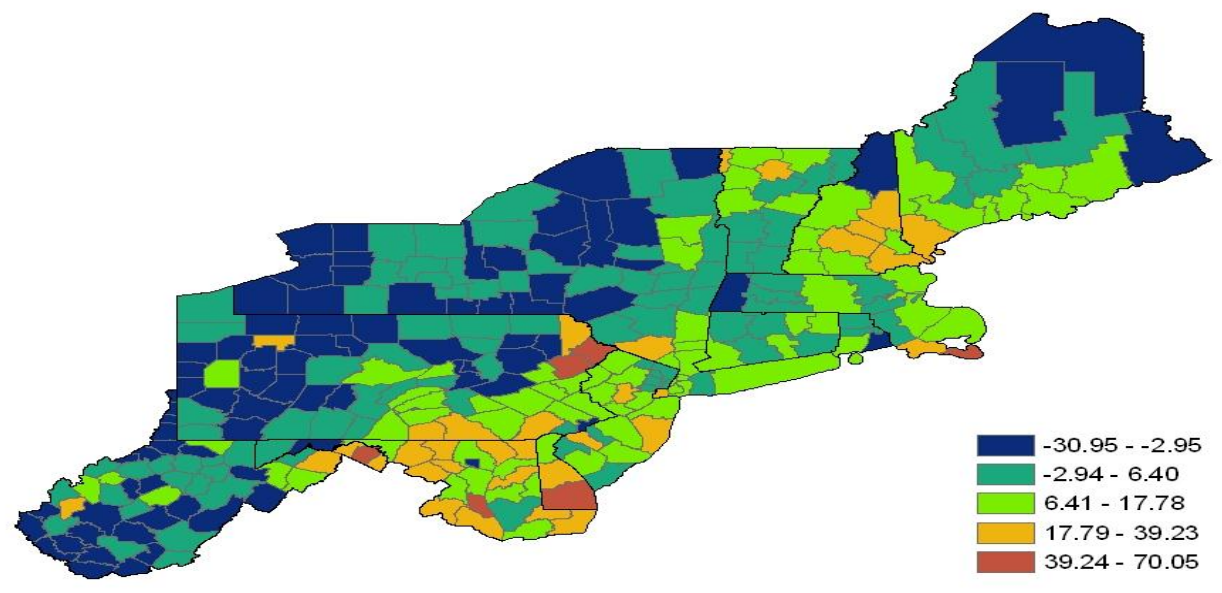

Source: US Census Bureau

Fig. 1.3: Growth in Employment

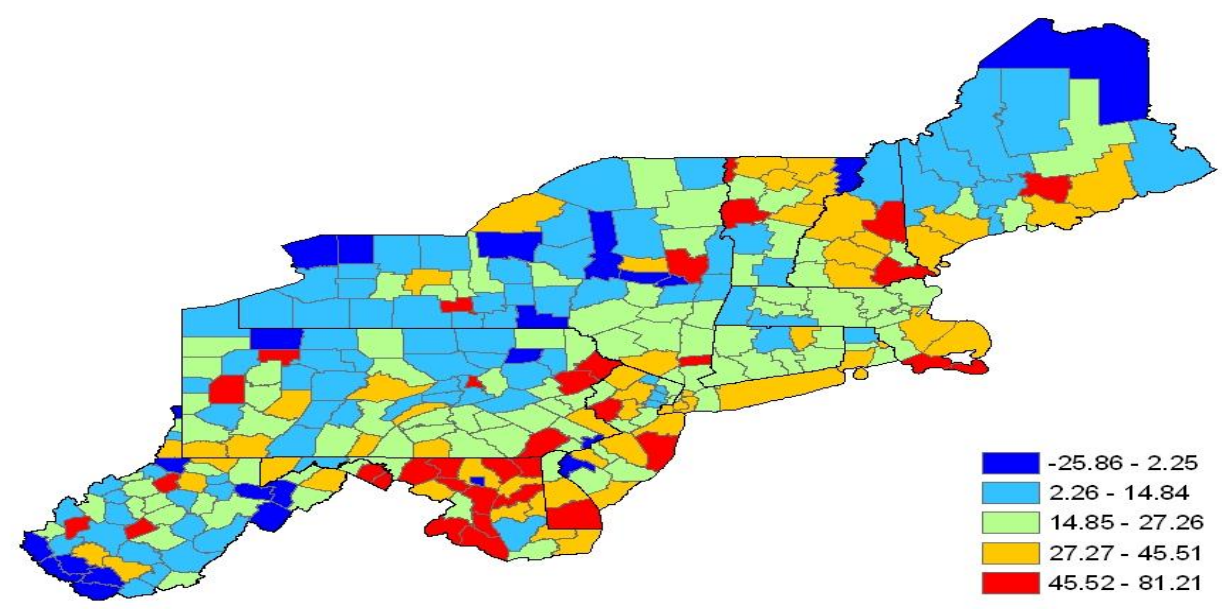

Source: US Census Bureau 
Fig. 1.4: Growth in Per Capita Income

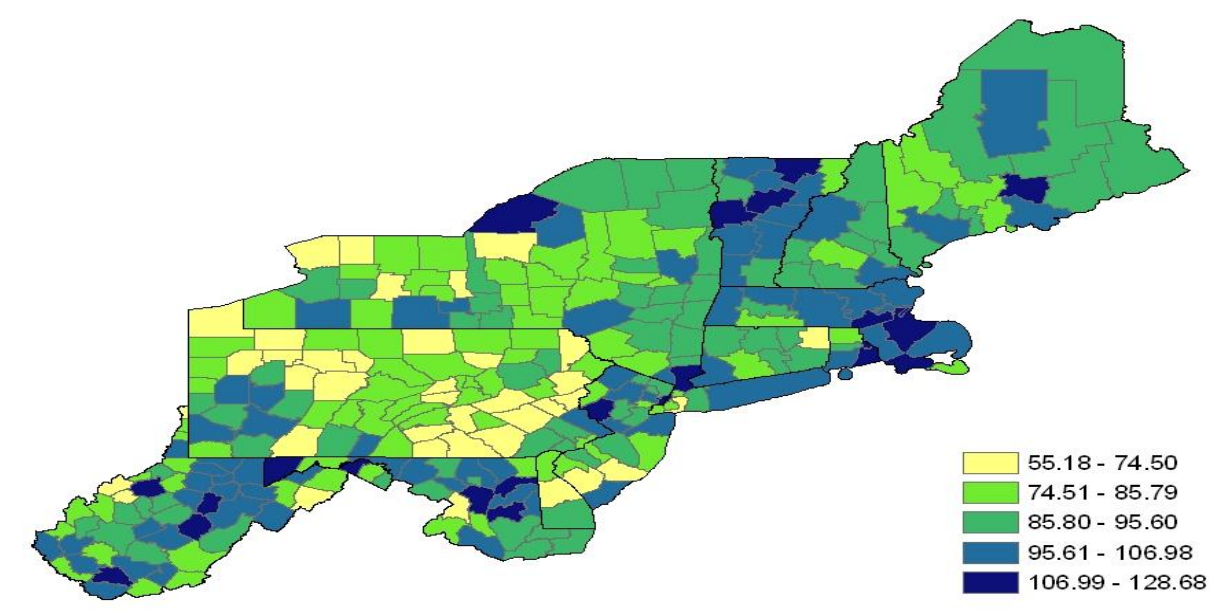

Source: US Census Bureau

Fig. 1.5: Growth in Number of Employees

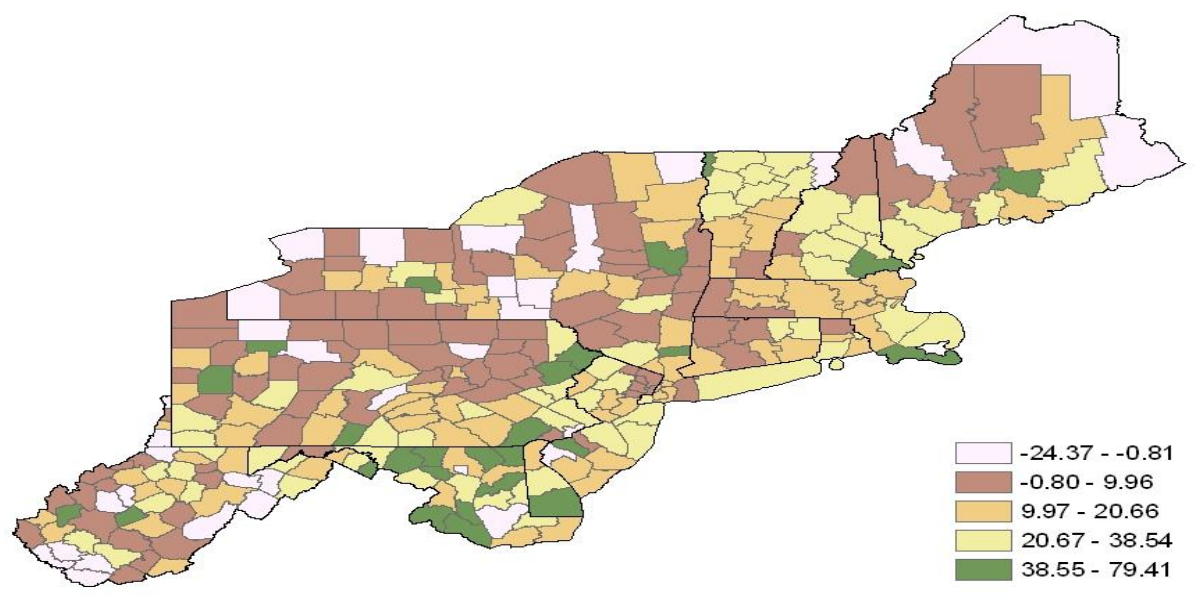

Source: US Census Bureau 


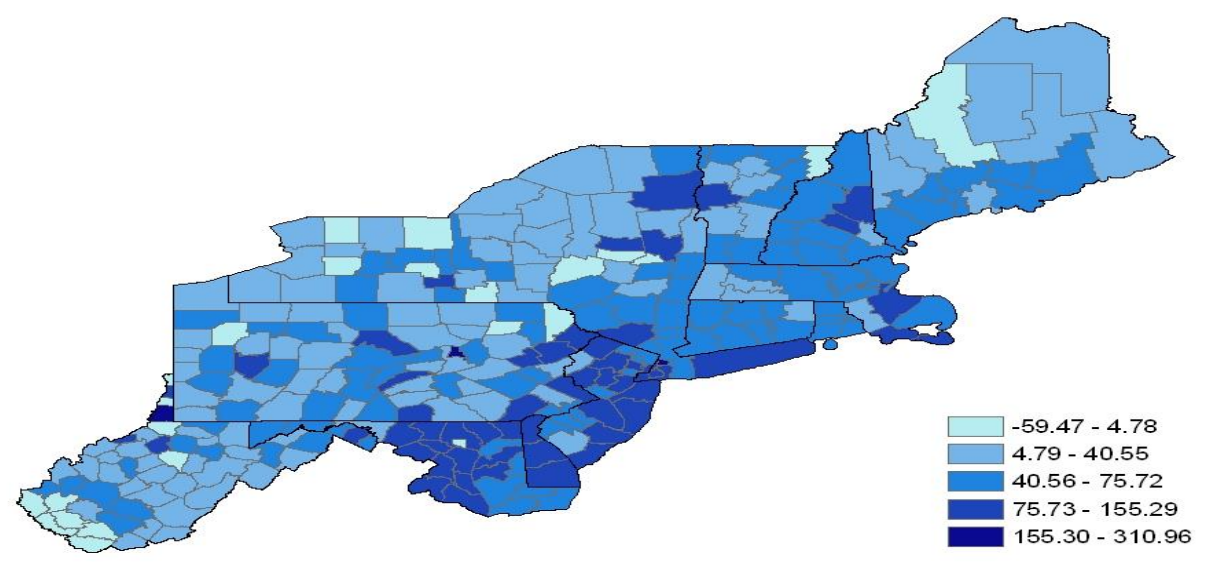

Source: US Census Bureau

According to the U.S. Census Bureau, three states in this region (Maine, Vermont, and West Virginia) have high rural populations with $40.2,61.8$, and 53.9 percent of total population of each state, respectively, as shown in the Figure 1.7. Delaware has almost 20 percent of its total population living in rural areas.

Figure1.7: Rural Population in the Northeast Region

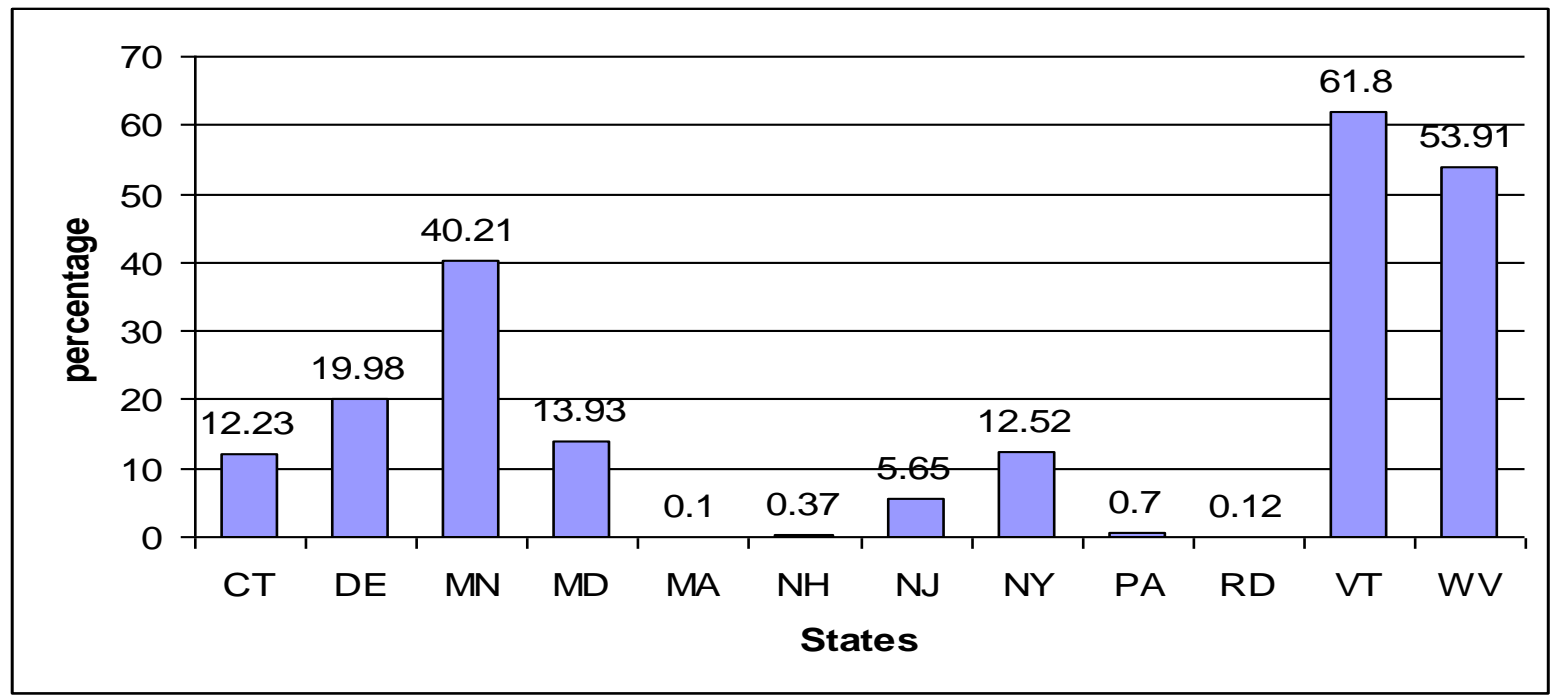

Source: U.S. Census Bureau 
Two main characteristics of northeast rural regions are low population density and an increasing gap in rural and urban population and they occur due to some serious economic development issues (Goetz, 1999). Other economic indicators that affect economic development are poverty level and unemployment rate, especially in rural areas and poor states such as Maine and West Virginia (Yang and Snyder, 2007). One of the main problems is low population density. Policy makers have noticed that rural areas failed to provide their share in the economic boom during the 1990s. Therefore, they were not able to receive the benefits of the "new economy" (Goetz, 1999). Although population had increased in most of the counties of the Northeast region from 1993 to 2008, growth in population density is very slow especially in rural areas and even negative in some counties.

The gap between rural and urban incomes is widening. Almost 7 million people living in rural areas in the region, approximately 11.6 percent of the total population, are experiencing the effects of the rural-urban income gap. Rural per capita income was 67.5 percent of the urban per capita income at the end of the 1990s, demonstrating the difficulty of attracting urban workers to rural areas (Goetz, 1999). According to the U.S. Census Bureau, median income varies among the states in the Northeast, such as median income for West Virginia in 2008 was $\$ 49,082$, while for New Jersey it was $\$ 85,761$.

Poverty levels also show large differences among states in 2008. For example, while 17.4 percent of West Virginians lived in poverty, only 7.8 percent of New Hampshirees population fell below the poverty line. Several counties in the study region, especially non-metro one, suffer from persistently high poverty rates: McDowell, Mingo, Summers, Wyoming, and Webster counties in West Virginia; Fayette, Forest, Philadelphia, and McKean counties in Pennsylvania; 
Bronx, Kings, St. Lawrence, and Tompkins counties in New York; and Somerset county in Maryland.

According to the U.S. Census Bureau and Bureau of Labor Statistics, the Northeast region has diverse urban characteristics with spatial variation in economic growth. It also has resources and opportunities to enhance entrepreneurial activities. Therefore, there is a need to determine entrepreneurial improvements for the welfare of the economy. In order to accomplish these improvements, policy makers need to introduce appropriate policies to improve the Northeastern environment for business formation for economic development. The differences in population, median income, and poverty level indicate that economic development is possible by enhancing entrepreneurship in the region.

\subsection{Problem Statement}

Policy makers dispute about the importance of new firm formation for economic development. Fritsch and Mueller (2004) and Henderson (2006) argued that as income level becomes higher, wealth increases, and this elevates markets due to jobs created by new businesses and self-employment. Job creation, a simultaneous process, is positively related with economic growth (Eamets et al., 2005). But these positive effects do not appear in the short-run (Fritsch and Mueller, 2004). One apparent augmentation of entrepreneurship to enhance the welfare of society is new jobs creation and supplementary income through a multiplier effect. Commercialization of new ideas and innovations in the market bring new wealth for entrepreneurs and regions (Cabarcos and Rodríguez, 2006; Mojica et al., 2009).

Self-employment helps to start new firms, creates jobs, promotes inventions and innovations, and ultimately brings increased well-being to society. Despite the unclear benefits of small businesses, governments provide subsidies or loans to individuals to start new small 
businesses and retain existing businesses activities. Researchers are interested in selfemployment if it can provide jobs to unemployed population and also for those who face job discrimination (Blanchflower, 2000; Parker, 2004).

Increasing population and little and/or zero progress in economic growth have created major concerns about regional economic growth. There have been many fluctuations in regional economic growth since the Second World War. Policy makers have paid particular attention to the possibility of increasing entrepreneurial activities in regions after realizing that existing manufacturing firms are not enough to meet the needs of local residents (Walzer, 1994). Over recent years, policy makers have been concerned about the role of entrepreneurship in increasing economic growth. The U.S. has focused on providing more support to entrepreneurs to have a competitive economy (Naudé, 2008).

\subsection{Research Motivation}

Identifying the most appropriate means to encourage entrepreneurship, especially in rural areas, and to enhance economic growth is a challenging task for private and public decision makers. To encourage entrepreneurship, it is essential to know about the dynamics between the needs of entrepreneurship and economic growth because some economic and demographic constraints affect entrepreneurship and economic conditions and growth of the region. Most of the rural areas in the Northeast region are facing the problem of death of firms which results from the reduction of resource extractive industries, unemployment and/or underdevelopment, slow population growth, higher poverty rates, and an increasing gap in per capita income between urban and rural areas.

The job of running a successful firm and enhancing economic growth is becoming more and more difficult as economic conditions, new technology and knowledge, and the information 
economy increase over time among states. Therefore, there is need to develop adoptable and straightforward entrepreneurial activities, especially in rural areas, by policymakers. A channel to encourage rural entrepreneurship is needed via existing programs. It is also necessary for potential entrepreneurs to have knowledge of their financial needs and financial assistance availability. Research and related policies can help people to establish entrepreneurial firms. Useful results can be obtained from this study by policymakers at local and state levels because the role of entrepreneurship and economic growth is determined simultaneously.

\subsection{Objective of the Study}

The overall objective of this study is to provide policy makers with information on the role of entrepreneurship in economic development in the Northeast region. The specific objectives are to:

1. Develop a database of socio-demographic and economic variables for the Northeast region.

2. Identify and estimate the impacts of entrepreneurship in the economic development of the Northeast region.

3. Identify the spatial distribution of entrepreneurship in the economic development process.

4. Based on the research findings, draw policy implications for the economic development of the region. 


\subsection{Organization of the Study}

This study consists of six chapters. Chapter 2 comprises an overview of existing literature on defining and measuring entrepreneurship, the relationship between entrepreneurship and economic growth, and relevant modeling approaches. Chapter 3 provides the theoretical foundation for modeling entrepreneurship and economic development. Chapter 4 consists of description of empirical models and types and sources of data. Chapter 5 gives the empirical analysis and interpretations. Chapter 6 provides a summary, conclusions and recommendations for future research. 


\section{CHAPTER 2: LITERATURE REVIEW}

\section{Introduction}

This chapter provides a review of the relevant studies on the relationship between entrepreneurship and economic development. The chapter is organized into four sections. The first section provides a review about the concept and types of entrepreneurship. The second section defines tools used to measure entrepreneurship. The third section provides a review about entrepreneurship and economic growth. The last section is devoted to methodological issues related to entrepreneurship in existing studies.

\subsection{Concept and Type of Entrepreneurship}

In recent years, economists have paid attention to the conceptual relationship between entrepreneurship and economic growth. Studies are well founded which relate expansion in entrepreneurial activities to rising economic growth at national as well as county levels. Since entrepreneurship vitalizes economic development and employment growth, innovation, and productivity, efforts for economic development at national and local levels have focused on increasing entrepreneurship. To explain the relationship between entrepreneurship and economic growth, the first thing to define is "entrepreneurship" (Ahmad and Hoffman, 2008). Cantillon (1680-1734) used the word "entrepreneur" for the first time. He divided economic agents into three classes: landlords, entrepreneurs, and employees. He defined an entrepreneur as an individual who takes part in business activities while facing uncertainty (Wennekers and Thurik, 1999). Today, entrepreneurship is studied by anthropologists, organizational theory researchers, and economists; therefore it has multidisciplinary definitions. Entrepreneurs are people who are risk-takers, operate and manage their businesses, experience success or failure, and create new ideas and innovations. Many types of entrepreneurs are defined in the literature. Naudé (2008) 
defined three types of entrepreneurs: occupational, behavioral, and outcome entrepreneurs. Four other types of entrepreneurs are given in the literature: survival entrepreneurs, lifestyle entrepreneurs, high growth entrepreneurs, and intrapreneurs.

Self-employment, considered as occupational entrepreneurship, can be estimated in both ways statically or dynamically (Wennekers and Thurik, 1999). This definition is most commonly used in economic literature. Self-employment is divided into two forms: opportunity entrepreneurs and choice entrepreneurs. Opportunity entrepreneurs are the ones who are selfemployed by necessity. Choice entrepreneurs are the ones who are self-employed by choice and try to avoid taxes (Henrekson, 2007; Coyne and Leeson, 2004; Wong et al., 2005).

Behavioral entrepreneurs are defined based on the known functions carried out. Schumpeter (1934) explained an entrepreneur as an agent who plays his role in the mechanism of change and economic development. He takes entrepreneurship as the activity of going for new ideas and innovations. Kirzner (1973) said that each firm which makes a profit from its business is an entrepreneur. Schultz (1975) defined an entrepreneur as an individual who can recognize an economic disequilibrium, determine its causes and if it is valuable to work on it, he uses his resources. Kanbur (1979) and Newman (2007) characterized an entrepreneur as a person who uses production functions and is responsible for the payment of all workers and faces risks and uncertainty.

Outcome entrepreneurs are defined differently by different researchers. This definition which considers one important aspect is that not all forms of entrepreneurship are necessarily beneficial for economic development. Baumol (1990, pp. 898-899) described "An entrepreneur can be productive, unproductive, or destructive." Under-development occurs not because of lack 
entrepreneurial supply, but because of insufficient profit opportunities that are linked to economic growth (Coyne and Leeson, 2004).

A survival entrepreneur is an entrepreneur who starts a new business due to his link in a certain community or due to his profession/skills. He creates new employment, but most of the time his share in growth is small because he usually does not like to move to other locations (Dabson, 2008; Yenerall, 2008). The survival entrepreneur performs in conditions of "destructive uncertainty." It means that he faces short-term shocks and some known dangers. He tries to avoid exploitative persons who would engage in his business (Wood, 2003). He starts his business due to unemployment or economic problems and does not like to expand his business. His main goal is to earn enough income for the survival of his family. He is not interested in growth-oriented businesses; rather he is just interested in survival, even if he has opportunities to expand his business (Berner et al., 2008). The main purpose of this type of entrepreneur is to survive not to enhance growth. He often has different sources of income due to his inability to obtain a specified level of welfare (Wood, 2003).

Amenities in rural communities impel a lifestyle entrepreneur to forgo some growth for lifestyle choices. He employs fewer people, but provides a major contribution to the economy and society. The lifestyle entrepreneur mainly has businesses in the services sector (Dabson, 2008; Yenerall, 2008). Because of the main objective of this type of entrepreneur, welfare acquired from his business affects only the local communities. Availability of services for local people attracts more and more people to live in rural areas (Henderson, 2006).

A high growth entrepreneur is an entrepreneur who starts and expands a large and valuable business. He prefers to enhance growth by obtaining necessary resources. He is the driving force of an increase in employment creation, careers, wealth and tax base. He likes to 
have business in schools, community services, and philanthropy (Dabson, 2008; Yenerall, 2008).

Economic researchers claim that the quality, not quantity, of entrepreneurs is a main factor to enhance economic development of a region. It is a commonly thought that the high growth entrepreneur is a major source of job creation, increasing income and wealth in a given community (Henderson, 2006; Hudson et al., 2007). In the U.S., a 70 percent increase in employment was due to high growth entrepreneurs during the 1990s (Hudson et al., 2007).

Intrapreneurs or corporate entrepreneurs are a part of an existing business organization. He introduces new products, processes, or markets to increase wealth for his business organization (Dabson, 2008; Yenerall, 2008). Pinchot (1985) defined intrapreneurs as „dreamers who do" those who take hands-on responsibility for creating innovation of any kind within an organization. They may be the creators or inventors, but are always the dreamers who figure out how to turn an idea into a profitable reality. Existing literature focuses on three main characteristics of intrapreneurs: proactiveness, risk-taking, and innovativeness. Proactiveness allows them to start on their own without needing to ask for permission. They might disregard any negative views about their ideas. Risk-taking allows intrapreneurs to focus on exploiting the opportunity without thinking about currently available resources. Innovativeness allows them to create new ideas and invent (Jong and Wennekers, 2008).

\subsection{Measuring Entrepreneurship}

Identification of the measures of entrepreneurship has become important in studying the relationship between entrepreneurship and regional economic growth. The measures of entrepreneurship are not defined properly despite its importance for economic growth. Researchers have to weigh particular measures to define dimensions of entrepreneurship. The 
most common measures are self-employment rate, start-ups of firms, and other growth measures (innovation, entrepreneurial capital, human capital, etc.).

Self-employment is a commonly used measure of entrepreneurship in studies because of the availability of data (Mandelman and Montes-Rojas, 2009; Parker, 2004; Hamilton, 2000; Henderson, 2006; Acs et al., 2005). Self-employment, which has become important in recent years, enables individuals to start their own businesses and be their own bosses (Blanchflower, 2000). A successful self-employer is a person who exploits new opportunities, invents new products, and improves production processes and distribution methods. As the self-employment rate grows, risk-taking environment and market development are encouraged (Earle and Sakova, 2000).

Freytag and Thurik (2007) used preferences for self-employment and actual selfemployment to determine entrepreneurial attitude and activities in the U.S. and 25 member states of the European Union. Preference for self-employment means "to want to be an entrepreneur" and an actual entrepreneur means "an entrepreneur." These measures of entrepreneurship were used as dependent variables in a statistical analysis to determine entrepreneurial attitude and activities in the U.S. and 25 member states of the European Union. The study used 26 dummy variables to estimate country-specific cultural and macro-economic aspects. The country-specific effects and culture reflect the decision of preference for an actual self-employed entrepreneur.

Another measure, new firm formation, has also been commonly used (Prusa and Schmitz, 1991; Fölster, 2000). New firm formation in the market implies an important phenomenon of invention of new products, improvement in processes and increased competition in the market (Fritsch, 1997; Mata and Portugal, 1994). Therefore, an increase in the number of new firms is deemed to have positive effects on regional employment (Fritsch, 1997). 
Shane (2001) used specific dimensions of the technology to estimate the rate of new firm formation. He used the age of technical field, the importance of segmentation, the effectiveness of patents, and the importance of complementary assets as four regimes of technology that affect the rate of new firm formation. The age of the technical field affects new firm formation because when a new technology is developed, at the beginning the market for it was always small. Market size gets larger as time passes. When a technical field is originated, all firms are in the same position. However, over time firms that enter first have an advantage over other firms due to adaptation of technology earlier. As time passes competition between firms changes because the importance of reduction in production cost and economies of scale increases compared to innovations in production over time. Additionally, the entry of new firms becomes more difficult as stable firms have control over complementary assets such as specialized manufacturing, a distribution system, or after-sales support.

The segmentation of technology is important for new firm formation. In the presence of segmentation, new firms adopt an invention before the large and established firms which attempt to meet the demand of customers using older technology. However, in the absence of segmentation, new firms have to face competition from large and existing firms as soon as they enter into the market. In this case, large and existing firms adopt inventions before the new firms. Patents provide strong legal rights to inventors to protect their invention from duplication. In the case of ineffective patent protection, new firms have a difficult time accessing and utilizing new technology (invention). Effective patents not only provide an opportunity to new firms to use new inventions first, but also provide enough time to use new technology according to market needs. Complementary assets are usually associated with an invention. Therefore, it is difficult to access them via market mechanisms. As the importance of complementary assets increase in 
marketing and distribution, to gain a competitive advantage in the industry, new firms have less control over the use of invention as compared to existing firms (Shane, 2001).

Iyigun and Owen (1999) used human capital as a measure of entrepreneurship to analyze the choice between entrepreneurship and professional employment development as an economy makes progress. The other purpose of the study was to observe the decisions made by individuals when they incorporate different types of human capital which affect the economy"s potential in the long-run. Human capital was characterized as entrepreneurial activities. Entrepreneurial activities were compiled via a work-experience-intensive. These activities help to develop economy-wide technology and some would be used in the R\&D sector. Entrepreneurs can affect technology status by new firm formation because existing firms are forced to innovate. Therefore, new firms increase innovation even though they do not introduce new products in the market.

Audretsch and Keilbach (2004) used entrepreneurial capital as the measure of entrepreneurship which was neglected in the neoclassic production function. Entrepreneurial capital was explained as "the capacity of economic agents to generate new firms." Economic output could be positively influenced by entrepreneurial capital for three reasons: a mechanism of knowledge spillover, an increase in number of enterprises (competition), and diversity between firms. Two techniques of knowledge spillover were explained. The first was the ability of firms to accept new technology and ideas developed in other firms. The second was the transfer of an observation unit from firms to individuals, i.e., scientists, engineers, and other knowledge workers. Increased competition by increased enterprises, more contributive to knowledge externalities than a local monopoly, was not competition within a product market, but rather competition of new ideas presented by economic agents. An increased number of 
enterprises provide more new ideas as well as more competition which helps new firms with new products to enter the market. The diversity means not only more firms, but also different firms in the same location which affect the possibility of economic growth in the location.

\subsection{Entrepreneurship and Economic Growth}

Previous studies tried to answer the question of whether economic growth is related to new firm formation which is a tool of entrepreneurship. These studies showed that if entrepreneurship is understood as new firm formation there is a strong relationship with new firm formation and economic growth. In other words, an increase in the number of new firms leads to economic growth through job creation. Similarly, another measure of entrepreneurship is selfemployment which also enhances the economic growth.

Bianchi (2010) developed a relationship between entrepreneurship and economic development. He formalized the view that a high rate of productive entrepreneurship is required for economic development. He demonstrated his analysis in two parts. In the first part he estimated the relationships of entrepreneurial talent, production technologies, and credit constraints with economic development. In the second part, he investigated a set of forces which blocked financial development and showed the appearance of an underdevelopment trap. Using theories developed in previous studies, he argued that his focus was to allocate entrepreneurial talent and to promote diverse productivity across occupations. His approach is closely related to an approach used in previous studies which estimated the relationship between entrepreneurial efficiency and credit constraints. The results of the study showed that financial development tends to increase production, create jobs, and enhance social mobility, assuming relaxation in credit constraints. These results also showed that economic development may increase until markets are operating properly. 
Wennekers and Thurik (1999) used distinct elements such as history of entrepreneurship and economic growth, industrial and evolutionary economics, and macro-economic growth theory. They assumed that this transformation process of linkage between entrepreneurs and the economy results in economic growth. They also argued that the payback of this process is correlated with market conditions. The conclusion indicated that entrepreneurship is a multidimensional concept which accounts for industries and national economies. In the last part of the framework, questions were addressed such as why some new start-ups are unsuccessful, what roles institutions play, and how to relate results of econometric models to policy implications.

Kreft and Sobel (2005) also consider the relationship between entrepreneurship and economic growth by examining the relationship between entrepreneurship and venture capital. They argued that local economies realized the importance of the relationship between entrepreneurship and economic growth and these economies have started to use different policies which increase entrepreneurship in local industries. They used state level data on entrepreneurship factors that had previously been shown to be correlated with the entrepreneur as well as the degree of economic freedom. They used state panel causality tests to show the relationship between state entrepreneurship and venture capital. This is one way to show that entrepreneurship affects the inflow of venture capital but venture capital does not affect entrepreneurship. The results of the empirical model showed that low taxes and regulations and secure property rights should be available to encourage entrepreneurship and, in turn, economic growth.

Lee et al. (2004) used new firm formation as a measure of entrepreneurship. They developed the relationship between regional social characteristics, human capital, and new firm 
formation. They argued that the new firm formation rate can be higher if it is easy to enter into a regional labor market. The existence of a varied culture is also necessary to provide a flow of human capital that encourages innovations and increases information flow. To analyze creativity and diversity effects on entrepreneurship, two geographic units (Metropolitan Statistical Areas (MSAs) and Primary Metropolitan Statistical Areas (PMSAs)) were used. The results showed that new firm formations are strongly related to creativity assuming other variables are constant. New firm formations are also strongly and positively related to diversity. They argued that close attention should be paid to the social habitat of a region to increase regional entrepreneurial activities.

Audretsch and Fritsch (2002) explored multiple approaches to determine the relationship between entrepreneurship and regional economic development. They used data for 74 regions in West Germany from 1983 to 1998 . For the analysis they defined four different growth systems (patterns). They argued that growth systems vary over time and space. The reason is that some regions had higher growth rates through large firms while other regions had the same level of economic growth through new firm formation. The results showed that some regions achieved a higher economic growth rate by focusing on actively encouraging a high rate of new firm formation. They also concluded that small firms and formation of new firms may not have great importance in the short-run, but they can be important for economic development in the longrun. They suggested that new firm formation should be the focus of economic development in regional policy because it is important to increase regional growth.

Kirchhoff and Phillips (1988) explored the significance of new firm formation and economic growth. They explored the role of small and large firms in job creation in the United States. They defined a small firm as a business with less than 100 employees. They argued that 
small firms create the major proportion of jobs. They found that the entry rate of firms is variable from time to time; therefore new firm formation is a major reason for an increase in the number of new firms. They showed that a net increase in the number of firms has a positive relationship with economic growth. They also found the same relationship between economic growth and job creation and loss. Job creation and loss is described by firm births, expansions, deaths, and contractions. Since the results showed that the firm birth rate is higher than the death rate, it was concluded that new firm formation plays an important role in economic growth.

Acs and Armington (2004) analyzed the link between regional economic growth and local entrepreneurship. They explained that entrepreneurship can be used to enhance regional employment growth. Their argument is based on recent growth theories that pay more attention to knowledge and knowledge externalities as basic sources of economic growth rather than scale economies. They also explained that scale economies function is defined at the plant level and knowledge externalities function at firm level. They concluded that increases in entrepreneurial activities are strongly related to regional economic growth. They also found that new firms play a significant role in economic growth which is expected from the manufacturing sector.

Acs and Mueller (2006) estimated the link between business dynamics and employment effects in the U.S. Their study focused on 320 Metropolitan Statistical Areas (MSA). They concluded that firm (entry) type and characteristics of the region are crucial for employment growth. They also concluded that initial economic conditions are advantageous for large firms and existing firms at new locations rather than small firms.

Seyfried (2005) estimated the link between economic growth and employment in the ten largest states of the U.S. He explained economic growth by real GDP and output gap. He used data from 1990 to 2003 and developed a model to measure the magnitude of employment on 
economic growth and the duration of the link between economic growth and employment. His lagged model showed that employment growth is positively and strongly related to economic growth. However, some of the effects appear completely only after some time. Therefore, economic growth may appear in one time period but not be felt immediately. He argued that once economic growth appears the combination of economic growth and employment persistence results in significant gains in employment.

Baptista et al. (2008) used regional data to examine the relationship between new business formation and changes in regional employment. To estimate the relationship, they used time differences. They found that although the indirect effect of new firm start-ups is much stronger than any direct effects, indirect effects can only be observed after eight years from the firm start-ups. They found that the effects of new firm start-ups on regional employment growth depend on the types and qualities of firm start-ups.

Carod et al. (2008) explained the effects of new firm formation on employment growth in manufacturing industries. The link between new firm formation and economic development in these industries is important but the degree of the link is not clear. They used a time lag to show time period effects of new firm formation on employment. The results showed that new firm formation has positive effects on employment in the short-term, negative in medium-term and positive in the long-term.

Andersson and Noseleit (2008) examined the link between new firm start-ups and employment. They used longitudinal data over a decade for analysis on the relationship between start-ups and employment. The results showed that knowledge-based firms have higher effects on the regional economy, especially high-end services such as real estate, finance and insurance, 
and R\&D services. They concluded that firm start-ups are an instrument for change in the regional industry.

Van Stel et al. (2005) estimated the effects of total entrepreneurial activity (TEA) on economic growth. They examined if these effects are based on the economic development which is measured by GDP per capita. The data of 36 countries from 1999 to 2003 was taken from the Global Entrepreneurship Monitor (GEM), the Global Competitiveness Report (GCR), and other sources. They also differentiated the magnitude of entrepreneurial effects for three types of countries: highly developed economies, transition economies, and developing economies. The results showed that TEA had an impact on GDP growth, but it was not a linear impact. They concluded that although economic growth was affected by nascent (or by necessity) entrepreneurs and self-employed in new firms, growth depended on per capita income. Therefore, entrepreneurship helped economic development increase at different stages in different countries.

Acs (2006) estimated the link between economic development and globalization and between entrepreneurship and economic development. He aimed to use an opportunity-necessity ratio as a composite indicator of entrepreneurial activity and economic development. He defined three main stages of economic development. In first stage, self-employment rate is usually high in which, the economy stays in the environment of production of agricultural products and smallscale manufacturing. In the second stage, the self-employment rate is reduced; however, the economy shifts from small-scale production to manufacturing. In the third stage, entrepreneurial activity increases along with increased wealth of the economy and the economy shifts from manufacturing to services. He also explained three reasons for increasing entrepreneurial activity in the third stage. First, in any economy, the contribution of manufacturing firms is reduced due 
to the increase of service firms. The number of service firms increases due to their small size. Second, returns from entrepreneurship increase due to the advancement in information technology, i.e., telecommunication (express-mail, photocopying, personal computers, the internet, web, and mobile-phone services). Third, at an economic development level, entrepreneurs and the number of small firms increase as aggregate elasticity of factor substitution increases. He used the Global Entrepreneurship Monitor (GEM) data for estimation. He concluded that economic development was related to successful entrepreneurship which was associated with established corporations. However, the value of this development varies from country-to-country based on GDP per capita. He also concluded that when people found stable employment, new firm formation is reduced. However, as income increased more, individuals had more resources to start new firms which again increased the entrepreneurial sector.

Carree et al. (2002) estimated the relationship between self-employment and economic development at the macro level. Their main focus was on three issues. The first was about the relationship between the equilibrium rate of self-employment and the stage of economic development. The second was about the convergence speed towards an equilibrium rate when the self-employment rate is not at an equilibrium point. The third was to show to what extent does deviating from the equilibrium rate of self-employment hinders economic growth. This concern leads to discovering the shape of the equilibrium rate, which could be L-shaped or U-shaped, the convergence speed to the equilibrium point, and the out-of equilibrium growth penalty. They used panel data of 23 OECD (Organization for Economic Co-operation and Development) countries from 1976 to 1996 . For empirical analysis, a two-equation model was used. The first equation examined the causes of changes in the self-employment rate and the second equation handled the consequences of these changes. They concluded that low barriers to the birth and 
death of self-employed/firms were necessary for the equilibrium that best promoted economic development. They made two extensions in their work (Carree et al., 2002). The first extension was the application of time-series data from 23 OECD countries from 1976 to 2004 to get a better idea about the shape of the equilibrium. The second was about the balance of the growth penalty assuming too few or too many self-employed/firms. They concluded that additional timeseries data did not produce any superiority of statistical fit of U-shaped over L-shaped. The second extension showed the growth penalty as having too few self-employed/firms. Therefore, it will be damaging for economic growth to have one self-employer/firm under the equilibrium.

Robbins et al. (2000) analyzed the relationship between the proportion of small businesses and four determinants of economic growth: productivity, gross state product (GSP), unemployment, and wage inflation at the state level in the U.S. They used panel data from 48 states from 1986 to 1995. A system of simultaneous equations with random effects was used for analysis. The study showed that very small businesses provided economic benefits at a macro level. They concluded that as the number of small businesses (20 employees or less) increased, the level of productivity and GSP growth increased at a state level. At the same time wages, inflation and unemployment rates were reduced. Therefore, macroeconomic policies were more beneficial to the states that were rich in small businesses. This was not true for small businesses which had 500 employees or less. Labor in these businesses was not more productive.

Blanchflower (2000) analyzed a number of issues related to self-employment. The first issue was to estimate the limit of variation in self-employers"e characteristics across countries. The second issue was to measure the relationship of self-employment and unemployment rates across countries. The third issue was to see if self-employers are satisfied with their jobs. The fourth issue was to estimate the relationship between self-employment level and real growth rate 
of the economy. The final issue was to explore the mobility of self-employed across neighborhoods, regions, and towns. Two types of data were used for empirical analysis. First, panel data from 23 countries from 1966 to 1996 was used. Second, for the same analysis, timeseries data from 1975 to 1996 was used. The results showed that non-farm self-employment has decreased in some countries like Austria, Belgium, Japan, Luxembourg, Netherlands, Norway, Spain and the U.S. and increased in some countries like Australia, Canada, Finland, Iceland, Ireland, New Zealand, Portugal, Sweden and the United Kingdom. Self-employment was reduced in most of the countries in 1996. The overall trend of being self-employed was greater among women instead of men and the rate increased as age increased. Self-employers were more satisfied with their jobs than regular employees. However, a rise in self-employment does not mean that the real growth of the economy will also increase. Self-employers do not like to move from their neighborhood, regions, and towns. Blanchflower (2000) developed a flexibility index across countries based on the information of whether self-employers wanted to move from their neighborhood, regions, and town. The results of this index showed that some economies are flexible in terms of self-employerse movement such as the U.S., Canada, Germany, and the Netherlands. Some economies were less flexible such as Russia and Hungary while others were low in terms of flexibility such as Austria and Ireland.

\subsection{Methodological issues}

The term "spillover" is associated with the transmission of knowledge between economic players. It is possible that these spillovers lead to important productivity gains. Endogenous growth theory holds that economic growth depends on the endogenous development of knowledge spillover effects between economic players. 
Knowledge of an entrepreneur"s awareness can be misleading about "discoverable profit opportunities." Spatial locations are also important due to unequal discoverable profit opportunities (Andersson, 2005). Two types of knowledge are explained: knowing that and knowing how. Knowing that means "knowledge of facts and theories." Knowing how means "the ability to perform the appropriative actions in order to achieve a desired result, and includes skill both in performance and in recognizing when and where that skillful performance is appropriate" (Loasby, 1999, p. 51).

The Knowledge Spillover Theory of Entrepreneurship explains that among many, one means of entrepreneurial opportunities is new knowledge and ideas. It assumes new knowledge and ideas developed in one"s background. New knowledge and ideas that produces entrepreneurial opportunities may not be commercialized or fully perceived by the sources (Audretsch et al. 2004; Audretsch and Keilbach, 2007). Audretsch (1995) introduced the Knowledge Spillover Theory of Entrepreneurship as:

"The findings challenge an assumption implicit to the knowledge production function-that firms exist exogenously and then endogenously seek out and apply knowledge inputs to generate innovative output..... It is the knowledge in the possession of economic agents that is exogenous and in an effort to appropriate the returns from that knowledge, the spillover of knowledge from its producing entity involves endogenously creating a new firm."

Acs et al. (2005) argued that knowledge spillover may not arise, in reality, as it is assumed to happen in the endogenous growth model. They used entrepreneurship as a mechanism of providing spillover of knowledge and ultimately to lead to economic growth. They used panel data for 18 countries. The results showed entrepreneurship is positively related to economic growth. In other words, new firm start-ups can be used as a means of spillover of knowledge because entrepreneurship is measured by the start-ups of new firms. They mentioned previous studies indicating that knowledge leads to economic growth in those countries which 
have higher levels of entrepreneurship. Therefore, the results of their study are consistent with the opinion that entrepreneurship can be a means of spillover of knowledge and ultimately lead to economic growth.

De Clercq et al. (2008) analyzed the proportion of export-oriented new ventures of a country and indicated that knowledge spillover is an outcome of foreign direct investment, export spillover, and entrepreneurial spillover. In their study, they used data from 34 countries from 2002 to 2005. The results showed that the link between foreign direct investment (FDI) and export spillover and their effect on the share of export-oriented new ventures of a country is not the same for low and high level of income countries. The share of export-oriented new ventures of a country also affects the start-ups of new firms. The study has some limitations. First of all, the study just deals with one aspect of productivity which is export spillover, but there are other aspects that can be of use to estimate knowledge spillover such as foreign licensing, franchising, etc. Secondly, the data set used is for a short period of time which is not appropriate to show spillover effects on entrepreneurship for a long period of time. Third, they explained a number of means to show spillover for new ventures, but it was not empirically estimated. Finally, it is possible to omit industry level effects while focusing on aggregate spillover effects.

Acs et al. (2009) explained that the main focus of entrepreneurship theories is identification of entrepreneurial opportunities and the decision to exploit them. Different studies on entrepreneurship took these opportunities as exogenous, but the existing economic growth theory suggested that entrepreneurial opportunities are endogenous. They made some extensions in endogenous growth theory at the microeconomic level by including knowledge spillover theory of entrepreneurship. To estimate the entrepreneurship rate, data from 1981 to 2002 was used. Results, consistent with predictions, showed that endogenous knowledge is a reason for 
knowledge spillover which helps entrepreneurs recognize and exploit opportunities. Therefore, there is a significant link between knowledge spillovers and entrepreneurial activity.

Andersson (2005) was concerned about four "spatial" implications from the theory of entrepreneurs. First, "unavoidable spatial positioning" helped entrepreneurs discover superior locations that provide profit opportunities. Second, entrepreneurial process, an important element of urban and regional economics, was linked to the results from von Thünen rent to dynamically create and exploit agglomeration economics. Third, a spatial approach should represent Kirzner"s theory and Frank Fetter's theory of rent and the procedure of urbanization and migration and at the same time explain the changes in profit, rent, and capital values because of the changes in land use. Fourth, a spatial theory can explain the relationship of profits and locations with institutions. It can also explain no or few equilibrium trends of some missing or underdeveloped institutions in certain markets and locations.

Audretsch and Lehmann (2005) examined the spatial link between knowledge-based new firm formation and their proximity to universities. For estimation purpose, they linked the investment in knowledge by universities and regions to entrepreneurial activities to each university. The dataset used for analysis was based on the 281 firms that were made public in Germany between the time periods of March 1997 to March 2002. Binomial regressions were used to analyze the relationship of the number of young and hi-tech firms with the regional factor and output of universities. They concluded that the knowledge capacity of the regions and knowledge capacity of the universities had positively affected the numbers of firm located near the universities. The existing studies showed that the Knowledge Spillover Theory of Entrepreneurship had little consideration for the spatial dimension. However, this study was based on a dataset for Germany and showed that the Knowledge Spillover Theory of 
Entrepreneurship not only holds for regions, but also for industries. They also showed that public policy behaved in two primary ways as comparative advantage was becoming more knowledge based. First, it facilitated new firms with an infrastructure that allowed them to use necessary resources. Second, it helped universities to produce well-educated students by affecting the research activities in universities, more specifically, in the natural sciences.

Armington and Acs (2002) also estimated the role regional variation on the firm birth rate in the U.S. The study used data from the Longitudinal Establishment and Enterprise Microdata (LEEM) file constructed by the U.S. Census Bureau for the study of entry, survival, and growth of different firms. Labor Market Areas (LMAs) or travel-to-work was used as a geographical unit for analysis. They combined the 3,141 counties of the U.S. into 394 geographical regions that consisted of high proportions of residential-work location trips. In order to have better control of aggregation effects in a region having different industries, they used six industry sectors. For estimation of firms ${ }^{\text {ee }}$ birth rate, a labor market approach and ecological approach were used. Firms"e birth rates vary across the regions due to the existence of regional externalities (or agglomeration/density effects), unemployment, industrial restructuring, and entrepreneurial culture. They concluded that firms ${ }^{\text {ee }}$ birth rate varies more across the regions compared to the variation over time.

Audretsch and Keilbach (2007) examined the Knowledge Spillover Entrepreneurship Proposition by estimating the relationship between knowledge investments and new firm formation within the same regions. Ordinary Least Square (OLS) was used for analysis. The start-up rate defined entrepreneurial activity, the dependent variable, between 1998 and 2000. They used four alternative measures for entrepreneurship to examine the Knowledge Spillover Entrepreneurship Proposition. The first measure most commonly used was new firm start-ups. 
The second measure was new firm start-ups in hi-tech industries where hi-tech industries were those which have a mean R\&D sales ratio equal to more than 2.5 percent. The third measure was new firm start-ups in the Information and Communication Technology industries (ICTindustries) including industries in both manufacturing and services. The fourth measure was new firm start-ups in the low-tech industries. They concluded that Knowledge Spillover Entrepreneurship Proposition implies that knowledge and new ideas-significantly necessary for entrepreneurial opportunities were invented, but may not be advertised comprehensively to the inventor firms or organizations. The results showed that as knowledge increased, entrepreneurial opportunities also increased and new ventures were a means of increasing knowledge. Therefore, the results were consistent with the hypothesis that entrepreneurial opportunities are composed of investment in knowledge by inventor firms and are organizations and, therefore, are not exogenous. As a result the knowledge spillover entrepreneurship, an important source of economic growth, acts as a channel for spatial variation of knowledge among the regions. The entrepreneur, a reason for change in the economy, identifies entrepreneurial opportunities that pursue new ideas into commercialization. 


\section{Introduction}

\section{CHAPTER 3: THEORETICAL MODEL}

Entrepreneurship, as an engine of economic growth, is an important part of economic development theory (Schmitz, 1989). Endogenous growth models have focused on the growth obtained by technological changes (Jones, 1995). The term "endogenous" in this context means innovations, those results from conscious research and development efforts to maximize profit with R\&D subsidies so that economic growth may be affected in the long-run (Romer, 1990; Aghion and Howitt, 1992 and 1998; Jones, 1995; Dinopoulos and Şener, 2007).

Schmitz"s (1989) entrepreneur is different from Schumpeter"s entrepreneur. In Schumpeter"s growth model, an entrepreneur is an inventor who has an important, though small, role of imitator in economic growth. He focused only on the role of imitator which refers to transmission and enforcement of new technology to enhance growth. Baumol (1986 and 1988) explained that imitator entrepreneurs have played a role in enhancing growth in most economies.

Although a positive relationship was found between entrepreneurship and economic growth, the question remains about the endogenous relationship between entrepreneurship and economic growth. Specifically, as the number of entrepreneurs increases, economic growth also increases, and this changes individual arbitrage between occupation and expected payoffs. The answer to the question is that supply of entrepreneurial activity and economic growth are not independent of each other. Therefore, factors that determined the choices of individuals about their occupation are important and the endogenous relationship between entrepreneurship and economic growth is recognized (Dejardin, 2000). 


\subsection{Entrepreneurship and Growth Theory}

Plehn-Dujowich and Li (2009), Jiang et al. (2009), and Lee and Yu (2005) developed models based on Romer"s (1990) growth model. They assumed that there are three sectors in any economy: research sector, intermediate goods, and final goods with discrete and infinite time. An entrepreneur starts a research firm to elaborate plans for a new intermediate good. The research firm has monopoly power over the new intermediate good due to the exclusive rights. The research firm then sells its plan to a monopolist who manufactures the intermediate good and sells it to a competitive firm. A competitive firm produces the final good by using the intermediate good and production workers.

The output of the final good is expressed as:

(3.1.1) $\quad Y=A L^{\beta} \int_{0}^{K} X_{i}^{1-\beta} d i$

where $Y$ is final output of a competitive firm having a constant returns to scale Cobb-Douglas technology, $L$ is labor employed for production, $K$ is the stock of intermediate goods, $X_{i}$ is quantity of intermediate goods $i$ purchased by the firm, $P_{i}$ is price of intermediate goods $X_{i}, A$ is a parameter used to measure the productivity of the final goods, and $\beta$ is output elasticity.

The firm solves the problem as:

$$
\underset{L, X i}{\operatorname{Max}} A L^{\beta} \int_{0}^{K} X_{i}^{1-\beta} d i-w L-\int_{0}^{K} P_{i} X_{i} d i
$$

FOC

(3.1.3) $w=\beta A L^{\beta-1} \int_{0}^{K} X_{i}^{1-\beta} d i$

(3.1.4) $\quad P_{i}=(1-\beta) A L^{\beta} X_{i}^{-\beta}$

Equation (3.1.4) explains the inverse demand function of the intermediate good $i$. 
Research firms sell their plans to monopolists to manufacture intermediate goods with constant marginal cost $c$. An intermediate goods monopolist solves the problem as:

(3.1.5) $\max _{X i}(1-\beta) A L^{\beta} X_{i}^{1-\beta}-c X_{i}$

FOC is:

(3.1.6) $\quad X_{i}=L\left[(1-\beta)^{2} A / c\right]^{1 / \beta}$

Equation (3.1.6) shows that all intermediate goods produced are of same quality.

The present value of profits from selling intermediate goods is:

(3.1.7) $\pi=(1+1 / r) \beta L\left[A(1-\beta)^{2-\beta} / c^{1-\beta}\right]^{1 / \beta}$

An agent becomes an entrepreneur when he creates a start-up research firm. The research firm invents new intermediate goods as:

(3.1.8) $n(I ; s)=\eta(s S)^{1-\alpha} I^{\alpha}$

where $n(I ; s)$ is an innovation production function, $I$ is the investment of the entrepreneur, $s$ is skill of the entrepreneur, $S$ is state of knowledge, $\eta$ is a parameter that measures the productivity of the research sector, $\alpha$ is a parameter that measures the extent to which new products are R\&D versus knowledge intensive and is between 0 and 1 . He solves the following problem with skill $s$ :

(3.1.9) $\max _{I(s)} \pi \eta(s K)^{1-\alpha} I(s)^{\alpha}-I(s)$

FOC is:

(3.1.11) $n(s)=\left(\alpha \pi \eta^{1 / \alpha}\right)^{\alpha /(1-\alpha)} s K$

(3.1.12) $\quad e(s)=(1-\alpha)\left(\alpha^{\alpha} \pi \eta\right)^{1 /(1-\alpha)} s K$

(3.1.13) $S(s)=\left(\alpha^{\alpha} \pi \eta\right)^{1 /(1-\alpha)} s K$ 
Equation (3.1.10) explains $R \& D$ investment, 3.1.11 shows the number of new intermediate goods and 3.1.12 represents the income of entrepreneurs. Finally, equation (3.1.13) shows the size of the firms. R\&D expenditures, number of innovations, income of entrepreneurs, and size of the firm have an increasing relationship with entrepreneurial skills. This relationship explains that the more skilled an entrepreneur is, the more he invents, the more new products put on the market, and, therefore, the more capable he is of running a large firm.

If an agent ${ }^{\text {ee }}$ income from entrepreneurial activity $E(s)$ is more than the wages paid to production workers $w$, then he is an entrepreneur. Since $E(s)$ is strictly increasing in skill, a unique level of skill $\hat{s}$ exists at which an agent becomes indifferent between an entrepreneur and production worker:

(3.1.14) $E(\hat{s})=(1-\alpha)\left(\alpha^{\alpha} \pi \eta\right)^{1 /(1-\alpha)} \hat{s} S \equiv w$

Where

$s \in[0, \hat{s})=$ Skill of agent who becomes a production worker, $s \in[0, \infty)=$ Skill of agent who becomes an entrepreneur.

In equilibrium, demand and supply of production workers are equal:

\section{(3.1.15) $L=F(\hat{s})$}

Thus, in equilibrium, the balanced growth path is:

$$
g=\left\{(1+1 / r) \alpha \beta \eta^{1 / \alpha} F(\hat{s})\left[A(1-\beta)^{2-\beta} / c^{1-\beta}\right]^{1 / \beta}\right\}^{\alpha /(1-\alpha)} \int_{\hat{S}}^{\infty} s d F(s)
$$

The number of intermediate goods that are invented by the research firm, the income of an entrepreneur, the firm size, the wage of production worker, the R\&D investment, and the final goods output grow at growth rate $g$. The profit from the invention of new products, intermediate 
goods output, and skill level are constant with the balanced growth path. Therefore, the balanced growth path is obtained immediately.

\subsection{New Growth Theory and Economic Growth}

Romer (1986) sets up the New Growth Technology theory. The theory examines the idea that knowledge and technology show increasing returns that lead to economic growth. In contrast, traditional economic models only considered decreasing returns. The New Growth Theory objects are on different points of the neoclassical model. The neoclassical exogenous growth models do not provide a justification for improving technology over time but instead stresses the importance of accumulating capital and improving the labor force to enhance economic growth while technology was assumed to be constant. Romer (1986) says that we now know that the classical suggestion that we can grow rich by accumulating more and more pieces of physical capital like fork-lifts is simply wrong. The reason provided is that physical capital faces decreasing returns at last because economies cannot get benefits of growth when additional units of the same type of capital are added (Cortright, 2001).

Now lete's look at New Growth models. The first generation of New Growth Theory tried to incorporate a range of growth mechanisms. The most significant mechanism is about the invention of new technical knowledge in R\&D departments of firms (Romer, 1986) and the other is about the foundation of human capital in education processes (Lucas, 1988). Both mechanisms are considered as the main engines of economic growth. These mechanisms depend on positive externalities and rate of profit (Kurz and Salvadori, 2008).

All factors except knowledge are assumed to be in limited supply in Romeres model. The stock of knowledge can be increased by spillover from private R\&D activities. Per capita income increases due to the positive externality. Agents ${ }^{\text {ee }}$ behavior also affects long-run economic 
growth. Similarly, in Lucase (1988) study, agents can either spend their non-leisure time in current production or in the accumulation of human capital. A positive externality increases output directly or indirectly by accumulating human capital.

The exogenous growth model of Solow (1956) does not use any resources for technological progress. However, the New Growth Theory pays particular attention to the activities associated with innovations ${ }^{\text {ee }}$ production that leads to technological progress. This progress distinguishes between the production of labor and capital and research and development (R\&D). Economic growth will be enhanced more and endogenous as R\&D is more developed using resources. The New Growth Theory likes to have monopolies in the economy to enhance economic growth because producers want to earn excess profits as in a monopoly and not break even as in perfect competition. The reason is that in perfect competition they are left with zero revenue for innovations (Castro, 1998).

Like other models, Solow (1956) and the Harrod-Domar model also have some shortcomings. These models emphasized knowledge and human capital but without providing a measurement of them. Returns to scale, marginal and average product, and growth rate cannot be defined clearly if these mechanisms are measured cardinally (Kurz and Salvadori, 2008). However, these models were used in different studies because some regions in the world lack human capital and technical knowledge. They have low per capita income regardless of having proper physical capital and labor forces. These regions should invest in their education systems and in infrastructure. They can get technical knowledge by facilitating the domestic industry sector with incentives for imitation and innovations.

Previous studies showed that technological change is a source to increase entrepreneurial activity. Entrepreneurial activity can be measured using two proxy tools: the possibility that 
people will participate as self-employers, and the possibility for people to start new firms (Acs and Varga, 2004). The self-employment rate of the non-agricultural labor force faced an increase in the early 1970s after a decline of self-employment in the previous two decades in the United States. Blau (1987) examined this change from 1973 to 1982 . The analysis showed that an increase in the rate of technological change leads to increase in self-employment rate.

\subsection{Entrepreneurship and Socially Optimum Growth}

The relationship between entrepreneurship and economic growth can be seen in two ways: entrepreneurial effect and production effect. The entrepreneurial effect occurs when entrepreneurship induces firms to invent more or new intermediate goods and ultimately increases economic growth. The production effect occurs when reductions in production workers leads to decreases in the demand for intermediate goods and profits from inventing new intermediate goods. Therefore, it reduces the investment in R\&D and ultimately economic

growth. The entrepreneurship effect holds that diminishing returns implies that if the number of agents who select the entrepreneurial occupation increases (proportion of each entrepreneur $p$ increases) then the entrepreneurship effect will be weaker compared to the production effect. This implies that entrepreneurship and growth have a U-shaped relationship with a highest level of proportion $\bar{p}$. If $\bar{p}>p$ then an increase in entrepreneurship leads to an increase in growth because entrepreneurial effect dominates. If $\bar{p}<p$ then the production effect dominates and an increase in entrepreneurship leads to decreases in growth (Plehn-Dujowich and Li, 2009).

To see these effects, we need to define all inefficiencies of the model as explained by Plehn-Dujowich and Li (2009). The model in part (3.1.1) has three types of inefficiency: static, dynamic, and occupational. Static inefficiency is when monopoly power urges the producers to produce too little in order to generate profits. Earned profits bring inventions that enhance 
endogenous growth. Dynamic efficiency is related to a positive externality in the innovative production function. It creates too little profit for each R\&D invention. Occupational inefficiency is when an agent wants to be an entrepreneur and ignores the fact that by being an entrepreneur he will decrease the number of production workers and, therefore, the return on entrepreneurship.

The magnitude of entrepreneurship with proportion defined by a social planner $p_{s p}=1-F\left(\hat{s_{s p}}\right)$ can be determined by threshold skill level $\hat{s}_{s p}$ which is defined as:

$$
\hat{s}_{s p}^{1-\alpha} F\left(\hat{s_{s p}}\right)+\int_{\hat{s}_{s p}}^{\infty}\left(s / \hat{s_{s p}}\right) d F(s)=\delta\left\{\eta(1-\alpha)^{1-\alpha}\left[\alpha \beta A^{1 / \beta}((1-\beta) / c)^{(1-\beta) / \beta}\right]^{\alpha}\right\}^{-1}
$$

Socially efficient growth is:

$$
g_{s p}=\eta\left\{(\alpha /(1-\alpha)) \beta A^{1 / \beta}[(1-\beta) / c]^{(1-\beta) / \beta}\right\}^{\alpha} \int_{\hat{s}_{s p}}^{\infty}\left(s / \hat{s_{s p}}\right) d F(s)
$$

At social optimum, if $p_{s p}<\bar{p}$ then the proportion $p_{s p}=1-F\left(\hat{s_{s p}}\right)$ is increasing $A$, the productivity of final goods, and $\eta$, the productivity of research sector. This proportion has decreasing returns in the marginal cost of intermediate good $c$ and discount rate $\delta$.

Entrepreneurship at a social optimum is the same as at a decentralized equilibrium which means that $p_{s p}<\bar{p}$ is the same as $\bar{p}>p$. Therefore, the results of a decentralized equilibrium and social optimum have the same meaning; an increase in entrepreneurship leads to increased economic growth. It is also a remedy for dynamic and occupational inefficiencies.

The magnitude of entrepreneurship can be determined by internalizing the tradeoff between entrepreneurship and growth. A rise in entrepreneurship leads to increase in the number of inventors and growth (entrepreneurial effect) along with a decrease in the number of production workers, output of final goods, innovations ${ }^{\text {ee }}$ returns and ultimately growth 
(production effect) in the decentralized equilibrium. Since the problem of dynamic inefficiency was solved, the entrepreneurship effect is stronger in the social optimum compared to the decentralized equilibrium. Undoubtedly, the social gain obtained from an innovation is greater than the private gain. When an agent adopts an entrepreneurial occupation at the social optimum it not only raises current rates of innovation, but also increases innovation in the future and, therefore, economic growth too. In this case, intermediate goods will increase the supply of knowledge. This is a positive externality that increases the entrepreneurial effect. Therefore, the entrepreneurial effect is stronger than the production effect and always shows a rise in economic growth when entrepreneurship increases at the social optimum. 


\section{CHAPTER 4: EMIRICAL MODEL AND DATA}

\section{Introduction}

Chapter 3 examined the theoretical link between entrepreneurship and economic development. Regional growth models have been used to see the effect of regional economic development on entrepreneurship. Chapter 4 develops the empirical model and presents the data description. This chapter is organized into six sections. Section 4.1 explores about the non-spatial growth model. Section 4.2 presents non-spatial equations of population, employment, per capita income, entrepreneurship. Section 4.3 defines spatial model. Section 4.4 presents spatial equations of population, employment, per capita income, entrepreneurship. Section 4.5 presents data types and sources and specification of variables used in the models. Section 4.6 introduces the estimation techniques to be used.

\subsection{Non-Spatial Growth Model}

As indicated earlier, the focus of this study is to analyze the relationship between entrepreneurship and economic development represented by changes in population, employment, and per capita income. Besides entrepreneurship, the empirical analysis uses other variables which affect economic growth. The empirical analysis of this study contains non-spatial and spatial models. The non-spatial model is derived from the two-equation simultaneous model of Carlino and Mills (1987). They build this model by modifying Steinnes"e model (1982). Deller et al. (2001) extended it into a three equation simultaneous model which incorporated the interdependencies among income, population and employment change. Some studies extended the model of Deller et al. (2001) to estimate simultaneous relationships of economic development with entrepreneurship, amenities, environmental regulation, and modeling small business growth, migration behavior, local public services and median household income 
(Gebremeriam, 2006; Kahsai, 2009, Mojica, 2009; and Nondo, 2009). This study also uses Deller"s model by specifying a four-equation model. The general form of four equations simultaneous model defining the interaction between population (POP), employment (EMP), per capita income (PCI), and entrepreneurship (ENT) is specified as:

(4.1.1a) $P O P^{*}=f\left(E M P^{*}, P C I^{*}, E N T^{*} / X^{P O P}\right)$

(4.1.1b) $E M P^{*}=f\left(P O P^{*}, P C I^{*}, E N T^{*} / X^{E M P}\right)$

(4.1.1c) $P C I^{*}=f\left(P O P^{*}, E M P^{*}, E N T^{*} / X^{P C I}\right)$

(4.1.1d) $E N T^{*}=f\left(P O P^{*}, E M P^{*}, P C I^{*} / X^{E N T}\right)$

Where $P O P^{*}, E M P^{*}, P C I^{*}$, and $E N T^{*}$ represent equilibrium levels of population, employment, per capita income, and entrepreneurship, respectively, in the ith county; $X^{P O P}, X^{E M P}, X^{P C I}$, and $X^{E N T}$ are a set of exogenous variables that have either direct or indirect effects on population, employment, per capita income, and entrepreneurship.

Equations (4.1.1a) to (4.1.1d) represent that actual population, employment, per capita income, entrepreneurship, and exogenous variables in $X s$ that determine the equilibriums of population, employment, per capita income, and entrepreneurship. The general equilibrium conditions specified in equations (4.1.1a) to (4.1.1d) expressed as a linear relationship can be explained as:

Mills and Price (1984) recommended that equilibrium levels of population, employment, income, and entrepreneurship are likely to be adjusting with distributed lags. The distributed lag adjustments models are specified as: 
(4.1.3a) $P O P_{t}=P O P_{t-1}+\lambda_{P O P}\left(P O P^{*}-P O P_{t-1}\right)$

(4.1.3b) $E M P_{t}=E M P_{t-1}+\lambda_{E M P}\left(E M P^{*}-E M P_{t-1}\right)$

(4.1.3c) $P C I_{t}=P C I_{t-1}+\lambda_{P C I}\left(P C I^{*}-P C I_{t-1}\right)$

(4.1.3d) $\mathrm{ENT} T_{t}=E N T_{t-1}+\lambda_{E N T}\left(E N T^{*}-E N T_{t-1}\right)$

The subscript (t-1) represents the initial conditions of endogenous variables; population, employment, per capita income and entrepreneurship and $\lambda_{P O P}, \lambda_{E M P}, \lambda_{P C I}$, and $\lambda_{E N T}$ are speed-of-adjustment coefficients to the desired level of population, employment, income, and entrepreneurship. Adjustment coefficients are assumed to be $0 \leq \lambda_{P O P}, \lambda_{E M P}, \lambda_{P C I}, \lambda_{\mathrm{ENT}} \leq 1$. Generally positive and higher values represent quicker growth rates.

Equations (4.1.3a)-(4.1.3d) indicate that present conditions of population, employment, income, and entrepreneurship depend on their initial conditions and a change between the equilibrium value and its lagged value. Rearranging equations (4.1.3a)-(4.1.3d), we have:

$$
\begin{aligned}
& \text { (4.1.4a) } \triangle P O P=P O P_{t}-P O P_{t-1}=\lambda_{P O P}\left(P O P^{*}-P O P_{t-1}\right) \Rightarrow P O P^{*}=\frac{1}{\lambda_{P O P}}\left(P O P_{t}-P O P_{t-1}\right) \\
& (4.1 .4 b) \Delta E M P=E M P_{t}-E M P_{t-1}=\lambda_{E M P}\left(E M P^{*}-E M P_{t-1}\right) \Rightarrow E M P^{*}=\frac{1}{\lambda_{E M P}}\left(E M P_{t}-E M P_{t-1}\right) \\
& (4.1 .4 c) \Delta P C I=P C I_{t}-P C I_{t-1}=\lambda_{P C I}\left(P C I^{*}-P C I_{t-1}\right) \Rightarrow P C I^{*}=\frac{1}{\lambda_{P C I}}\left(P C I_{t}-P C I_{t-1}\right) \\
& \text { (4.1.4d) } \Delta E N T=E N T_{t}-E N T_{t-1}=\lambda_{E N T}\left(E N T^{*}-E N T_{t-1}\right) \Rightarrow E N T^{*}=\frac{1}{\lambda_{E N T}}\left(E N T_{t}-E N T_{t-1}\right)
\end{aligned}
$$

where $\Delta$ represents a region"s change of the growth rate of population, employment, income, and entrepreneurship, respectively. The changes in endogenous variables are gained from the difference between the log values of the observations of 2008 and the observations of 1993 as depicted below: 


$$
\begin{array}{ll}
(4.1 .5 a) & \triangle P O P=\operatorname{LOG}\left(P O P_{2008}\right)-\operatorname{LOG}\left(P O P_{1993}\right) \\
(4.1 .5 b) & \triangle E M P=\operatorname{LOG}\left(E M\left[_{2008}\right)-\operatorname{LOG}\left(E M P_{1993}\right)\right. \\
(4.1 .5 c) & \triangle P C I=\operatorname{LOG}\left(P C I_{2008}\right)-\operatorname{LOG}\left(P C I_{1993}\right) \\
(4.1 .5 d) & \triangle E N T=\operatorname{LOG}\left(E N T_{2008}\right)-\operatorname{LOG}\left(E N T_{1993}\right)
\end{array}
$$

By substituting equation (4.1.4a) through equation (4.1.4d) in equation (4.1.2a) through equation (4.1.2d), respectively, and rearranging the equations, we can obtain the linear form of the estimation model. Therefore, the non-spatial estimation model is formed of a system of four simultaneous equations explaining population, employment, per capita income, and entrepreneurship, respectively. This system is defined as:

$$
\begin{aligned}
& \text { (4.1.6a) } \triangle P O P= \alpha_{0 P O P}+\beta_{1 P O P} \Delta E M P+\beta_{2 P O P} \Delta P C I+\beta_{3 P O P} \Delta E N T+\beta_{4 P O P} P O P_{1993}+ \\
& \beta_{5 P O P} E M P_{1993}+\beta_{6 P O P} P C I_{1993}+\beta_{7 P O P} E N T_{1993}+\sum \delta_{1 P O P} X^{P O P}+u_{1} \\
& \text { (4.1.6b) } \triangle E M P= \alpha_{0 E M P}+\beta_{1 E M P} \Delta P O P+\beta_{2 E M P} \Delta P C I+\beta_{3 E M P} \Delta E N T+\beta_{4 E M P} P O P_{1993}+ \\
& \beta_{5 E M P} E M P_{1993}+\beta_{6 E M P} P C I_{1993}+\beta_{7 E} E N T_{1993}+\sum \delta_{2 E M P} X^{E M P}+u_{2} \\
& \text { (4.1.6c) } \triangle P C I= \alpha_{0 P C I}+\beta_{1 P C I} \Delta P O P+\beta_{2 P C I} \Delta E M P+\beta_{3 P C I} \Delta E N T+\beta_{4 P C I} P O P_{1993}+ \\
& \beta_{5 P C I} E M P_{1993}+\beta_{6 P C I} P C I_{1993}+\beta_{7 P C I} E N T_{1993}+\sum \delta_{3 P C I} X^{P C I}+u_{3} \\
& \text { (4.1.6d) } \triangle E N T= \alpha_{0 E N T}+\beta_{1 E N T} \Delta P O P+\beta_{2 E N T} \Delta E M P+\beta_{3 E N T} \Delta P C I+\beta_{4 E N T} P O P_{1993}+ \\
& \beta_{5 E N T} E M P_{1993}+\beta_{6 E N T} P C I_{1993}+\beta_{7 E N T} E N T_{1993}+\sum \delta_{4 E N T} X^{E N T}+u_{4}
\end{aligned}
$$

The endogenous variables $\triangle P O P, \triangle E M P, \triangle P C I$, and $\triangle E N T$ indicate a county"s growth rates in population density, employment, per capita income, and entrepreneurship, respectively. Error terms are shown by $u_{1}, u_{2}, u_{3}$, and $u_{4}$ and an exogenous variable vector is represented by $X$. Initial period (subscript $\mathrm{t}-1$ ) is the year of 1993. The lag adjustment models assume that endogenous variables are adjusted over a period of time not adjusted instantaneously to their equilibrium levels. Deller and Lledo (2007) and Deller et al. (2001) identified that the speed-ofadjustment coefficients are embedded in the coefficients $\alpha, \beta$, and $\delta$. This framework permits one to estimate the structural relationship while simultaneously isolating the effects of entrepreneurship on regional economic growth. Thus, the estimation of equations (4.1.6a) to 
(4.1.6d) is for a short-run adjustment of population, employment, per capita income, and entrepreneurship to long-run equilibriums ( $P O P^{*}, E M P^{*}, P C I^{*}$, and $\left.E N T^{*}\right)$.

\subsection{Non-Spatial Model}

\subsubsection{Population Density Growth Equation}

The endogenous variable, growth in population $(G R P O P)$, is defined as the difference in the $\log$ values of population density of 2008 and 1993 in ith county. Change in population density is described as a function of growth in employment (GREMP), growth in per capita income $(G R P C I)$, growth in entrepreneurship (GRENT), the initial condition of population (POPBASE), employment (EMPBASE), per capita income (PCIBASE), entrepreneurship (ENTBASE); and their interaction terms. It is hypothesized that growth in population over time has a negative relationship with the initial condition of population. This negative relationship indicates that growth in population will be slower in the counties with high levels of population compared to the counties that have lower levels of population.

The population equation contains other control variables such as per capita income taxes (PCITAX), per capita local government expenditure $(E G O V)$, crime rate $(C R I M E)$, median housing values $(\mathrm{CMHV})$, and poverty rate (POVERTY). It is hypothesized that growth in population has a negative relationship with PCITAX as it refers to additional cost to households and firms and stimulates out-migration. Government expenditure enlarges public goods and services provision such as highways, education, health, and public safety services (police, fire departments, etc.); therefore, per capita government taxes have a positive relationship with population growth. Unemployment is hypothesized to have a negative relationship with population growth because a high unemployment rate in ith county represents less economic opportunities. Living cost in ith county is represented by county ${ }^{\text {ee }}$ median housing value 
$(C M H V)$. High median housing value has a negative relationship with population growth and low median housing value has a positive relationship with population growth.

A dummy variable represents in location metropolitan counties (METRO) and another dummy variable represents counties adjacent to metropolitan counties (METROADJ) as controls

to the differences in growth patterns. Due to the presence of agglomeration economies, it is hypothesized that $M E T R O$ variable helps population to grow faster.

$$
\begin{aligned}
& \text { GRPOP }=\beta_{0}+\beta_{1} \text { GREMP }+\beta_{2} \text { GRPCI }+\beta_{3} \text { GRENT }+\beta_{4} P O P B A S E+\beta_{5} \text { EMPBASE } \\
(4.2 .1) & +\beta_{6} \text { PCIBASE }+\beta_{7} \text { ENTBASE }+\beta_{8} \text { PCITAX }+\beta_{9} \text { POVERTY }+\beta_{10} E G O V+\beta_{11} C R I M E \\
& +\beta_{12} C M H V+\beta_{13} M E T R O+\beta_{14} M E T R O A D J+\beta_{14} N F I R M+\varepsilon_{1}
\end{aligned}
$$

\subsubsection{Employment Growth Equation}

Growth in employment is defined as the difference in the log values of employment of 2008 and 1993 in ith county. Growth in employment is defined as a function of growth in population (GRPOP), growth in per capita income (GRPCI), and growth in entrepreneurship (GRENT); the initial conditions of employment (EMPBASE), and per capita income (PCIBASE); and some control variables.

Control variables, included in the equation, measure economic effects. Per capita local government expenditure (EGOV) increases public goods and services provision. Therefore, it is hypothesized that local government expenditure has positive relationship with employment growth. Per capita income tax (PCITAX), another economic variable, is included as a control variable and hypothesized to have a negative relationship with employment growth. It is hypothesized that number of firms (NFIRM) in ith county has positive impacts on employment due to the demand for labor.

Another important variable is percentage of population of 25 years or over with bachelor"s degree or higher education $(C O L L D)$ which captures the educational attainment 
effects and represents human capital variables, is included in the per capita income equation as a control variable. As educational attainment increases productivity and entrepreneurial ability and skills of individuals COLLD is expected to have a positive relationship with per capita income. Entrepreneurial ability and skills can be a motivation for expansion of existing firms and startups of new firms as well. Availability variables included in the employment equation are a dummy for metropolitan counties (METRO) and a dummy for counties adjacent to metro counties (METROADJ).

$$
\begin{aligned}
& \text { GREMP }=\beta_{0}+\beta_{1} \text { GRPOP }+\beta_{2} G R P C I+\beta_{3} \text { GRENT }+\beta_{4} \text { EMPBASE }+\beta_{5} \text { PCIBASE } \\
(4.2 .2) \quad & +\beta_{6} \text { PCITAX }+\beta_{7} E G O V+\beta_{8} C M H V+\beta_{9} C O L L D+\beta_{10} M E T R O+\beta_{11} \text { METROADJ } \\
& +\beta_{12} \text { NFIRM }+\varepsilon_{2}
\end{aligned}
$$

\subsubsection{Per Capita Income Growth Equation}

Growth in per capita income is defined as the difference in the log values of per capita income of 2008 and 1993 in ith county. The equation is defined as a function of dependent variables such as growth in population (GRPOP), growth in employment (GREMP), and growth in entrepreneurship (GRENT); the initial conditions of population (POPBASE), per capita income (PCIBASE), and entrepreneurship (ENTBASE); and some control variables.

The control variables are included to measure economic and other effects in the equation. Per capita local government expenditure $(E G O V)$ increases public goods and services provision. Therefore, it is hypothesized that local government expenditure has a positive relationship with per capita income. Per capita income tax (PCITAX), another economic variable, is included as a control variable. A negative relationship is expected between per capita income tax and per capita income. Poverty rate (POVERTY) is expected to have negative effects on per capita income, while holding other things constant, due to slow growth in per capita income when a 
high percentage of population is below the poverty line. It is hypothesized that number of firms (NFIRM) in ith county has positive impacts on per capita income due to the demand for labor.

Control variables that measure demographic effects are percentage of population 65 years or older representing the retired labor force (RETIRE) and percentage of non-white population (NONWTE). Holding other things constant, RETIRE should have a negative relationship with per capita income because the main source of income for retired people is social security benefits. Therefore, a high percentage of retired population in the ith county will only allow per capita income to increase slowly. NONWTE includes all population other than the white population. It captures the relative effects of other populations (African Americans, Asians, and Africans etc.). It is hypothesized that NONWTE has negative effects on per capita income.

The share of the population older than 18 and younger than 64 years represents the active labor force (OPERATIVE), and the percentage of the population of 25 years and older with bachelor"s degree or higher education (COLLD) represents human capital. They are included in the per capita income equation as control variables. It is hypothesized that OPERATIVE affects per capita income positively because at high level more people are working earning high OPERATIVE income from wages and salaries. Since educational attainment is expected to increase productivity and entrepreneurial ability and skills of individuals, COLLD should have positive relationship with per capita income.

$$
\begin{array}{ll} 
& \text { GRPCI }=\beta_{0}+\beta_{1} \text { GRPOP }+\beta_{2} \text { GRENT }+\beta_{3} \text { POPBASE }+\beta_{5} \text { PCIBASE }+\beta_{5} \text { ENTBASE } \\
(4.2 .3) & +\beta_{6} \text { PCITAX }+\beta_{7} \text { EGOV }+\beta_{8} \text { NFIRM }+\beta_{9} \text { POVERTY }+\beta_{10} \text { RETIRE }+\beta_{11} N O N W T E \\
& +\beta_{12} \text { OPERATIVE }+\beta_{13} C O L L D+\beta_{14} G R P R O+\beta_{15} M E T R O+\beta_{16} M E T R O A D J+\varepsilon_{3}
\end{array}
$$

\subsubsection{Entrepreneurship Growth Equation (Equation 1)}

Number of new firms is used as a measure of entrepreneurship. Growth in entrepreneurship is defined as the difference in the log values of number of new firms of 2008 
and 1993 in ith county. The entrepreneurial equation is defined as a function of growth in per population (GRPOP), growth in employment (GREMP), and growth in per capita income (GRPCI); the initial conditions of per capita income (PCIBASE), entrepreneurship (ENTBASE); and some control variables.

The entrepreneurial equation contains control variables such as poverty rate in ith county (POVERTY), a dummy variable for metro counties (METRO), and a dummy variable for counties adjacent to metro counties (METROADJ). A low income level and high poverty rate lead to less entrepreneurial activities in ith county. It measures economic conditions in the county; therefore, a high poverty rate (POVERTY) is expected to be negatively related with entrepreneurship. Generally, metro areas are centers of economic and business activities. High accumulation of business activities increases the demand for labor. Therefore, to control for metro effects a dummy for metro county (METRO) is included in entrepreneurial equation. It is expected that metro county (METRO) is positively related to entrepreneurship.

Some entrepreneurial variables include the ratio of new employers in the county per 1000 in the labor force (WORKER), county business density (DENSITY), intensity of industry (INTENSITY), death of existing firms per county (DEATH), and firm size per county (SIZE). Most new employment is created by small and rapid growth enterprises which accounted for almost 66 percent of all new jobs created in the U.S. during 1979 (Bhide, 2000). Therefore, it is hypothesized that WORKER has a positive relationship with entrepreneurship. To control for differences in density on economic activity, DENSITY is used. It is hypothesized that DENSITY is positively related with entrepreneurship.

To measure the flow of entrepreneurial activity, death of existing firms (DEATH) is included in the equation. It is hypothesized that DEATH has a negative relationship with 
entrepreneurship. The difference in entrepreneurial density due to population is an important aspect. Therefore, INTENSITY is used and hypothesized to be positively related to entrepreneurship. To control for the size distribution of employees, SIZE is used, when hypothesized as positively related with entrepreneurship.

$$
\begin{array}{ll} 
& \text { GRENT }=\beta_{0}+\beta_{1} \text { GRPOP }+\beta_{2} \text { GREMP }+\beta_{3} \text { GRENT }+\beta_{4} \text { PCIBASE }+\beta_{5} \text { ENTBASE } \\
(4.2 .4) & +\beta_{6} \text { POVERTY }+\beta_{7} I N T E N S I T Y+\beta_{8} W O R K E R+\beta_{9} S U R V U V A L+\beta_{10} D E A T H+ \\
& +\beta_{11} \text { SIZE }+\beta_{12} M E T R O+\beta_{13} \text { METROADJ }+\beta_{14} D E N S I T Y+\varepsilon_{4}
\end{array}
$$

\subsubsection{Entrepreneurship Growth Equation (Equation 2)}

Number of non-farm proprietors is used as a measure of entrepreneurship. Growth in entrepreneurship is defined as the difference in the log values of non-farm proprietors of 2008 and 1993 in ith county. This entrepreneurial equation is defined as function of growth in per population (GRPOP), growth in employment (GREMP), and growth in per capita income (GRPCI); the initial conditions of per capita income (PCIBASE), entrepreneurship (ENTBASE); and some control variables. This equation contains control variables such as poverty rate in ith county (POVERTY), a dummy variable for metro counties (METRO), and a dummy variable for counties adjacent to metro counties (METROADJ).

Entrepreneurial variables included in the equation are business density per county (DENSITY), start-up of new firms per county (START), death of existing firms per county (DEATH), number of expansions per county (EXPAND), and survival rate of firms (SURVIVAL). High survival rates of firms encourage more people to start their businesses as proprietors. Therefore, it is hypothesized that if the relationship between SURVIVAL and entrepreneurship is positive the survival rate is high otherwise the relationship is negative.

$$
\begin{aligned}
& \text { GRENT }=\beta_{0}+\beta_{1} \text { GRPOP }+\beta_{2} \text { GREMP }+\beta_{3} \text { GRENT }+\beta_{4} P C I B A S E+\beta_{5} \text { ENTBASE } \\
(4.2 .5) & +\beta_{6} \text { POVERTY }+\beta_{7} S T A R T+\beta_{8} \text { WORKER }+\beta_{9} S U R V U V A L+\beta_{10} D E A T H+ \\
& +\beta_{11} \text { SIZE }+\beta_{12} M E T R O+\beta_{13} \text { METROADJ }+\beta_{14} \text { EXPAND }+\varepsilon_{5}
\end{aligned}
$$




\subsection{Spatial Growth Model}

Audretsch and Lehmann (2005) argued that the Knowledge Spillover Theory of Entrepreneurship applies to regions and industries, and that new firms tend to locate close to universities (source of knowledge). Opportunities to benefit from knowledge spillovers also affect the location decisions of start-ups firms. Human capital is a major factor that influencing a firm "s location decision. LeSage and Fischer (2009) showed spatial dependence as an important factor in regional economic growth analysis, especially in terms of population, employment, and per capita income. Therefore, there is a need to consider the cross-sectional spatial dependences since change in entrepreneurship and growth in one county may be affected by changes in adjacent counties. Therefore, the model represented by equations (4.1.6a)-(4.1.6d) considers the spatial spillovers.

Audretsch and Keilbach (2007) found that entrepreneurship has a great influence on spatial knowledge spillovers and local systems of innovation. An entrepreneur takes part in the knowledge spillover process by investigating new knowledge which can be unexplored if he does not realize that he can earn more from new products rather than being an employee. The cause and effect of entrepreneurship have a real spatial magnitude if entrepreneurship has a major role in the knowledge spillover process. For example, an improvement in entrepreneurial activities in one county is likely to attract investors from other areas. This may result in increased population, employment, and income in the area with improved entrepreneurial activities.

Audretsch and Keilbach (2006) argued that the process of entrepreneurship has significant spatial autocorrelation and affects neighboring counties. Anselin (1988) argued that in the presence of spillover effects, estimation of the econometric model will be biased or inefficient if spatial dependencies are ignored in the model. He also showed that OLS estimation 
results are inconsistent. This means that the non-spatial simultaneous equations should be estimated by incorporating spatial dependency.

The non-spatial simultaneous equations should be estimated by incorporating spatial dependency. Two widely used approaches, which incorporate spatial dependencies, are Spatial Autoregressive (SAR) model and Spatial Error Model (SEM). The SAR model is:

$$
\text { (4.3.1) } \quad Y=X \beta+\rho W Y+\varepsilon \quad \text { with } \quad \varepsilon \sim N\left(0, \sigma^{2} I\right)
$$

Where $Y$ is an $n \times 1$ vector of observations of the dependent variable, $X$ is the $n \times k$ design matrix of explanatory variables, $\beta$ is the $k \times 1$ vector of regression coefficient, $W$ is $n \times n$ spatial weight matrix, $\rho$ is spatial autocorrelation parameter $(1 \times 1), W Y$ is the spatial lag of dependent variable, and $\varepsilon$ is the $n \times 1$ disturbance term and assumed to have a normal distribution with mean of zero. The SAR model is used when spatial autocorrelation is presented in dependent variable which may occur because of "copy-cat" behavior or strategic interaction among economic agents (Brueckner, 2003).

On the other hand, Anselin and Bera (1998) mentioned that the Spatial Error Model (SEM) postulates that spatial dependence is caused either by spatial data that do not match with the actual behavioral features being studied or omitted variable bias (misspecification bias). The correlation of spatial error across variables is the general assumption of the model. The SEM model is

$$
\text { (4.3.2) } \quad Y=X \beta+\varepsilon
$$

Where $Y$ is an $n \times 1$ vector of observations of dependent variable, $X$ is the $n \times k$ design matrix of explanatory variables, $\beta$ is the $k \times 1$ vector of regression coefficient, and $\varepsilon$ is the $n \times 1$ disturbance term that follows

$$
\text { (4.3.3) } \quad \varepsilon=\lambda W \varepsilon+\mu
$$


$W$ is a $n \times n$ spatial weight matrix, $\lambda$ is a spatial autocorrelation parameter $(1 \times 1)$, and $\mu$ is the $n \times 1$ vector of innovations. It is impossible to include all relevant variables in the model and also the independent variables included can illustrate spatial dependence. Therefore, LeSage and Pace (2009) show that SDM incorporates not only spatial lag of the dependent variable but also spatial lag of independent variables. LeSage and Fischer (2009) indicated that SDM also deals with omitted variable bias. The Spatial Durbin model is given by:

(4.3.4) $Y=\rho W Y+X \beta+\theta W X+\varepsilon$ with $\varepsilon \sim N\left(0, \sigma^{2} I\right)$

where $Y$ is the $n \times 1$ vector of observations of dependent variable, $X$ the $n \times k$ design matrix of explanatory variables, $\beta$ the $k \times 1$ vector of regression coefficient, $W$ a $n \times n$ spatial weight matrix, $\rho$ is spatial autocorrelation parameter $(1 \times 1), \theta$ the $k \times 1$ vector, $W X$ the spatial lag of independent variables, and $\varepsilon$ the $n \times 1$ disturbance term, assumed to have a normal distribution with mean zero. The use of SDM implies that entrepreneurship in and the economic development of county $i$ depend on the county ${ }^{\text {ee }}$ own independent variables as well as and entrepreneurship in and economic development of neighboring counties.

The Spatial Autoregressive Model (SAR), Spatial Error Model (SEM), and Spatial Durbin Model (SDM) incorporate spatial dependence. However, model specification requires tests to be carried out to enable us to select one of the models. To select one model for estimation, as shown Table 4.3.1 below, the Lagrange Multiplier (LM) test for specification is employed (Elhorst, 2009). Null hypothesis is:

$$
\mathrm{H}_{\mathrm{o}} \text { : no spatial correlation }
$$

The results of LM test shows that null hypothesis is rejected in population density growth equation, employment equation and entrepreneurship equation and provide the evidence of existence of spatial correlation. Next, model choice continues by choosing model with highest 
LM. The model with the highest value of the LM is the Spatial Error Model. However, the Spatial Error Model would result in spatial dependence in the error terms due to omitted variables (LeSage and Pace, 2009). Therefore SDM is used for spatial analysis.

Table 4.3.1: Lagrange Multiplier Test Results

\begin{tabular}{|c|c|c|c|c|}
\hline & GRPOP & GREMP & GRPCI & GRENT \\
\hline \multicolumn{5}{|l|}{ LM-Lag } \\
\hline LM value & $29.2857 *$ & $4.8175 * *$ & 1.2508 & $31.3317^{*}$ \\
\hline Prob. & 0.0000 & 0.0282 & 0.2634 & 0.0000 \\
\hline \multicolumn{5}{|l|}{ LM-Error } \\
\hline LM value & $41.2920 *$ & $4.0877 * *$ & 0.0156 & $37.9381 *$ \\
\hline Prob. & 0.0000 & 0.0432 & 0.9007 & 0.0000 \\
\hline \multicolumn{5}{|c|}{ LM-Lag Robust } \\
\hline LM value & 1.1170 & 0.9519 & $7.6740 * * *$ & 0.0087 \\
\hline Prob. & 0.2906 & 0.3292 & 0.0056 & 0.9255 \\
\hline \multicolumn{5}{|c|}{ LM-Error Robust } \\
\hline LM value & $13.7385^{*}$ & 0.2325 & $6.4448 * * *$ & $6.8572 * * *$ \\
\hline Prob. & 0.0000 & 0.6297 & 0.0111 & 0.0088 \\
\hline
\end{tabular}

The spatial estimation treats the equations as individual linear equations estimated using Spatial Durbin Model (SDM). The spatial equations to be estimated are explained in section 4.4.

\subsection{Spatial Equations}

To determine the spatial dependence among the endogenous variables of the model, we use a spatial equation of population, employment, income, and entrepreneurship. Following the Carlino and Mills (1987) and Boarnet (1994), a model incorporating own-county and neighboring counties effects is specified as:
(4.4.1a) $P O P^{*}=f_{1}\left[\left(E M P^{*}, \Psi E M P^{*}\right),\left(P C I^{*}, \Psi P C I^{*}\right),\left(E N T^{*}, \Psi E N T^{*}\right), \Psi P O P^{*}, X_{t-1}^{P O P}\right.$
(4.4.1b) $E M P^{*}=f_{2}\left[\left(P O P^{*}, \Psi P O P^{*}\right),\left(P C I^{*}, \Psi P C I^{*}\right),\left(E N T^{*}, \Psi E N T^{*}\right), \Psi E M P^{*}, X_{t-1}^{E M P}\right.$
(4.4.1c) $P C I^{*}=f_{3}\left[\left(P O P^{*}, \Psi P O P^{*}\right),\left(E M P^{*}, \Psi E M P^{*}\right),\left(E N T^{*}, \Psi E N T^{*}\right), \Psi P C I^{*}, X_{t-1}^{P C I}\right.$
(4.4.1d) $E N T^{*}=f_{4}\left[\left(P O P^{*}, \Psi P O P^{*}\right),\left(E M P^{*}, \Psi E M P^{*}\right),\left(P C I^{*}, \Psi P C I^{*}\right), \Psi E N T^{*}, X_{t-1}^{E N T}\right.$ 
where $P O P^{*}, E M P^{*}, P C I^{*}$, and $E N T^{*}$ are vectors of $n \times 1$ dimension representing equilibrium population, employment, per capita income, and entrepreneurship level, respectively, and $\Psi$ is an $n \times n$ matrix which can be expressed as $\Psi=W$ with $W$ as a spatial weights matrix of $n \times n$ dimension. The contiguity weight matrix $(W)$ can be represented by $W=\left\{w_{i j}\right\}_{i=1, j=1}^{n}$ and $\Psi P O P^{*}, \Psi E M P^{*}, \Psi P C I^{*}$, and $\Psi E N T^{*}$ are the values of effects of neighboring counties. Additional exogenous variables in matrix form which are included in the spatial equations are $X_{t-1}^{P O P}, X_{t-1}^{E M P}, X_{t-1}^{P C I}$, and $X_{t-1}^{E N T}$, respectively. The description of these variables is given in table 4.6.1. A log-log form of the model will be used which implies a constant-elasticity form for the equilibrium levels in equations (4.4.1a) to (4.4.1d). A log-log representation of these equilibrium levels can be expressed as:

$$
\begin{aligned}
P O P^{*}= & \alpha_{1}+\beta_{1} E M P^{*}+\beta_{2} P C I^{*}+\beta_{3} E N T^{*}+\beta_{4} P O P_{t-1}+\beta_{5} E M P_{t-1}+\beta_{6} P C I_{t-1}+\beta_{7} E N T_{t-1} \\
& +\beta_{8} \Psi P O P^{*}+\beta_{9} \Psi E M P^{*}+\beta_{10} \Psi P C I^{*}+\beta_{11} \Psi E N T^{*}+\beta_{12} \Psi \sum_{k=1}^{K} X_{k}^{P O P}+\beta_{13} \sum_{k=1}^{K} X_{k}^{P O P}+\varepsilon_{1} \\
E M P^{*}= & \alpha_{2}+\beta_{1} P O P^{*}+\beta_{2} P C I^{*}+\beta_{3} E N T^{*}+\beta_{4} P O P_{t-1}+\beta_{5} E M P_{t-1}+\beta_{6} P C I_{t-1}+\beta_{7} E N T_{t-1} \\
& +\beta_{8} \Psi P O P^{*}+\beta_{9} \Psi E M P^{*}+\beta_{10} \Psi P C I^{*}+\beta_{11} \Psi E N T^{*}+\beta_{12} \Psi \sum_{k=1}^{K} X_{k}^{E M P}+\beta_{13} \sum_{k=1}^{K} X_{k}^{E M P}+\varepsilon_{2} \\
P C I^{*}= & \alpha_{3}+\beta_{1} P O P^{*}+\beta_{2} E M P^{*}+\beta_{3} E N T^{*}+\beta_{4} P O P_{t-1}+\beta_{5} E M P_{t-1}+\beta_{6} P C I_{t-1}+\beta_{7} E N T_{t-1} \\
& +\beta_{8} \Psi P O P^{*}+\beta_{9} \Psi E M P^{*}+\beta_{10} \Psi P C I^{*}+\beta_{11} \Psi E N T^{*}+\beta_{12} \Psi \sum_{k=1}^{K} X_{k}^{P C I}+\beta_{13} \sum_{k=1}^{K} X_{k}^{P C I}+\varepsilon_{3} \\
E N T^{*}= & \alpha_{4}+\beta_{1} P O P^{*}+\beta_{2} E M P^{*}+\beta_{3} P C I^{*}+\beta_{4} P O P_{t-1}+\beta_{5} E M P_{t-1}+\beta_{6} P C I_{t-1}+\beta_{7} E N T_{t-1} \\
& +\beta_{8} \Psi P O P^{*}+\beta_{9} \Psi E M P^{*}+\beta_{10} \Psi P C I^{*}+\beta_{11} \Psi E N T^{*}+\beta_{12} \Psi \sum_{k=1}^{K} X_{k}^{E N T}+\beta_{13} \sum_{k=1}^{K} X_{k}^{E N T}+\varepsilon_{4}
\end{aligned}
$$

Where $P O P^{*}, E M P^{*}, P C I^{*}$, and $E N T^{*}$ represent the log differences between the values of population, employment, income, and entrepreneurship, respectively, from 1993 to 2008 . They denote the growth rates of the respective variables. Parameters are represented by $\alpha_{j}$ for $j=1, \ldots$, 4and $\varepsilon_{j}$ are vectors of error terms for $\mathrm{j}=1, \ldots, 4$. 


\subsection{Data Description}

The empirical models are used to analyze the effects of entrepreneurship in regional economic growth using changes in population, employment, and per capita income. The models are explained as a system of equations with endogenous variables as a function of entrepreneurship, human capital, accessibility, economic, and demographic variables. The focus of the study is 299 counties of the Northeast region of the U.S. The secondary data being used in the study is from 1993 to 2008 . All endogenous variables are formulated as growth rates from 1993 to 2008. Table 4.5.1 provides the description of the endogenous variables and initial condition variables and also cites the sources of data. The data for population, employment, per capita income, and entrepreneurship are from the U.S. Census Bureau, Bureau of Economic Analysis, Regional Economic Information System (REIS), and County and City Data Book (C\&CDB) from 1993 to 2008.

The study formulates and uses percentage growth in population density (GRPOP), employment (GREMP), per capita income (GRPCI), and entrepreneurship (GRENT), from 1993 to 2008 as endogenous variables. The initial conditions influence the beginning of period value of population density, employment, per capita income, and entrepreneurship. These variables are collected from County and City Data Book (C\&CDB) and Bureau of Economic Analysis (BEA). Other than entrepreneurial measures, a number of exogenous variables such as human capital, accessibility, economic, and demographic variables are included for empirical analysis. All exogenous variables used to explain percentage growth rate in population, employment, per capita income, and entrepreneurship are shown in Table 4.6.1. This table also presents the description of the exogenous variables included in the empirical models and sources of these variables. 
Table 4.5.1: Definition and Data Sources for the Endogenous and Initial Condition Variables

\begin{tabular}{|c|c|c|}
\hline $\begin{array}{l}\text { Variable } \\
\text { Name }\end{array}$ & Variable Definitions & Data Source \\
\hline \multicolumn{3}{|c|}{ Endogenous variables } \\
\hline GRPOP & $\begin{array}{l}\text { Growth in population density from } 1993 \text { to } \\
2008\end{array}$ & \begin{tabular}{|l|} 
C\&CDB \\
/Computed
\end{tabular} \\
\hline GREMP & Growth in employment from 1993 to 2008 & BEA / Computed \\
\hline GRPCI & $\begin{array}{l}\text { Growth in per capita income from } 1993 \text { to } \\
2008\end{array}$ & $\begin{array}{l}\text { C\&CDB / } \\
\text { Computed }\end{array}$ \\
\hline GRENT & $\begin{array}{l}\text { Growth in number of new firms from } 1993 \text { to } \\
2008\end{array}$ & BEA/Computed \\
\hline GRENT & $\begin{array}{l}\text { Growth in number of nonfarm proprietors from } \\
1993 \text { to } 2008\end{array}$ & BEA/Computed \\
\hline \multicolumn{3}{|c|}{ Spatially Lagged Endogenous variables } \\
\hline$\Psi P O P^{*}$ & Spatial Lag of Population & Computed \\
\hline$\Psi E M P^{*}$ & Spatial Lag of Employment & Computed \\
\hline$\Psi P C I^{*}$ & Spatial Lag of Per capita income & Computed \\
\hline$\Psi E N T^{*}$ & Spatial Lag of Entrepreneurship & Computed \\
\hline \multicolumn{3}{|c|}{ Initial Condition Variables } \\
\hline POPBASE & Population density 1993 & $\mathrm{C} \& \mathrm{CDB}$ \\
\hline EMPBASE & Employment 1993 & BEA \\
\hline PCIBASE & Per capita income 1993 & C\&CDB \\
\hline ENTBASAE & number of non-farm employees 1993 & BEA \\
\hline ENTBASE & number of nonfarm proprietors from 1993 & BEA \\
\hline
\end{tabular}

All exogenous variables are defined in five categories as explained below:

\section{Accessibility Variables}

Accessibility variables include counties characterized as metro (METRO), inter-state road density (ROADDEN), and counties adjacent to metro areas (METROADJ). The data on accessibility variables are collected from the publication of the U.S. Department of Agriculture Economic Research Services (ERS) and WVU“es Natural Resource Analysis Center.

\section{Human Capital Variables}

Human capital variables include the share of the population between 18 years and 64 years (OPERATIVE) and percentage of population of 25 years and older with a bachelor degree 
or higher $(C O L L D)$. The data on human capital variables are collected from the publication of City and County Data Book (C\&CDB).

\section{Economic Variables}

Economic variables include per capita income tax (PCITAX), unemployment rate $(U N E M P)$, percentage of all age population below poverty (POVERTY), serious crime rate (CRIME), county ${ }^{\text {ee }}$ median housing value $(C M H V)$, and per capita government expenditures $(E G O V)$. The data on economic variables are collected from the publication of the US Census Bureau and City and County Data Book (C\&CDB).

\section{Demographic Variables}

Demographic variables include percentage of population above 65 years (RETIRE), and percentage of non-white population (NONWTE). The data on demographic variables are collected from the publication of City and County Data Book (C\&CDB).

\section{Entrepreneurial Variables}

Entrepreneurial variables include the ratio of new employers in the county in the labor force (WORKER). Other measures of entrepreneurship are; intensity of industry (INTENSITY), start-up of new firms per county $(S T A R T)$, death of existing firms per county $(D E A T H)$, number of expansions per county (EXPAND), firm size per county (SIZE), survival rate of firms (SURVIVAL), number of non-farm proprietors (GRPRO), and business density per county (DENSITY). First, to measure entrepreneurship, the ratio of new employers in the county in the labor force (WORKER) is derived by dividing the number of new employers by total of all employer firms. New jobs are the contribution of new firms when they start and grow in the economy. It is strongly supported by previous studies that the new firms tend to surpass the excellence in their performance in terms of job creation (Baptista et al., 2008; Audretsch et al., 
2004; Geroski, 1995). Intensity of industry (INTENSITY) is derived by dividing total number of private-sector firms in the region by the region"s population. This measure is similar to the specialization measure used by Acs and Armington (2004) and Glaeser et al. (1992). Average county firm size (SIZE) is derived by dividing the number of employees by the number of firms. County business density (DENSITY) is derived by dividing the number of firms by the land area. Data on entrepreneurial variables are collected from the publication of the U.S. Census Bureau's Statistics of the U.S. Businesses (USBS) and Business Dynamics Statistics.

\subsection{Estimation Method}

The equations specified from (4.2.1) to (4.2.4) and equations specified from (4.2.1) to (4.2.3) and (4.2.5) define a non-spatial systems of simultaneous equations. The three stages least squares (3SLS) approach is used for estimation of the non-spatial model. The equations specified from (4.4.1a) to (4.4.1d) defines Spatial Durbin Model (SDM) what will be estimated using the codes in James LeSage"s Econometrics MATLAB toolbox.

Table 4.6.1 presents the description of explanatory variables used in the models. Table 4.6.2 presents the summary statistics of the explanatory and endogenous variables used in the models. In column2, average values of the variables are given, while columns 4 and 5 show the minimum and maximum value of the variables and column 6 shows the standard deviation. 
Table 4.6.1: Definition and Data Sources for the Exogenous Variables

\begin{tabular}{|c|c|c|}
\hline Variables & Definitions & Source \\
\hline OPERATIVE & $\begin{array}{l}\text { The share of population between } 18 \text { years } \\
\text { and } 64 \text { years }\end{array}$ & $\mathrm{C} \& \mathrm{CDB}$ \\
\hline COLLD & $\begin{array}{l}\text { Percentage of population of } 25 \text { years and } \\
\text { older with bachelor degree or higher }\end{array}$ & $\mathrm{C} \& \mathrm{CDB}$ \\
\hline PCITAX & Per capita income tax & C\&CDB \\
\hline UNEMP & Unemployment rate & C\&CDB \\
\hline POVERTY & $\begin{array}{l}\text { Percentage of total population below } \\
\text { poverty line }\end{array}$ & US Census Bureau \\
\hline CRIME & Serious crime rate & C\&CDB \\
\hline $\mathrm{CMHV}$ & County $^{\text {ee }}$ median housing value & $\mathrm{C} \& \mathrm{CDB}$ \\
\hline EGOV & Per capita government expenditures & $\mathrm{C} \& \mathrm{CDB}$ \\
\hline METRO & $\begin{array}{l}\text { Dummy variable, } 1 \text { if county is metro and } 0 \\
\text { otherwise }\end{array}$ & ERS \\
\hline NFIRM & Number of existing firms per county & BEA \\
\hline ROADDEN & Inter-state road density & NRAC \\
\hline METROADJ & $\begin{array}{l}\text { Dummy variable, } 1 \text { if county is adjacent to } \\
\text { a metro and } 0 \text { otherwise }\end{array}$ & ERS \\
\hline RETIRE & Percentage of population above 65 year & $\mathrm{C} \& \mathrm{CDB}$ \\
\hline NONWTE & Percentage of non-white population & $\mathrm{C} \& \mathrm{CDB}$ \\
\hline WORKER & $\begin{array}{l}\text { Ratio of new employers in the county per } \\
1000 \text { in the labor force }\end{array}$ & BDS/Computed \\
\hline INTENSITY & $\begin{array}{l}\text { Number of firm per county divided by land } \\
\text { area of county }\end{array}$ & BDS/Computed \\
\hline EXPAND & Number of expansions per county & USBS \\
\hline START & Start-up of new firms per county & USBS \\
\hline SIZE & $\begin{array}{l}\text { Firm size with less than } 500 \text { employees per } \\
\text { county }\end{array}$ & USBS \\
\hline SURVIVAL & Number of firms survived for five years & USBS/Computed \\
\hline DENSITY & $\begin{array}{l}\text { Number of firms per county divided by } \\
\text { population of county }\end{array}$ & USBS/Computed \\
\hline DEATH & Death of existing firms per county & USBS \\
\hline
\end{tabular}




\begin{tabular}{|l|l|l|}
\hline GRPRO & Number of non-farm proprietors & BEA \\
\hline
\end{tabular}

Table 4.6.2: Descriptive Statistics for the Northeastern Counties, 1993-2008

\begin{tabular}{|l|l|l|l|l|l|}
\hline Variables & Units & Mean & Maximum & Minimum & $\begin{array}{l}\text { Standard } \\
\text { Deviation }\end{array}$ \\
\hline OPERATIVE & percentage & 1.78656 & 1.861851 & 1.733692 & 0.019854 \\
\hline COLLD & percentage & 20.58963 & 54.6 & 5.6 & 9.360455 \\
\hline PCITAX & percentage & 1.120319 & 2.487604 & 0.430979 & 0.407014 \\
\hline PRTAX & percentage & 2.85046 & 3.593286 & 0.0 & 0.420212 \\
\hline UNEMP & percentage & 8.107023 & 19.2 & 3.4 & 2.962096 \\
\hline POVERTY & percentage & 13.95552 & 38.8 & 3.2 & 6.361255 \\
\hline CRIME & percentage & 0.0 & 2.903988 & -1.3862 & 0.845059 \\
\hline CMHV & $\log$ & 4.960054 & 6.0 & 4.198657 & 0.232395 \\
\hline EGOV & $\log$ & 3.306841 & 3.74904 & 0.0 & 0.409429 \\
\hline METRO & $\log$ & 0.548495 & 1.0 & 0.0 & 0.498477 \\
\hline ROADDEN & $\log$ & 2.95057 & 4.046916 & 2.00101 & 0.297006 \\
\hline METROADJ & $\log$ & 0.314381 & 1.0 & 0 & 0.465047 \\
\hline RETIRE & percentage & 1.14113 & 1.365077 & 0.784264 & 0.0885 \\
\hline NFIRM & $\log$ & 3.196920 & 5.0142711 & 1.7708979 & 0.615940 \\
\hline NONWTE & $\log$ & 9.624415 & 73.0 & 0.6 & 12.03228 \\
\hline WORKER & $\log$ & 1.696274 & 4.091867 & -0.11828 & 1.180686 \\
\hline INTENSITY & $\log$ & 1.27437388 & 1.84004206 & 0.90443473 & 0.123170 \\
\hline EXPAND & $\log$ & 2.674859 & 4.349841 & 1.0 & 0.622925 \\
\hline START & $\log$ & 1.274374 & 1.840042 & 0.904435 & 0.123171 \\
\hline SIZE & $\log$ & 3.188427 & 5.010213 & 1.757905 & 0.617018 \\
\hline SURVIVAL & $\log$ & 0.0315808 & 0.35459 & -0.145167 & 0.074494 \\
\hline DENSITY & $\log$ & 0.491821 & 3.653299 & -1.19345 & 0.716136 \\
\hline DEATH & $\log$ & 2.207353 & 4.018409 & 0.69897 & 0.621231 \\
\hline
\end{tabular}




\section{CHAPTER 5: EMPIRICAL ANALYSIS AND RESULTS}

\section{Introduction}

This chapter concentrates on estimation of the empirical models for determining the relationship between entrepreneurship and regional economic development. Regional economic development is indicated by growth in population density, employment, and per capita income. New firm formation and self-employment are two measures of entrepreneurship used in this study. The empirical models are estimated using three stage least squares (3SLS) method and Spatial Durbin Model (SDM). This chapter consists of two major sections and two subsections within each section. Section 5.1 presents the results of non-spatial model and Section 5.2 present the results of the spatial model.

\subsection{Non-Spatial Growth Model Results}

The non-spatial model is used to analyze the relationship between the endogenous variables growth of population density, employment, per capita income, and entrepreneurship. First, the non-metro data set of the region is used to examine the effects of economic development on rural counties in the region. Second, the data set of the region is used to evaluate the effects of economic development in the whole region. The second column of Tables 5.1.15.2.4 presents the results of the three stage least squares (3SLS_NE1) using a system of simultaneous equations of non-metro counties. The third column of the eight tables presents the results (3SLS_NE2) of the Northeast region. All endogenous variables are not included as all four equations such as GREMP, GRPCI, and GRENT are included in population density growth equation (GRPOP). The reason is, for three-stage least squares, some of the explanatory variables enter the model as instruments when the parameters are estimated. However, since the objective of this study is to estimate the system of simultaneous equation (structural model), the 
actual values, not the instruments for the endogenous right-hand-side variables, are used to determine the model sum of squares (MSS). Including all endogenous variables as explanatory variables in all equations, result in higher residual sum of square (RSS) than total sum of square (TSS). When RSS exceeds TSS, the MSS and then $R^{2}$ will be negative (Sribney et al., 1999).

\section{The Results of Entrepreneurship Represented by New Firm Formation and its}

\section{Relationship with Economic Development}

The non-spatial model analyzes the relationship of new firm formation as a measure of entrepreneurship and economic development. Economic development is represented by growth in population density, employment, and per capita income. Three stage least square (3SLS) is used to overcome the problem of correlation of error term of each equation. 3SLS takes into accounts all restrictions on parameters in the system of simultaneous equations.

\subsubsection{Population Density Growth Equation}

The results of the population growth equation for the Northeast region using 3SLS are presented in Table 5.1.1. The population density growth equation is estimated against endogenous variables of growth in employment (GREMP), per capita income (GRPCI), and entrepreneurship (GRENT); the initial conditions of population (POPBASE), employment (EMPBASE), per capita income (PCIBASE), and entrepreneurship (ENTBASE); and control variables are included to measure economic effects. The goodness of fit $\left(\mathrm{R}^{2}\right)$ of the empirical results ranges from 24 to 59 percent in population density growth. An assumption is made in developing the empirical model that growth depends on initial conditions.

The results of 3SLS_NE1 for non-metro counties are presented in Table 5.1.1 which indicates the region specific 3SLS estimation for population density growth. Special attention is required for analysis of these results. The sample size is relatively small as the northeast has only 
135 non-metro counties. In 3SLS_NE1, an increase in number of jobs attracts in-migration. The empirical results show that growth in population density $(G R P O P)$ is positively and significantly related to growth in employment (GREMP) which explains that an increase in the number of jobs also increases population. A significant and negative relationship between population growth $(G R P O P)$ and growth in per capita income $(G R P C I)$ indicates that in several areas of the Northeast region population increases as per capita income decreases. As the number of new firms increases the demand for labor also increases which leads to in-migration. There is a significant and positive relationship between population growth (GRPOP) and entrepreneurship

Table 5.1.1: Three Stage Least Squares Results of Growth in Population Density

\begin{tabular}{|c|c|c|c|c|}
\hline \multirow[t]{2}{*}{ Variables } & \multicolumn{2}{|l|}{ 3SLS_NE1 } & \multicolumn{2}{|l|}{ 3SLS_NE2 } \\
\hline & Coefficient & Z-stat & Coefficient & Z-stat \\
\hline GREMP & $.6162721 * * *$ & 5.10 & & \\
\hline GRPCI & $-.0352373 *$ & -1.69 & & \\
\hline GRENT & $.1915825 * * *$ & 3.66 & & \\
\hline POPBASE & -.0408771 & -1.30 & -.0109853 & -0.48 \\
\hline EMPBASE & -.0560094 & -1.34 & $-.0714773 * * *$ & 2.89 \\
\hline PCIBASE & -.0829203 & -1.39 & $-.1634532 * * *$ & -5.05 \\
\hline ENTBASE & $.0744874 * *$ & 2.63 & $.0373085 * *$ & 2.07 \\
\hline POVERTY & -.0001361 & -0.23 & $-.0020972 * * *$ & -4.50 \\
\hline CRIME & .0031012 & 0.87 & $.0186451 * * *$ & 5.23 \\
\hline PCITAX & -.0096923 & -0.91 & $-.0206257 * * *$ & -3.01 \\
\hline EGOV & -.0252269 & -1.04 & -.0074732 & -1.32 \\
\hline CMHV & $.1405681 * * *$ & 3.29 & $.2161032 * * *$ & 9.04 \\
\hline METRO & & & $.0138954 * *$ & 2.01 \\
\hline METROADJ & & & .0041116 & 0.66 \\
\hline $\mathrm{N}$ & 135 & & 299 & \\
\hline $\mathrm{R}^{2}$ & 0.2397 & & 0.5893 & \\
\hline
\end{tabular}

growth (GRENT). The initial condition of entrepreneurship (ENTBASE) also has a positive and significant relationship with population growth $(G R P O P)$. This relationship implies that counties 
with initial lower numbers of new firms in the 1993 experience faster growth in population than counties which had a larger number of firms. A county"s median housing value $(C M H V)$ and GRPOP are significantly and positively related to each other.

In 3SLS_NE2, the initial condition of employment (EMPBASE), the initial condition of entrepreneurship (ENTBASE), per capita income tax (PCITAX), and county"s median housing value $(C M H V)$ have the same relationship with population growth as in 3SLS_NE1. The initial condition of per capita income (PCIBASE) indicates a significant and negative relationship with population growth (GRPOP). It shows that counties with high per capita income had low population growth rates compared to counties with lower initial per capita income, a result that was unexpected. Poverty rate (POVERTY) has a significant and negative relationship with population growth $(G R P O P)$ which might imply that people tend to move out of the counties that have high poverty rates. The dependent variable GRPOP is significantly and positively related to a dummy variable for metro counties (METRO) which shows that metro counties are growing more rapidly than rural counties. The metro counties are getting denser more rapidly.

\subsubsection{Employment Growth Equation}

The results of the employment growth equation for the Northeast region using 3SLS are presented in Table 5.1.2. The employment growth equation is estimated against endogenous variables of growth in population (GRPOP), per capita income (GRPCI), and entrepreneurship (GRENT); the initial condition of employment (EMPBASE) and per capita income (PCIBASE); with control variables included to measure economic effects. The goodness of fit $\left(\mathrm{R}^{2}\right)$ of the empirical results ranges from 62 to 63 percent in employment growth.

In 3SLS_NE1, growth in employment (GREMP) is positively related with growth in population density (GRPOP) and significant at the 1 percent level. This result indicates that jobs 
follow people. Since, the population growth rate in the Northeast region is low; it indicates a low supply of labor and ultimately an increase in wage rate. Then, firms do not have any option other than employing labor with high wage rates. There is a significant and positive relationship between employment growth (GREMP) and per capita income growth (GRPCI) as expected. There is a significant and negative relationship between a county's median housing value $(C M H V)$ and employment growth (GREMP). An increase in median housing value $(C M H V)$ helps people to make a decision to not start a job if the cost of living is too high in that county.

Table 5.1.2: Three Stage Least Squares Results of Growth in Employment

\begin{tabular}{|c|c|c|c|c|}
\hline \multirow[t]{2}{*}{ Variables } & \multicolumn{2}{|l|}{ 3SLS_NE1 } & \multicolumn{2}{|l|}{ 3SLS_NE2 } \\
\hline & Coefficient & z-stat & Coefficient & z-stat \\
\hline GRPOP & $.8668667 * * *$ & 4.60 & $.7135554 * * *$ & 4.91 \\
\hline GRPCI & $.076947 * * *$ & 3.18 & $.1085531 * * *$ & 4.02 \\
\hline GRENT & -.0672075 & -1.09 & .0684541 & 1.01 \\
\hline EMPBASE & .0541042 & 0.53 & $.2160123 * *$ & 2.30 \\
\hline PCIBASE & .1166269 & 1.37 & .0843211 & 1.27 \\
\hline PCITAX & .0107681 & 0.66 & $.0306346^{* * *}$ & 2.62 \\
\hline EGOV & .0380577 & 1.06 & .009295 & 0.98 \\
\hline CMHV & $-.1439909 * *$ & -2.14 & $-.1666223^{* * *}$ & -3.33 \\
\hline COLLD & -.0007487 & -0.87 & .0004746 & 0.71 \\
\hline NFIRM & -.0310281 & -0.31 & $-.1825132 *$ & -1.94 \\
\hline ROADDEN & -.0021116 & -0.11 & .0053374 & 0.27 \\
\hline METRO & & & -.0083988 & -0.74 \\
\hline METROADJ & & & .0108204 & 1.04 \\
\hline $\mathrm{N}$ & 135 & & 299 & \\
\hline $\mathrm{R}^{2}$ & 0.6217 & & 0.6335 & \\
\hline
\end{tabular}

In 3SLS_NE2, population growth (GRPOP), per capita income growth (GRPCI), and the county"s median housing value $(C M H V)$ have the same relationships with employment growth as in 3SLS_NE1. Number of firms (NFIRM) and employment growth (GREMP) are significantly 
and negatively linked with each other indicating that counties with larger number of existing firms have slower employment growth rates. The initial condition of employment (EMPBASE) is significantly and positively linked with GREMP. This result shows that counties with low employment in 1993 had low employment growth compared to counties with high employment in 1993. An increase in per capita income tax $($ PCITAX) raises more revenue for government and ultimately is used in provision of local government spending programs such as education, health care, highways, crime prevention etc.

\subsubsection{Per Capita Income Growth Equation}

The results of the per capita income growth equation for the Northeast region using 3SLS are presented in Table 5.1.3. The per capita income growth equation is estimated against endogenous variables of growth in population (GRPOP) and entrepreneurship (GRENT); the initial condition of population (PCIBASE), and entrepreneurship (ENTBASE); and control variables included to measure economic effects. The goodness of fit $\left(\mathrm{R}^{2}\right)$ of the empirical result ranges from 84 to 85 percent in the per capita income growth equation.

In 3SLS_NE1, non-metro counties, the initial condition of per capita income (PCIBASE), has a negative relationship with GRPCI and indicates that counties with a low level of income in 1993 had higher growth rates later compared to counties with higher incomes in 1993 . The coefficient of initial condition of population (POPBASE) is significant and has positive effects on per capita income growth (GRPCI). This implies that a high level of population density growth represents a larger supply of labor which positively affects output and ultimately per capita income. As number of new firm increases in a county, demand for labor also increases which leads to an increase in per capita income in the county. Job opportunities for unemployed or under-employed people increase due to an increase in number of proprietors. This implies a 
positive relation between $G R P C I$ and growth rate of number of proprietors (GRPRO). The

Table 5.1.3: Three Stage Least Squares Results of Growth in Per Capita Income

\begin{tabular}{|c|c|c|c|c|}
\hline \multirow[t]{2}{*}{ Variables } & \multicolumn{2}{|l|}{ 3SLS_NE1 } & \multicolumn{2}{|l|}{ 3SLS_NE2 } \\
\hline & Coefficient & Z-stat & Coefficient & Z-stat \\
\hline GRPOP & .2277485 & 0.29 & $-.7941519 *$ & -1.67 \\
\hline GRENT & -.4728812 & -1.53 & .2470463 & 1.08 \\
\hline POPBASE & $.4682641 * *$ & 2.11 & & \\
\hline PCIBASE & $-1.026793 * * *$ & -2.85 & $-.9778639 * * *$ & -5.51 \\
\hline ENTBASE & .0632621 & 0.28 & $.4600828 * * *$ & 3.69 \\
\hline GRPRO & $.3069994 * * *$ & 12.26 & $.2164576^{* * *}$ & 14.60 \\
\hline POVERTY & .0019477 & 0.49 & .0014498 & 0.66 \\
\hline PCITAX & .0751059 & 1.55 & .0139715 & 0.58 \\
\hline EGOV & $-.1733352 *$ & -1.62 & .0186251 & 0.91 \\
\hline COLLD & .0025411 & 0.60 & $-.0030402 *$ & -1.93 \\
\hline NFIRM & -.3055695 & -1.48 & $-.275007 * *$ & -2.27 \\
\hline OPERATIVE & $2.059266 * *$ & 2.34 & $2.342517 * * *$ & 5.91 \\
\hline RETIRE & -.038902 & -0.15 & .0451554 & 0.37 \\
\hline NONWTE & -.0038815 & -1.15 & & \\
\hline METRO & & & -.003469 & -0.14 \\
\hline METROADJ & & & -.0105013 & -0.44 \\
\hline $\mathrm{N}$ & 135 & & 299 & \\
\hline $\mathrm{R}^{2}$ & 0.8516 & & 0.8446 & \\
\hline
\end{tabular}

empirical results confirm economic theory by presenting a significant and positive link between GRPCI and GRPRO. The active population represented by the share of population between 18 years and 64 years (OPERATIVE) derive most of their income from wage and salaried jobs. Hence, OPERATIVE is significantly and positively related to GRPCI. There is a significant and negative relationship for rural counties, between local government expenditure $(E G O V)$ and per capita income $(G R P C I)$ as expected.

In 3SLS_NE2, the empirical results show that growth in population (GRPOP) is 
negatively related with growth rate of per capita income $(G R P C I)$ which indicates that as the population growth increases, the per capita income growth rate decreases. As the number of new firms increases in a county, the demand for labor also increases which leads to increase in per capita income in the county. The initial condition of per capita income (PCIBASE), growth in number proprietors (GRPRO), and share of population between 18 and 64 years (OPERATIVE) have the same relationships with per capita income growth $(G R P C I)$ as in 3SLS_NE1. The significant and positive coefficient of the initial condition of entrepreneurship (ENTBASE) is as expected. The coefficient of number of existing firms (NFIRM) is significant and negative at the 5 percent significance level. An increase in educational attainment (COLLD) increases number of skilled labor in the county. Skilled labor earns more compared to unskilled labor. However, a significant and negative link has found between educational attainment (COLLD) and growth in per capita income growth $(G R P C I)$ which was unexpected. The active population represented by the share of population between 18 years and 64 years (OPERATIVE) derive most of their income from wage and salaried jobs. Hence, OPERATIVE is significantly and positively related to GRPCI.

\subsubsection{Entrepreneurship Growth Equation}

The results of the entrepreneurship growth equation for the Northeast region using 3SLS are presented in Table 5.1.4. The entrepreneurship growth equation is estimated against endogenous variables of growth in population (GRPOP), employment (GREMP), and per capita income $(G R P C I)$; the initial condition per capita income (PCIBASE) and entrepreneurship (ENTBASE); and control variables are included to measure economic effects. The goodness of fit $\left(\mathrm{R}^{2}\right)$ of the empirical result ranges from 66 to 75 percent in entrepreneurship growth.

In 3SLS_NE1, the empirical results show that for rural counties growth in population 
$(G R P O P)$ is significantly and positively related with growth in entrepreneurship (GRENT). It shows that as population increases a large number of unskilled laborers is available which attracts entrepreneurs to start their businesses in that county, or new business firms are attracted by low wages in the rural areas. A large supply of labor causes growth in per capita income to decrease. This implies a negative relationship between per capita income growth (GRPCI) and growth in entrepreneurship (GRENT). The empirical results confirm a negative link between GRPCI and GRENT. The coefficient of initial condition of entrepreneurship (ENTBASE) is significant and negative with entrepreneurship growth (GRENT). It implies that a large number of firms in 1993 indicate a possibly high wage rate and discourages entrepreneurs to start new businesses. The coefficient of number of firm density (INTENSITY) is significant and negative at the 5 percent significance level. As the size of existing firms (SIZE) increases, entrepreneurs are attracted to start new businesses. A significant and positive coefficient of firm size (SIZE) is as expected. Firms ${ }^{\text {ee death }}($ DEATH) and poverty rate (POVERTY) have significant and positive links with entrepreneurship growth (GRENT). However, the signs of both coefficients are unexpected.

In 3SLS_NE2, population growth (GRPOP), per capita income growth (GRPCI), initial condition of entrepreneurship (ENTBASE), firms"e density (INTENSITY), firms" death (DEATH), and firm size (SIZE) have the same significant relationships with entrepreneurship growth rates(GRENT) as in 3SLS_NE1. A significant and negative coefficient of a dummy variable for counties that are adjacent to metro counties (METROADJ) indicates that entrepreneurial growth (GRENT) is slower in those counties. However, the coefficient of dummy variable is very low (near zero) which indicates that it has very little effect on the growth of entrepreneurship. There is negative and significant relationship between a dummy variable for metro (METRO) and 
entrepreneurship growth (GRENT). However, the sign of this coefficient is unexpected but also low in value.

Table 5.1.4: Three Stage Least Squares Results of Growth in Entrepreneurship

\begin{tabular}{|c|c|c|c|c|}
\hline \multirow[t]{2}{*}{ Variables } & \multicolumn{2}{|l|}{ 3SLS_NE1 } & \multicolumn{2}{|l|}{ 3SLS_NE2 } \\
\hline & Coefficient & z-stat & Coefficient & z-stat \\
\hline GRPOP & $2.21181 * * *$ & 7.73 & $1.397199 * * *$ & 7.45 \\
\hline GREMP & & & .2604139 & 0.65 \\
\hline GRPCI & $-.0916593 * *$ & -2.29 & $-.0920302 *$ & -1.68 \\
\hline PCIBASE & -.022616 & -0.68 & .0155627 & 0.83 \\
\hline ENTBASE & $-.6630347^{* * *}$ & -7.94 & $-.6402078 * * *$ & -11.35 \\
\hline POVERTY & $.003226 *$ & 1.88 & -.0007749 & -0.80 \\
\hline INTENSITY & $-.2054614^{* *}$ & -2.31 & $-.1730116^{* * *}$ & -3.52 \\
\hline WORKER & -.00070079 & -.10 & .0035978 & 0.89 \\
\hline DENSITY & .0087082 & 0.35 & .0194856 & 1.45 \\
\hline SURVIVAL & .1128181 & 1.07 & .0649145 & 0.67 \\
\hline DEATH & $.266692 * * *$ & 3.49 & $.3022766^{* * *}$ & 5.22 \\
\hline SIZE & $.4056307 * * *$ & 5.45 & $.31845^{*}$ & 6.26 \\
\hline METRO & & & $-.0416672 * * *$ & -2.83 \\
\hline METROADJ & & & $-.030082 * *$ & -2.27 \\
\hline $\mathrm{N}$ & 135 & & 299 & \\
\hline $\mathrm{R}^{2}$ & 0.6695 & & 0.7503 & \\
\hline
\end{tabular}

The results of Entrepreneurship represented by self-employment and its relationship with

\section{Economic Development}

\subsubsection{Population Density Growth Equation}

The results of the population growth equation for the Northeast region using 3SLS are presented in Table 5.1.5. The population growth equation is estimated against growth in employment (GREMP), per capita income (GRPCI), the initial condition of population (POPBASE), employment (EMPBASE), per capita income (PCIBASE), entrepreneurship (ENTBASE), and some control variables included to measure economic effects. The goodness of 
fit $\left(\mathrm{R}^{2}\right)$ of the empirical results ranges from 28 to 57 percent for population growth. The initial conditions of the endogenous variables are used under the assumption that growth depends on initial conditions. In empirical results of 3SLS_NE1 and 3SLS_NE2, the initial condition of population density is significant and negative. It indicates that counties with initial high population densities are growing slower compared to counties with low initial population densities. This result is consistent with previous studies (Deller et al., 2001). 3SLS_NE1 indicates the 3SLS estimation results of non-metro counties for population growth. 3SLS_NE2 presents 3SLS estimation results of the region for population growth. The estimation results of 3SLS_NE2 are more significant in the region as a whole than non-metro counties.

In 3SLS_NE1, growth in employment (GREMP) and the initial condition of population (POPBASE) and the initial condition of per capita income (PCIBASE) are significant. GREMP has a positive relationship with GRPOP explaining that an increase in employment growth probably leads to an increase in-migration. The significant and negative relationship of POPBASE with population density growth is as expected. However, the negative sign of PCIBASE is unexpected. A county"s median housing value $(C M H V)$, percentage of non-white population (NONWTE), and road density (ROADDEN) have significant and positive relationships with population growth.

In 3SLS_NE2, poverty rate (POVERTY) and number of existing firms (NFIRM) are significantly and negatively related to population growth. Both variables lead to out-migration which reduces population density in the region. A high poverty rate forces people to move out from that county to another county where the poverty rate is less. Similarly, if number of firms is high in 1993 in a county then there is lower probability of starting new firms. Hence, less new job opportunities encourage people to move out from that county. Start-up of firms (START) and 
the share of population between 18 and 64 years (OPERATIVE) have significant and positive coefficients. The initial conditions of population density (POPBASE) and employment

Table 5.1.5: Three Stage Least Squares Results of Growth in Population Density

\begin{tabular}{|c|c|c|c|c|}
\hline \multirow[t]{2}{*}{ Variables } & \multicolumn{2}{|l|}{ 3SLS_NE1 } & \multicolumn{2}{|l|}{ 3SLS_NE2 } \\
\hline & Coefficient & z-stat & Coefficient & z-stat \\
\hline GREMP & $.3281952 *$ & 1.95 & & \\
\hline GRPCI & .0660876 & 1.15 & & \\
\hline POPBASE & $-.1266332 * *$ & -2.40 & $-.0836082 * * *$ & -3.36 \\
\hline EMPBASE & .0702944 & 0.64 & $.3324974 * *$ & 1.90 \\
\hline PCIBASE & $-.1643391 *$ & -1.78 & $-.2613422 * * *$ & -5.56 \\
\hline ENTBASE & .004835 & 0.15 & -.2049625 & -1.29 \\
\hline POVERTY & -.0001039 & -0.11 & $-.0023824 * * *$ & -4.43 \\
\hline START & & & $.1193088 * * *$ & 5.64 \\
\hline EGOV & -.0192558 & -0.80 & -.0023824 & -0.87 \\
\hline CMHV & $.1913144 * * *$ & 4.88 & $.1566702 * * *$ & 6.76 \\
\hline NONWTE & $.0011585^{*}$ & 1.68 & & \\
\hline NFIRM & .023308 & 0.27 & $-.1861283 * * *$ & -3.31 \\
\hline ROADDEN & $.0562414 * * *$ & 2.73 & .0125681 & 0.91 \\
\hline OPERATIVE & -.0912668 & -0.46 & $.289263 * * *$ & 2.76 \\
\hline METRO & & & $.0182174 * * *$ & 2.54 \\
\hline METROADJ & & & .0028179 & 0.44 \\
\hline $\mathrm{N}$ & 135 & & 299 & \\
\hline $\mathrm{R}^{2}$ & 0.2849 & & 0.5758 & \\
\hline
\end{tabular}

(EMPBASE) are significant with expected signs. But PCIBASE is significant with an unexpected sign. Countyes median housing value $(C M H V)$ and GRPOP are significantly and positively related to each other. A significant and positive coefficient of the metro dummy variables (METRO) shows that population density growth is higher in metro counties in the Northeast region. However, the coefficient of dummy variable is close to zero indicating not a large difference in population growth rate in metro and non-metro counties.

\subsubsection{Employment Growth Equation}


The 3SLS results for the employment growth equation for the Northeast region are presented in Table 5.1.6. The employment growth equation is estimated against endogenous variables of growth in population (GRPOP), employment (GREMP), and entrepreneurship (GRENT); the initial condition of endogenous variables of employment (EMPBASE) and per capita income (PCIBASE); and control variables are included to measure economic effects. The goodness of fit $\left(\mathrm{R}^{2}\right)$ of the empirical estimation ranges from 61 to 67 percent of employment growth.

In 3SLS_NE1, growth in population (GRPOP) has a significant and positive relationship with employment growth. It implies that "jobs follow people." Road density (ROADDEN) is used to represent quality of infrastructure. The coefficient of road density is significant at the 10 percent level and but negatively related with employment growth (GREMP) representing an unexpected sign. Other control variables are not significant, possibly due to low employment growth rates in rural counties in the region.

In 3SLS_NE2, growth in population (GRPOP) has the same significant relationships with employment growth as in 3SLS_NE1. Population growth rates in the Northeast region are low indicating a low supply of labor and ultimately wage rate increases. Firms do not have any option other than employing labor at higher wage rate. Hence, a significant and positive relationship between GREMP and GRPCI is as expected. The initial condition of employment is significant at the 5 percent significance level but with an unexpected sign. A county"s median housing value $(C M H V)$ is significant and negatively related with employment growth (GREMP). There is a significant and positive relationship between employment growth (GREMP) and per capita income tax (PCITAX) which indicates that people pay more per capita income taxes in growing counties. 
Table 5.1.6: Three Stage Least Squares Results of Growth in Employment

\begin{tabular}{|l|l|l|l|l|}
\hline \multirow{2}{*}{ Variables } & 3SLS_NE1 & 3SLS_NE2 \\
\cline { 2 - 5 } & Coefficient & z-state & Coefficient & z-stat \\
\hline GRPOP & $.6886161^{* * *}$ & 3.08 & $.825905^{* * *}$ & 5.88 \\
\hline GRPCI & .0155636 & 0.33 & $.0986824^{* *}$ & 2.01 \\
\hline GRENT & .0096037 & 0.33 & .0256974 & 1.37 \\
\hline EMPBASE & .0266711 & 0.15 & $.1486874^{*}$ & 1.61 \\
\hline PCIBASE & .1313152 & 1.27 & .0886068 & 1.39 \\
\hline PCITAX & .0092603 & 0.58 & $.0231532^{* *}$ & 2.10 \\
\hline EGOV & .0060049 & 0.14 & .0099246 & 1.10 \\
\hline CMHV & -.0970975 & -1.33 & $-.1632344^{* * *}$ & -3.28 \\
\hline NFIRM & .0045229 & 0.03 & -.0974332 & -1.04 \\
\hline ROADDEN & $-0.0501278^{*}$ & -1.63 & .0118166 & 0.61 \\
\hline METRO & \multicolumn{5}{|l}{} & -.0078812 & -0.67 \\
\hline METROADJ & \multicolumn{5}{|l}{} \\
\hline \multicolumn{5}{|l|}{} \\
\hline N & 135 & .0109901 & 1.03 \\
\hline$R^{2}$ & 0.6730 & 299 \\
\hline Note: ***,**** represents significance at $1,5,10 \%$, respectively \\
\hline
\end{tabular}

\subsubsection{Per Capita Income Growth Equation}

The results of the per capita income growth equation for the Northeast region using 3SLS are presented in Table 5.1.7. The per capita income growth equation is estimated against endogenous variables of growth in employment (GREMP) and entrepreneurship (GRENT); the initial conditions of endogenous variables of per capita income (PCIBASE) and entrepreneurship (ENTBASE); and control variables included to measure economic effects. The goodness of fit $\left(\mathrm{R}^{2}\right)$ of the empirical results ranges from 64 to 78 percent for per capita income growth.

In 3SLS_NE1, the coefficient of initial condition of per capita income (PCIBASE) is significant at the 1 percent level and the sign is negative as expected. This shows that counties with low per capita incomes in 1993 have higher per capita income growth rates later compared to the counties which have high per capita incomes in 1993. The share of population between 18 
and 64 years (OPERATIVE) is significantly and positively related with per capita income growth (GRPCI). This result shows that counties a larger share of active population experience a higher per capita income growth rates than other counties.

Table 5.1.7: Three Stage Least Squares Results of Growth in Per capita Income

\begin{tabular}{|c|c|c|c|c|}
\hline \multirow[t]{2}{*}{ Variables } & \multicolumn{2}{|l|}{ 3SLS_NE1 } & \multicolumn{2}{|l|}{ 3SLS_NE2 } \\
\hline & Coefficient & z-stat & Coefficient & z-stat \\
\hline GREMP & .6065662 & 1.00 & .8731767 & 1.55 \\
\hline GRENT & -.0169272 & -0.18 & \begin{tabular}{|l|}
.0402539 \\
\end{tabular} & 0.85 \\
\hline PCIBASE & $-.9176009 * * *$ & -2.48 & $\begin{array}{l}-.5819753 * * * \\
\end{array}$ & -3.22 \\
\hline ENTBASE & .1803542 & 0.31 & -.126479 & -0.47 \\
\hline PCITAX & .0152956 & 0.28 & .0186441 & 0.58 \\
\hline NFIRMS & -.1815602 & -0.29 & .1643224 & 0.59 \\
\hline ROADDEN & .0569245 & 0.55 & & \\
\hline OPERATIVE & $2.090143 * * *$ & 2.96 & $1.590782 * * *$ & 4.52 \\
\hline COLLD & -.00142116 & $\begin{array}{l}-0.37 \\
-0.37\end{array}$ & -.0470247 & -1.88 \\
\hline UNEMP & .010579 & 1.55 & $.0086705^{* *}$ & 2.41 \\
\hline RETIRE & & & -.0712275 & -0.54 \\
\hline METRO & & & $-.0470247^{*}$ & -1.66 \\
\hline METROADJ & & & $-.0448674 *$ & -1.71 \\
\hline $\mathrm{N}$ & 135 & & 299 & \\
\hline $\mathrm{R}^{2}$ & 0.6416 & & 0.7814 & \\
\hline
\end{tabular}

In 3SLS_NE2, the initial condition of per capita income (PCIBASE) has the same relationship with per capita income growth as in 3SLS_NE1. The active population represented by the share of population between 18 years and 64 years (OPERATIVE) derive most of their income from wages and salary jobs. Hence, OPERATIVE is significantly and positively related with per capita income growth (GRPCI). The significant and positive coefficient of unemployment rate (UNEMP) was not expected. The significant and negative coefficient of a dummy variable for counties adjacent to metro counties (METROADJ) shows that per capita 
income growth is lower in counties that are adjacent to metro counties. A dummy variable for metro $(M E T R O)$ is significant with unexpected sign.

\subsubsection{Entrepreneurship Growth Equation}

The results of the entrepreneurship growth (self-employment) equation for the Northeast region using 3SLS are presented in Table 5.1.8. The entrepreneurship growth equation (GRENT) is estimated against endogenous variables of growth in employment (GREMP) and per capita income (GRPCI); the initial condition of per capita income (PCIBASE) and entrepreneurship (ENTBASE); and control variables included to measure economic effects. The goodness of fit $\left(\mathrm{R}^{2}\right)$ of the empirical result ranges from 28 to 46 percent in entrepreneurship growth.

In 3SLS_NE1, employment growth has a significant and positive relationship with entrepreneurship growth (GRENT). The coefficient of initial condition of entrepreneurship $(E N T B A S E)$ is significant and positive. This shows that counties with fewer entrepreneurs in 1993 have fewer entrepreneurs as self-employed later compared to the counties which had a higher number of entrepreneurs as self-employed in 1993. The significant and negative coefficient of the number of new jobs (WORKER) indicates that high wage and salary rates for the number of new jobs created discourages people to be self-employed and makes them search for high paying jobs rather than working as self-employees. Another factor which affects entrepreneurship is firm size (SIZE). The significant and negative coefficient of firm size is as expected.

In 3SLS_NE2, employment growth (GREMP) and number of new jobs created (WORKER) have the same relationships as in 3SLS_NE1. Growth in entrepreneurship (GRENT) has a positive relationship with per capita income (GRPCI) which means that counties with high growth rates of self-employed population have high per capita income growth compared to counties that have a higher proportion of waged and salaried labor force. However, the 
coefficient of GRPCI is insignificant. The poverty rate (POVERTY) has a significant and negative relationship with entrepreneurship growth (GRENT) as expected. The significant and Table 5.1.8: Three Stage Least Squares Results of Growth in Entrepreneurship

\begin{tabular}{|c|c|c|c|c|}
\hline \multirow[t]{2}{*}{ Variables } & \multicolumn{2}{|l|}{ 3SLS_NE1 } & \multicolumn{2}{|l|}{ 3SLS_NE3 } \\
\hline & Coefficient & z-stat & Coefficient & z-stat \\
\hline GREMP & $3.93488 * * *$ & 2.50 & 3.621377 & 1.40 \\
\hline GRPCI & -.5110726 & $\mid-0.82$ & .106767 & 0.22 \\
\hline PCIBASE & -.4768187 & -1.17 & .365146 & 1.40 \\
\hline ENTBASE & $2.809231 * * *$ & 2.35 & .4238344 & 0.51 \\
\hline POVERTY & -.0017635 & \begin{tabular}{|l|l|}
-0.17 \\
\end{tabular} & $-.0201494 * * *$ & -2.86 \\
\hline START & -.4999718 & \begin{tabular}{|l|}
-0.93 \\
\end{tabular} & $-.6355234 *$ & -1.82 \\
\hline WORKER & $-.0801815^{*}$ & $\mid-1.74$ & $-.0428099 *$ & -1.62 \\
\hline SURVIVAL & .1598513 & 0.21 & -.2636774 & -0.44 \\
\hline DEATH & .364452 & \begin{tabular}{|l|l|}
0.68 \\
\end{tabular} & .470825 & 1.18 \\
\hline SIZE & $-2.421913^{* *}$ & -2.09 & -.1828506 & -0.24 \\
\hline EXPAND & -.8312544 & $\mid-0.96$ & -.7925024 & -1.32 \\
\hline METRO & & & $-.2173202 * *$ & -2.28 \\
\hline METROADJ & & & $-.1635648^{*}$ & -1.86 \\
\hline $\mathrm{N}$ & 135 & & 299 & \\
\hline $\mathrm{R}^{2}$ & 0.2869 & & 0.4581 & \\
\hline
\end{tabular}

negative coefficients of start of new firms (START) and new jobs created (WORKER) indicate a decline in self-employed growth rate. The significant and negative coefficient of a dummy variable for counties those are adjacent to metro counties (METROADJ) shows that entrepreneurship growth is slower in non-metro counties that are adjacent to metro counties. However, a dummy variable for metro (METRO) is significant and negative relationship with entrepreneurship growth which shows that metro counties have slower rate of growth of selfemployed. 


\subsection{Spatial Model Results}

The empirical results presented in previous section were established upon a no spatial dependence assumption. It is discussed earlier that ignoring space when data are collected from regions located in space is not reasonable. The empirical results will be biased and inconsistent without considering spatial dependence. This section provides estimation results of the spatial model developed in Chapter 4. The Spatial Durbin Model (SDM) analyses spillover effects by including spatial lags for dependent and independent variables and is used as a method of spatial analysis. This model captures the direct and indirect effects of entrepreneurship in regional economic development.

The interpretation of the coefficients in spatial model is important. In order to interpret variables, this study follows Kirby and LeSage (2009) who states that in the spatial model, changes in the independent variables $\mathrm{x}_{\mathrm{i}}$ are represented by a direct effect on the county"s marginal regional economic development and a spatial spillover (indirect) effect on neighboring countieses marginal regional economic development. This study estimates two cases as nonspatial models. First, the model is estimated using entrepreneurship represented by new firm

formation as a measure. Second a separate estimation is made using entrepreneurship represented by self-employment as a measure. For comparison, the results of the estimation of population density growth, employment growth, and per capita income growth equation of self-employment measure are given in an appendix. The strength of the estimated spatial dependence is measured by rho which is given in Table 5.2.1. 
Table 5.2.1: Estimated Value of the Spatial Dependence Statistic, RHO

\begin{tabular}{|c|c|c|c|c|}
\hline \multirow{2}{*}{ Equations } & \multicolumn{2}{|c|}{ New Firm Formation } & \multicolumn{2}{c|}{ Self-employment } \\
\cline { 2 - 5 } & RHO & P-level & RHO & P-level \\
\hline GRPOP & 0.403997 & 0.000000 & 0.413986 & 0.000000 \\
\hline GREMP & 0.527967 & 0.000000 & 0.543980 & 0.000000 \\
\hline GRPCI & 0.366989 & 0.000004 & 0.589942 & 0.000000 \\
\hline GRENT & 0.485946 & 0.000000 & 0.495995 & 0.000000 \\
\hline N & \multicolumn{2}{|c|}{299} & \multicolumn{2}{c|}{299} \\
\hline
\end{tabular}

\section{Spatial Results of Entrepreneurship as New Firm Formation and Economic Development \\ Relationship}

\subsubsection{Population Density Growth Equation}

The results of Spatial Durbin Model for the population growth equation are presented in Table 5.2.1. The statistically significant value (0.404) of the spatial measure (RHO) indicates the existence of spatial dependence of population density growth among counties. In terms of significance, entrepreneurship growth $(G R E N T)$ has highest direct positive effect while the initial condition of per capita income (PCIBASE) has highest effect in decreasing population growth.

The estimated results indicate that growth in entrepreneurship has a positive direct effect on population growth rate. This result indicates that an increase in demand for labor increases job opportunities due to higher entrepreneurial activities which attracts in-migration to the county and leads to an increase in population density growth. This implies "people follow jobs." The indirect effect of entrepreneurship growth is insignificant. This shows the growth of entrepreneurship in neighboring counties does not have any impact on the population growth rate in the county. This indicates population growth in neighboring counties has a positive spillover effect.

The direct effect of POVERTY is significant and negative. This shows that a high poverty level discourage people to reside in the county and encourages out-migration. The spillover 
effect of POVERTY is also significant and negative which explains that population growth in a county does not get any benefits from neighboring counties. The direct effect of the crime rate is

Table 5.2.1: SDM results for Growth in Population Density Equation

\begin{tabular}{|l|l|l|l|}
\hline Variable & Direct Effect & Indirect Effect & Total Effect \\
\hline GRPCI & 0.004118 & 0.057826 & 0.061943 \\
\hline GRENT & $0.188522^{*}$ & 0.102157 & $0.290679^{*}$ \\
\hline POPBASE & $-0.074284^{* *}$ & 0.028720 & -0.045564 \\
\hline EMPBASE & $-0.085223^{*}$ & -0.127792 & $-0.213014^{* *}$ \\
\hline PCIBASE & $-0.261404^{*}$ & 0.135318 & -0.126086 \\
\hline ENTBASE & $0.135329^{*}$ & 0.082671 & 0.218000 \\
\hline POVERTY & $-0.002177^{*}$ & $-0.002959 * * *$ & $-0.005135^{*}$ \\
\hline CRIME & $0.012449^{*}$ & -0.000135 & 0.012314 \\
\hline EGOV & $-0.015701^{*}$ & -0.007430 & -0.023131 \\
\hline PCITAX & -0.005125 & -0.020362 & $-0.025486^{* * *}$ \\
\hline CMHV & $0.173896^{*}$ & $-0.135057^{* * *}$ & 0.038838 \\
\hline METRO & $0.009812^{* *}$ & $0.039908 * *$ & $0.049720^{*}$ \\
\hline \multicolumn{5}{|l|}{} & & \\
\hline RHO & $0.403997^{* * *}$ & & \\
\hline SIGMA ${ }^{2}$ & 0.0008 & & \\
\hline$R^{2}$ & 0.6864 & & \\
\hline Note: $* * * *$, and & represent $1,5,10 \%$ significance, respectively \\
\hline
\end{tabular}

significant and positive which indicates that as the crime rate increases the population growth rate also increases which is unexpected. The direct effect of the initial condition of population growth is negative indicating convergence in population growth in the county. A county with high population density in 1993 was growing slower compared to those with low population densities. The significant and positive direct effect of a county"s median housing value implies that population density growth is higher where median housing value is high.

A high per capita income tax in the region has a significant and negative total effect on population growth. The initial condition of entrepreneurship has a significant and positive direct effect on population density growth. This implies that counties with a large numbers of firms in 
1993 grew more slowly than counties that had few firms in 1993. An increase in housing prices attracts people to real-estate business especially to residential real-estate business which creates job opportunities and encourages in-migration. The significant and positive direct, indirect, and total effects of a dummy variable for metro (METRO) shows that population grows faster in metro counties in the region. However, this growth is not very high due to the coefficients of direct, indirect, and total effects which are close to zero.

\subsubsection{Employment Growth Equation}

The results of the Spatial Durbin Model for the employment growth equation are presented in Table 5.2.2. The statistically significant value (0.528) of the spatial measure (RHO) represents the existence of spatial dependence of employment growth among counties. In terms of significance, a county"s median housing value $(C M H V)$ has highest direct positive effect while the initial condition of per capita income (PCIBASE) has highest effect in decreasing employment growth.

The estimated results indicate that growth in entrepreneurship has a positive direct and indirect effect on employment growth. This shows an increase in new created jobs in the county and in neighboring counties due to new firm formation leads to an increase in employment growth. Per capita income growth has a significant and positive indirect effect on employment growth. This indicates that an increase in per capita income in neighboring counties leads to increases in demand for goods and services and encourages entrepreneurs to start new firms which ultimately increase employment growth. The value of RHO which also represents the coefficient of employment growth in neighboring counties is significant and positive. This indicates employment growth in neighboring counties has positive spillover effects. The coefficient of a county ${ }^{\text {ees }}$ median housing value significantly and negatively affects employment growth in the county. 
The positive direct effect of a county"s median housing values shows that entrepreneurs are attracted to new business which leads to increase employment. A high per capita income tax has negative spillover effects on employment growth. The significant and positive direct, indirect, and total effects of a dummy variable for metro (METRO) shows that there are growth injob opportunities available in metro counties compared to rural counties in the region.

\section{Table 5.2.2: The SDM Results of Employment Growth Equation}

\begin{tabular}{|c|c|c|c|}
\hline Variable & Direct Effect & Indirect Effect & Total Effect \\
\hline GRPCI & 0.009587 & $0.115334 * *$ & $0.124920^{* *}$ \\
\hline GRENT & $0.140625 *$ & $0.152278^{* * *}$ & $0.292903 *$ \\
\hline EMPBASE & -0.028896 & -0.049831 & -0.078727 \\
\hline PCIBASE & $-0.174805^{*}$ & 0.117395 & -0.057410 \\
\hline PCITAX & 0.000877 & $-0.038895 * * *$ & $-0.038018 * * *$ \\
\hline EGOV & -0.006136 & 0.006888 & 0.000752 \\
\hline NFIRM & 0.006862 & -0.008736 & -0.001874 \\
\hline $\mathrm{CMHV}$ & $0.214600 *$ & -0.018820 & $0.195780 *$ \\
\hline ROADDEN & -0.019198 & 0.005428 & -0.013769 \\
\hline COLLD & 0.000606 & 0.001387 & 0.001993 \\
\hline METRO & $0.011132^{* *}$ & $0.062402^{*}$ & $0.073533 * *$ \\
\hline RHO & $0.527967 * * *$ & & \\
\hline SIGMA $^{2}$ & 0.0009 & & \\
\hline $\mathrm{R}^{2}$ & 0.5824 & & \\
\hline
\end{tabular}

\subsubsection{Per Capital Income Growth Equation}

The results of Spatial Durbin Model for the per capita income growth equation are presented in Table 5.2.3. The statistically significant value (0.367) of the spatial measure (RHO) represents the existence of spatial dependence of per capita income growth among counties. In terms of significance, entrepreneurship growth (GRENT) has highest direct positive effect while the number of exiting firms (NFIRM) has largest effect in decreasing per capita income growth. 
The estimated results indicate that growth in entrepreneurship has a positive and direct effect on per capita income growth. This implies that higher entrepreneurial activities increases per capita income in a county by reducing unemployment or under-employment. The value of RHO which also represents the coefficient of per capita income growth in neighboring counties is significant and positive. This indicates per capita income growth in neighboring counties has positive spillover effect. Unemployment and per capita government expenditures have negative direct effects on per capita income growth. This shows that due to a high unemployment rate local government expenditures might increase which leads to lower per capita income growth.

Table 5.2.3: The SDM Results of Per Capita Income Growth Equation

\begin{tabular}{|c|c|c|c|}
\hline Variable & Direct Effect & Indirect Effect & Total Effect \\
\hline GRENT & $0.202602 *$ & $0.149132 *$ & $0.351733^{*}$ \\
\hline PCIBASE & 0.007108 & -0.016982 & -0.009873 \\
\hline ENTBASE & $0.149042 *$ & $0.130240 *$ & $0.279283^{*}$ \\
\hline UNEMP & $-0.003350 *$ & -0.003598 & $-0.006947 *$ \\
\hline PCITAX & 0.010311 & -0.024762 & -0.014451 \\
\hline EGOV & $-0.009288 * *$ & 0.004041 & -0.005247 \\
\hline COLLD & 0.000085 & -0.001007 & -0.000922 \\
\hline NFIRM & $-0.164172 *$ & $-0.142753 * *$ & $-0.306925 *$ \\
\hline OPERATIVE & 0.161508 & 0.837442 & 0.998950 \\
\hline RETIRE & $-0.081441^{*}$ & 0.026320 & -0.055121 \\
\hline METRO & 0.005199 & 0.023529 & $0.028728 * * *$ \\
\hline $\mathrm{RHO}$ & $0.366989 * * *$ & & \\
\hline SIGMA $^{2}$ & 0.0008 & & \\
\hline $\mathrm{R}^{2}$ & 0.6552 & & \\
\hline
\end{tabular}

The negative direct effect of the proportion of retired population shows that a large size of retired population in a county leads to slower growth in per capita income since a main source of income for the retired population generally is social security benefits. The positive total effect of 
a dummy variable for metro (METRO) shows per capita income growth is higher in metro counties in the region.

\subsubsection{Entrepreneurship Growth Equation}

The results of the Spatial Durbin Model for the entrepreneurship growth equation where entrepreneurship is represented by new firm formation are presented in Table 5.2.4. The statistically significant value (0.486) of the spatial measure (RHO) represents the existence of spatial dependence of entrepreneurship growth among counties. In terms of significance, survival rate of firms (SURVIVAL) has highest direct positive effect while the size of firms (SIZE) has largest negative effect in decreasing entrepreneurship growth. The value of RHO, which also represents the coefficient of entrepreneurship growth in neighboring counties, is significant and positive. This indicates entrepreneurship growth in neighboring counties has a positive spillover effect.

The direct and indirect effect of POVERTY is significant and negative. This indicates that a high poverty rate in a county and in neighboring counties discourages entrepreneurs to start new firms. A higher survival rate of firms indicates favorable business conditions in a county and entrepreneurial activities are encouraged by forming new firms. Therefore, the positive direct effect is as expected. The negative direct and spillover effect of existing firm size shows that if the size of existing firms increases due to favorable business conditions, entrepreneurial activities related to new firm formation are reduced. The positive spillover effect of dummy variable for metro $(M E T R O)$ counties shows that entrepreneurial activities are also grow faster in metro counties in the region. 
Table 5.2.4: The SDM Results of Entrepreneurship Growth Equation

\begin{tabular}{|c|c|c|c|}
\hline Variable & Direct Effect & Indirect Effect & Total Effect \\
\hline GRPCI & -0.015338 & -0.036814 & -0.052152 \\
\hline PCIBASE & -0.037982 & -0.139103 & -0.177086 \\
\hline ENTBASE & $0.069222 *$ & $0.239889 * *$ & 0.309112 \\
\hline POVERTY & $-0.002272^{*}$ & $-0.002643^{* * *}$ & -0.004915 \\
\hline INTENSITY & 0.041868 & 0.117403 & $0.159271 * * *$ \\
\hline WORKER & 0.000276 & 0.000070 & 0.000347 \\
\hline SURVIVAL & 0.201136 * & -0.069202 & 0.131935 \\
\hline DEATH & 0.001859 & 0.051229 & 0.053087 \\
\hline SIZE & $-0.088350^{*}$ & $-0.286721^{*}$ & $-0.375071 *$ \\
\hline METROADJ & -0.000724 & 0.031618 & 0.030894 \\
\hline METRO & 0.007827 & $0.057846^{* *}$ & $0.065673^{*}$ \\
\hline RHO & $0.485946^{* * *}$ & & \\
\hline SIGMA $^{2}$ & 0.0010 & & \\
\hline $\mathrm{R}^{2}$ & 0.5396 & & \\
\hline
\end{tabular}

\section{Spatial Results of Entrepreneurship as Self-employment and Economic Development Relationship}

The empirical results of first three equations; population density growth, employment growth, and per capita income growth equation when entrepreneurship represented by selfemployment are given in the appendix to make a comparison with population density growth, employment growth, and per capita income growth equation when entrepreneurship represented by new firm formation. However, the results of entrepreneurship growth equation are presented below.

\subsubsection{Growth in Entrepreneurship Equation}

The results of the Spatial Durbin Model for entrepreneurship growth equation represented by self-employment growth are presented in Table 5.2.8. The statistically significant value $(0.496)$ 
of the spatial measure (RHO) represents the existence of spatial dependence of entrepreneurship growth among counties.

The direct effect of POVERTY and survival rate of firms has same relationship with entrepreneurship represented by self-employment as with entrepreneurship represented by new firm formation. The positive direct effect of firm death rate on entrepreneurship indicates that an increase in death rate of firms reduces job opportunities in the county and encourages people to be self-employed. The positive spillover effect shows that an increase in the firm death rate in neighboring counties encourages people to be self-employed. The expansion of existing firms in

Table 5.2.8: The SDM Results of Self Employment Entrepreneurship Growth Equation

\begin{tabular}{|l|l|l|l|}
\hline Variable & Direct Effect & Indirect Effect & Total Effect \\
\hline GREMP & -0.025379 & -0.062878 & -0.088257 \\
\hline GRPCI & -0.014235 & -0.048178 & -0.062413 \\
\hline PCIBASE & 0.001493 & -0.214975 & -0.029329 \\
\hline ENTBASE & 0.095521 & -0.030822 & -0.119453 \\
\hline POVERTY & $-0.002446^{*}$ & $-0.003478^{*}$ & $-0.005924 *$ \\
\hline WORKER & 0.002068 & $0.013117^{*}$ & $0.015185^{*}$ \\
\hline SURVIVAL & $0.229986^{*}$ & 0.101117 & $0.331102^{*}$ \\
\hline DEATH & $0.065386^{* *}$ & $0.430673^{*}$ & $0.496059^{*}$ \\
\hline SIZE & -0.128817 & 0.109556 & -0.019261 \\
\hline EXPAND & -0.053002 & $-0.328489^{* * *}$ & $-0.381491^{* * *}$ \\
\hline METROADJ & -0.000700 & 0.016904 & 0.016203 \\
\hline METRO & 0.005166 & 0.034543 & 0.039709 \\
\hline \multicolumn{4}{|l|}{} \\
\hline RHO & $0.495995^{* * *}$ & & \\
\hline SIGMA ${ }^{2}$ & 0.0010 & & \\
\hline $\mathrm{R}^{2}$ & 0.5356 & & \\
\hline Note: $^{* * *}, * *$, and & represent $1,5,10 \%$ significance, respectively \\
\hline
\end{tabular}

neighboring counties provides employment opportunities in the county which is represented by a negative spillover effect on entrepreneurship in the county. The new jobs created in neighboring 
counties either by starting new firms or increasing the size of existing firms tends to encourage entrepreneurship in the county. 


\section{CHAPTER 6: SUMMARY AND CONCLUSION}

\section{Introduction}

The main objective of this study is to examine the relationship between entrepreneurship and regional economic development among counties in the northeast region of the United States. The objective is obtained by answering two types of questions: first, how much does entrepreneurship affect regional economic development? and second, how much do regional factors affect entrepreneurship? This study assumes simultaneity of endogenous variables of population density, employment, per capita income, and entrepreneurship by using three stage least squares (3SLS) the non-spatial model is estimated. The study area is the Northeast region of the United States which is composed of 12 states with 135 non-metro counties and 164 metro counties. This chapter is composed of three sections. Section 6.1 presents the summary and conclusions of the empirical results. Section 6.2 states policy recommendations. Section 6.3 presents future work related to this study.

\subsection{Summary and Conclusions}

The general conclusion of the study is that entrepreneurship is positively associated with regional economic development during 1993 to 2008. Based on the empirical analyses this study provides policy makers with information on the role of entrepreneurship in the economic development of the Northeast region, especially in the rural counties of the region.

Two econometric models were used for estimation. First, a system of four simultaneous equations using three stage least squares (3SLS) method. Second, a Spatial Durbin Model was used with a contiguity weight matrix. A database of accessibility, demographic, economic, and entrepreneurial variables of the Northeast region from 1993 to 2008 was collected. 


\subsubsection{Non-spatial Models}

In the non-spatial model, three stage-least squares with new firm formation as a measure of entrepreneurship for the Northeast region are estimated. The behavior of entrepreneurship is examined in the rural counties and whole region.

In the population growth equation, employment and entrepreneurship have positive relationships with population growth. However, per capita income has a negative relationship with population growth in rural counties of the Northeast region. A county ${ }^{\text {ee }}$ median housing value positively influences the growth in population in the rural counties of the region. Per capita income tax negatively affects growth in population in the region. Poverty rate and per capita government expenditures did not have significant effects upon population growth in the rural counties.

In the employment growth equation, population growth and per capita income growth have significant and positive relationships with employment growth. A high per capita income tax significantly increases employment growth in the region. The county's median housing value and the number of existing firms negatively influence employment growth in the region and county ${ }^{e e}$ s median housing value has a strong negative effect on employment in the rural areas.

In the per capita income growth equation, population growth negatively affects per capita income growth in the region. Entrepreneurship positively affects per capita income growth indicating that an increase in the number of firms creates more jobs which ultimately increases per capita income. However, the coefficient is insignificant. Number of self-employed labor and the share of population between 18 and 64 year have a significant and positive relationship with per capita income growth in rural areas and the region. The educational attainment significantly and negatively influences per capita income growth in the region. 
In the entrepreneurship growth equation (new firm formation), population growth positively effects entrepreneurship in rural counties and region. However, per capita income growth negatively affects entrepreneurship growth in rural counties and the region. The poverty rate in non-metro counties is negatively related to entrepreneurship showing that an increase in the poverty rate reduces the entrepreneurship. The size of firms and death rate of firms were positively related with entrepreneurship growth in the rural counties. However, firms ${ }^{\text {ee }}$ density towards population has negative effects on new firm formation growth in both rural counties and the region.

A non-spatial model, three stage-least squares, with self-employment as a measure of entrepreneurship for the Northeast region was also used to analyze the rural counties and whole region. In the population growth equation, an increase in employment leads to an increase in population growth in the rural counties. The county"s median housing value positively influences the growth in population in the rural counties and the region. Start-ups of firms positively affectpopulation growth in the region. However, poverty rate negatively affects population growth in the region. The proportion of non-white population is positively related with population growth in rural counties.

In the employment growth equation, an increase in growth in population also increases employment growth in rural areas. The county"s median housing value and road density positively influenced employment growth in rural areas. Furthermore, an increase in the number of existing firms decreases employment growth in the region. The proportion of non-white population increases employment growth in the rural areas. Start of new firms and the share of population between 18 and 64 years enhance employment growth in the region. 
In the per capita income growth equation, population growth and entrepreneurship as self-employment positively affects per capita income in the region but the coefficients are not significant. The proportion of population between 18 and 64 was positively related with per capita income growth in the rural counties and region, indicating that rural counties as well as the region with large shares of population between 18 and 64 years have increased per capita income growth rates. The empirical results also indicate that educational attainment and number of existing firms have negative relationships with per capita income in the rural areas but the coefficients are insignificant.

In the entrepreneurship growth equation, employment growth positively affects entrepreneurship growth in rural counties. Per capita income growth and employment growth have positive relationships with entrepreneurship in the region but the coefficients are insignificant. Some other factors such as new jobs created and size of firms were negatively related with entrepreneurship growth in rural counties. Start-up of firms, new jobs created, and poverty rate are negatively linked with entrepreneurship in the region.

The non-spatial models are analyzed using data for non-metro counties separately and then for the whole region. The results in non-spatial impact models of entrepreneurship on regional economic development in three estimations are mixed. Entrepreneurship represented by new firm formation plays a significant role in the process of population density growth and per capita income growth. Entrepreneurship represented by self-employment does not have significant effect on any other endogenous variable, i.e., population density growth, employment growth, and per capita income growth. However, if we compare the non-spatial results of new firm formation and self-employment, the clearly new firm formation model found more 
significant impacts in regional economic development than the self-employment model in the region.

\subsubsection{Spatial Models}

The main focus of the spatial model is to estimate the relationship between entrepreneurship and economic development in the Northeast region using spatial concepts. The spatial interdependencies between regional economic development and entrepreneurship are estimated using the Spatial Durbin Model (SDM). In the spatial model, growth in population density, employment, per capita income, and entrepreneurship as endogenous variables $\left(\mathrm{Y}_{\mathrm{i}}\right)$, their spatial lags $\left(\mathrm{W}^{*} \mathrm{Y}_{\mathrm{i}}\right)$, spatial lags of independent variables $\left(\mathrm{W}^{*} \mathrm{X}_{\mathrm{i}}\right)$, and other control variables $\left(\mathrm{X}_{\mathrm{i}}\right)$ are proposed to affect regional economic development.

Entrepreneurship growth within a specific county plays a significant and direct role in population growth. A county"s median housing value and entrepreneurship growth increase population growth in the region. The spillover effect of county"s median housing value is negative on population growth. Some independent other variables such as poverty rate, local government expenditures, and per capita income tax exhibit negative direct effects on population density growth. The positive direct effect of crime rate on population density growth is unexpected.

Entrepreneurship growth within the county and also in neighboring counties positively affects employment opportunities in the region. Per capita income indirectly affects employment growth in the region. Per capita income tax has a negative spillover effect on employment growth in the typical county. A county"s median housing value directly increases the employment growth rate. Educational attainment directly increases employment but the coefficient is insignificant and close to zero. 
Entrepreneurship growth has direct effects on per capita income in the region. This shows an increase in economic development through one of its indicators in the region. Higher unemployment rates, local government expenditures, and the share of retired population lead to decreases in per capita income growth. Number of existing firm has negative direct and spillover effects on per capita income growth.

Using new firm formation as a measure of entrepreneurship, the negative direct effect of size of firms shows that as the size of firm increases entrepreneurial activities that increase the number of new firms is reduced. Higher survival rate from existing firms encourages entrepreneurial activities and enhance the number of new firms in the region. Poverty rate has negative direct and spillover effect on entrepreneurship growth. The size of firms also has anegative spillover effect on entrepreneurship growth which leads to decrease in growth of the number of new firms.

When using self-employment as a measure of entrepreneurship, the results of spatial model are a little different than from using new firm formation as a measure of entrepreneurship. Survival rate of existing firms and poverty rate have same effect as in new firm formation equation. But a higher death rate of firms in the county and neighboring counties enhances selfemployment rate in the whole region. The expansion in existing firms has a negative spillover effect on entrepreneurship indicating a decline in self-employment due to increase in expansion of existing firms in neighboring counties.

As indicated in chapter five, the spatial models are analyzed using data for the Northeast region. The results of spatial impact of entrepreneurship on regional economic development are mixed. Entrepreneurship in the county and neighboring counties plays a strong role in the process of increasing population density growth, employment growth, and per capita income 
growth. However, if we compare the spatial results of new firm formation as entrepreneurship and self-employment as entrepreneurship clearly new firm formation had stronger spatial impacts in regional economic development. In general, SDM results are consistent by explaining that entrepreneurship has positive effect on population density, employment, and per capita income growth. It is evident that changes in growth rates of population density, employment, per capita income, and entrepreneurship depend on direct effects (county"s characteristics) and indirect effects (neighboring counties ${ }^{\text {ee }}$ characteristics). The direct effects arise due to spatial dependence among the counties of the region. Therefore, the second contribution of the study consists of SDM having the ability to estimate and explain the significant role of indirect effects in the regional economic development.

\subsection{Policy Recommendations}

Based on the empirical results of this study some recommendations can be proposed to provide information to policy makers for economic development of the Northeast region of the United States.

(1) The empirical results indicate that entrepreneurship is positively related to regional economic development from 1993 to 2008. Entrepreneurial activities should be encouraged. Since the findings show that survival rate, death and size of firms significantly affect regional economic development. Therefore, policy makers should identify and develop policies that enhance entrepreneurship especially in rural areas in the region.

(2) Entrepreneurial activities can be used as a weapon against poverty and unemployment in the region. The empirical findings indicate significant effects on regional economic development. The availability of cheap labor can help entrepreneurs to start businesses in non-metro areas and ultimately can help to reduce differences of per capita income 
between metro and rural areas. Here, policy makers can help to develop and implement policies that can provide information about the use and management of resources for transportation.

\subsection{Future Work}

This study can be extended in many ways. Future research can focus on significant contributions of entrepreneurship to economic development of the region.

(1) Some measures of entrepreneurship other than new firm formation and self-employment such as inventions and innovations can be used.

(2) A weight matrix other than contiguity weight matrix such as five or eight nearest neighbors, distance, and inverse distance weight matrices can be used for future work.

(3) Extension of this study using non-metro counties of the United States is also possible and logical.

(4) Other spatial models such as the spatial autoregressive model with autoregressive errors using a system of simultaneous equation is another possible extension. 


\section{REFERENCES}

Acs, Z. (2006). "How is Entrepreneurship Good for Economic Growth." Innovations, 1(1).

Acs, Z. J., Audretsch, D. B., Braunerhjelm, P., and Carlsson, B. (2005). "Growth and Entrepreneurship: An Empirical Assessment." Max Planck Institute of Economics: Discussion Paper on Entrepreneurship, Growth and Public Policy.

Acs, Z., Braunerhjelm, P., Audretsch, D., and Carlsson, B. (2009). "The Knowledge Spillover Theory of Entrepreneurship." Small Business Economics, 32(1), 15-30.

Acs, Z. J., and Armington, C. (2004). "Employment Growth and Entrepreneurial Activity in Cities." Max Planck Institute of Economics: Discussion Paper Entrepreneurship, Growth and Public Policy Group

Acs, Z. J. and Mueller, P. (2006). "Employment Effects of Business Dynamics: Mice, Gazelles, and Elephants." Max Planck Institute of Economics: Discussion Paper on Entrepreneurship, Growth and Public Policy.

Acs, Z. J. and Varga, A. (2004). "Entrepreneurship, Agglomeration and Technological Change." Max Planck Institute of Economics: Discussion Paper on Entrepreneurship, Growth and Public Policy Group.

Aghion, P., and Howitt, P. (1992). "A Model of Growth Through Creative Destruction." Econometrica, 60(2), 323-351.

Aghion, P., and Howitt, P. (1998). "Endogenous Growth Theory." Cambridge, MA: MIT Press:.

Ahmad, N., and Hoffmann, A. (2008). "A Framework for Addressing and Measuring Entrepreneurship." OECD Statistics Working Papers.

Andersson, D. (2005). "The Spatial Nature of Entrepreneurship." Quarterly Journal of Austrian Economics, 8(2), 21-34.

Andersson, M., and Noseleit, F. (2008). "Start-Ups and Employment Growth - Evidence from Sweden." Working Paper Series in Economics and Institutions of Innovation, Royal Institute of Technology, CESIS - Centre of Excellence for Science and Innovation Studies.

Anselin, L. (1988). "Spatial Econometrics: Methods and Models." Cambridge MA: MIT Press

Anselin, L. and Bera, A. K. (1998). "Spatial Dependence in Linear Regression Models with an Introduction to Spatial Econometrics." In AmanUllah and David Giles (Eds.).Handbook of Applied Economic Statistics (pp. 237-289). New York: Marcel Dekke

Armington C. and Z.J. Acs (2002). "The Determinant of Regional Variation in New Firm Formation." Regional Studies, 36: 1, 33-45 
Audretsch, D. B. (1995). "Innovation and Industry Evolution.” Cambridge, MA: MIT Press

Audretsch, D. B., and Fritsch, M. (2002). “Growth Regimes over Time and Space.” Regional Studies, 36(2), 113-124.

Audretsch, D., and Keilbach, M. (2004). "Entrepreneurship Capital and Economic Performance." Regional Studies, 38(8), 949 - 959.

Audretsch, D. B., and Keilbach, M. (2006). "Entrepreneurship as Conduit for Knowledge Spillover: A Panel Analysis of Spatial Interaction for Germany." Presented at ADRES International Conference, France.

Audretsch, D. B., and Keilbach, M. (2007). "The Theory of Knowledge Spillover Entrepreneurship." Journal of Management Studies 44(7)

Audretsch, D. B., Feldman, M. P., Henderson, J. V., and Jacques-François, T. (2004). "Knowledge Spillovers and The Geography of Innovation." Handbook of Regional and Urban Economics4, 2713-2739

Audretsch, D. B., and Lehmann, E. E. (2005). "Does the Knowledge Spillover Theory of Entrepreneurship hold for Regions"? Research Policy, 34(8), 1191-1202.

Baltagi, B. and Liu, L. (2011). "Instrument Variable Estimation of A Spatial Autoregressive Panel Model with Random Effects." Working Paper No. 127: Center for Policy Research

Baptista, R., Escária, V., and Madruga, P. (2008). "Entrepreneurship, Regional Development and Job Creation: The Case of Portugal.” Small Business Economics, 30(1), 49-58.

Baumol, W. J. (1968). "Entrepreneurship in Economic Theory." American Economic Review, $58(2), 64$.

Baumol, W. J. (1988). "Entrepreneurship: Productive, Unproductive and Imitative: or the Rule of the Rules of the Game." Working Papers: C.V. Starr Center for Applied Economics, New York University.

Baumol, W. J. (1990). "Entrepreneurship: Productive, Unproductive, and Destructive." The Journal of Political Economy 98(5).

Baumol, W. J. (1996). "Entrepreneurship: Productive, Unproductive, and Destructive.” Journal of Business Venturing, 11(1), 3-22.

Berner, E., Gómez, G. M., and Knorringa, P. (2008). "Helping a Large Number of People Become A Little Less Poor ${ }^{\text {ee }}$ The Logic of Survival Entrepreneurs." Paper Presented at 
the UNU-WIDER Workshop on Entrepreneurship and Economic Development, Helsinki, Finland, 21-23, August

Bhide, A., (2000). The Origin and Evaluation of New Businesses. New York: Oxford University Press

Bianchi, M. (2010). "Credit Constraints, Entrepreneurial Talent, and Economic Development." Small Business Economics, 34(1), 93-104.

Blanchflower, D. G. (2000). "Self-employment in OECD Countries." Labour Economics, 7(5), 471-505.

Blau, D. M. (1987). "A Time-Series Analysis of Self-Employment in the United States." The Journal of Political Economy, 95(3), 445-467.

Boarnet, M. G. (1994). "An Empirical Model of Intrametropolitan Population and Employment Growth.” Regional Science, 73(2), 135-153.

Brueckner, J. K. (2003). "Strategic Interaction Among Governments: An Overview of Empirical Studies." International Regional Science Review, 26(2), 175-188.

Cabarcos, M. Á. L., and Rodríguez, P. V. (2006). "Enterprising Vocation in Europe: The Spanish Case." International Journal of Entrepreneurship 10, 71.

Carod, J., D. Liviano Solís, and M. Bofarull (2008). "New Business Formation and Employment Growth: Some Evidence for the Spanish Manufacturing Industry." Small Business Economics, 30, 73-84.

Carlino, G. A., and Mills, E. S. (1987). "The Determinants of County Growth." Journal of Regional Science, 27(1), 39.

Carree, M. A., Van Stel, A., Thurik, R., and Wennekers, S. (2000). "Economic Development and Business Ownership: An Analysis Using Data of 23 OECD Countries in the Period of 1976-1996." Small Business Economics 19: 271-290.

Castro, S. D. (1998). "Technological Implications of New Growth Theory for South." Cooperation South

Choi, Y., and Phan, P. (2006). "The Influences of Economic and Technology Policy on the Dynamics of New Firm Formation." Small Business Economics, 26(5), 493-503.

Cortright, J. (2001). "New Growth Theory, Technology and Learning: A Practitioner's Guide." Reviews of Economic Development Literature and Practice.

Coyne, C. J., and Leeson, P. T. (2004). "The Plight of Underdeveloped Countries." Cato Journal, 24(3), 235-249. 
Dabson, B. (2008). "Entrepreneurs, Entrepreneurship and Regional Development." Presented in Australian Regional Economies Conference, Terrigal, NSW.

De Clercq, D., Hessels, J., and van Stel, A. (2008). "Knowledge Spillovers and New Ventures' Export Orientation." Small Business Economics, 31(3), 283-303.

Dejardin, M. (2000). "Entrepreneurship and Economic Growth: An Obvious Conjunction"? Institute for Development Strategies.

Deller, S.C. and Lledo, V. (2007). "Amenities and Rural Appalachia Economic Growth." Agricultural and Resource Economic Review36, 107-132.

Deller, S. C., Tsai, T.H., Marcouiller, D. W., and English, D. B. K. (2001). "The Role of Amenities and Quality of Life in Rural Economic Growth." American Journal of Agricultural Economics, 83(2), 352-365.

Dinopoulos, E., and Şener, F. (2007). "New Directions in Schumpeterian Growth Theory." Forthcoming in Horst Hanusch and Andreas Pyka (eds.), Elgar Companion to NeoSchumpeterian Economics, Edward Elgar, Cheltenham.

Eamets, R., Masson, J., and Philips, K. (2005). "Job Creation and Job Destruction in Estonia: Labour Reallocation and Structural Changes." Discussion Paper, Institute for the Study of Labor

Earle, J. S., and Sakova, Z. (2000). "Business Start-ups or Disguised Unemployment? Evidence on the Character of Self-Employment from Transition Economies." Labour Economics, 7(5), 575-601.

Elhorst, J. P. (2009). Spatial Panel Data Models. In Fischer MM, Getis A (Eds.) Handbook of Applied Spatial Analysis, pp. 377-407. Springer: Berlin Heidelberg New York.

Fölster, S. (2000). "Do Entrepreneurs Create Jobs?" Small Business Economics, 14(2), 137-148.

Freytag, A., and Thurik, R. (2007). "Entrepreneurship and Its Determinants in a Cross-Country Setting. Scientific Analysis of Entrepreneurship and SMEs.

Fritsch, M. (1997). "New Firms and Regional Employment Change." Small Business Economics, 9(5), 437-448.

Fritsch, M., and Mueller, P. (2004). "Effects of New Business Formation on Regional Development over Time." Regional Studies, 38(8), 961-975.

Gebremeriam, G.H., (2006). "Modeling Small Business Growth, Migration Behavior, Local Public Services and Median Household Income in Appalachia: A Spatial Simultaneous Equations Approach." Ph. D.Dissertation, West Virginia University. 
Geroski, P. A. (1995). "What Do We Know About Entry?" International Journal of Industrial Organization, 13(4), 421-440.

Glaeser, E. L., Kallal, H. D., Scheinkman, J. A., and Shleifer, A. (1992). "Growth in Cities." The Journal of Political Economy, 100(6), 1126-1152.

Goetz, S. (1999). "Rural Development Issue in the Northeast: 2000 - 2005." Rural Development Paper No. 2: The Northeast Regional Center for Rural Development.

Goetz, S. J., Partridge, M., and Deller, S. C. (2009). "Evaluating Rural Entrepreneurship Policy." Rural Development Paper no. 46: The Northeast Regional Center for Rural Development.

Gries, T., and Naudé, W. (2008). "Entrepreneurship and Regional Economic Growth: Towards A General Theory of Start-Ups." UNU-WIDER, United Nations University.

Hamilton, B. H. (2000). "Does Entrepreneurship Pay? An Empirical Analysis of the Returns of Self-Employment." The Journal of Political Economy, 108(3), 604-631.

Henderson, J. (2006). "Understanding Rural Entrepreneurship at the County Level: Data Challenges." Presented at the Frameworks for Entrepreneurship Research in Food, Agriculture and Rural Development Workshop.

Henrekson, M. (2007). "Entrepreneurship and Institutions.'IFN Working Paper No. 707: Research Institute of Industrial Economics.

Herrick, B. and Kindleberger, C. P. (1983), The Theory of Economic Development. Harvard University Press.

Hudson, R. L., Moran, N., and Wrobel, P. (2007). "High-Growth Entrepreneurship The Policy Challenge for Europe." Report of a Roundtable Discussion: The Science|Business Innovation Board.

Iyigun, M. F., and Owen, A. L. (1999). "Entrepreneurs, Professionals, and Growth." Journal of Economic Growth 4, 213-232.

Jhingan, M. L. (1988). Micro Economic Theory. Konark Publishers.

Jiang, N., Wang, P., and Wu, H. (2009). "Ability-heterogeneity, Entrepreneurship, and Economic Growth." Journal of Economic Dynamics and Control, 34(3), 522-541.

Jones, C. I. (1995). "R \& D-Based Models of Economic Growth." The Journal of Political Economy, 103 (4), 759-784.

Jovanovic, B (1982). "Selection and the Evolution of Industry.” Econometrica, 50 (3), 649-670. 
Kahsai, M. S. (2009). "An Analysis of Amenity-Led Rural Economic Development in Northeast Region: A Spatial Simultaneous Equations Approach.” Ph.D. Dissertation, West Virginia University.

Kanbur, S. M. (1979). "Of Risk Taking and the Personal Distribution of Income." The Journal of Political Economy, 87(4), 769-797.

Kirby, D.K., and LeSage, J. P. (2009). "Changes in Commuting to Work Times Over the 1990 to 2000 Period." Regional Science and Urban Economics 39(4): 460-471.

Kindleberger, C. P. (1965). Economic Development. $2^{\text {nd }}$ ed. New York: McGraw-Hill.

Kirchhoff, B. A. and Phillips, B. D. (1988). "The Effect of Firm Formation and Growth on Job Creation in the United States." Journal of Business Venturing 3, 261-272.

Kirzner, I. M. (1973). Competition \& Entrepreneurship. The University of Chicago Press, Chicago.

Kreft, S. F., and Sobel, R. S. (2005). "Public Policy, Entrepreneurship, and Economic Freedom.'Cato Journal, 25(3), 595-616.

Kurz, H. D., and Salvadori, N. (2008). New Growth Theory and Development Economics: International Handbook of Development Economics. Cheltenham (U.K.): Edward Elgar.

Lee, J. W., and Yu, B. G. (2005). "An Endogenous Growth Model Approach to the Korean Economic Growth Factors." Presented in Korea and the World Economy, IV Conference.

Lee, S. Y., Florida, R., and Acs, Z. J. (2004). "Creativity and Entrepreneurship: A Regional Analysis of New Firm Formation." Regional Studies38 (8), 879-891.

LeSage, J. P. and Fisher, M. M. (2009). "The Impact of Knowledge Capital on Regional Total Factor Productivity." Working Paper Series, Social Science Research Network.

LeSage, J. P., and Pace, K. R. (2009). Introduction to Spatial Econometrics. Boca Raton, London and New York: CRC Press (Taylor \& Francis Group).

LeSage, J. P. and F., Manfred M. (2009). "The Impact of Knowledge Capital on Regional Total Factor Productivity.” Working Paper Series, Social Science Research Network.

Loasby, Brian J. 1999. Knowledge, Institutions, and Evolution in Economics. London: Roudedge.

Lucas, R. E. (1988). "On The Mechanics of Economic Development." Journal of Monetary Economics, 22, 3-42. 
Mandelman, F. S., and Montes-Rojas, G. V. (2009). "Is Self-employment and Microentrepreneurship a Desired Outcome?" World Development, 37(12), 1914-1925.

Mata, J., and Portugal, P. (1994). "Life Duration of New Firms." The Journal of Industrial Economics, 42(3), 227-245.

McDaniel, B. (2000). "A Survey on Entrepreneurship and Innovation." The Social Science Journal 37, 277-284

Mills, E. S., and R. Price. (1984). "Metropolitan Suburbanization and Central City Problems." Journal of Urban Economics 15(1), 1-17.

Minniti, M (2008). “The Role of Government Policy on Entrepreneurial Activity: Productive, Unproductive, or Destructive?” Entrepreneurship Theory and Practice, 779-790.

Mojica, M. (2009). "Examining the Role of Entrepreneurship in Economic Development in Appalachia." Ph.D. Dissertation. West Virginia University.

Mojica, M., Gebremedhin, T. G., and Schaeffer, P. (2009). "An Empirical Analysis of the Link Between Entrepreneurship and Economics Growth in West Virginia." Selected Paper prepared for presentation at the Southern Agricultural Economics Association Annual Meeting, Atlanta, Georgia.

Naude, W. (2008). "Entrepreneurship in Economic Development." Working Papers: World Institute for Development Economic Research (UNU-WIDER).

Newman, A. F. (2007). "Risk-bearing and Entrepreneurship." Journal of Economic Theory, 137(1), 11-26.

Nondo, C. (2009). "An Empirical Analysis of the Interactions Between Environmental Regulations and Economic Growth.” Ph.D. Dissertation. West Virginia University.

Parker, S. C. (2004). "The Economics of Entrepreneurship: What We Know and What We Don"t." Foundations \& Trends in Entrepreneurship 1, 1-55.

Pinchot, G. (1985). “Intrapreneuring: why you don't have to leave the corporation to become an Entrepreneur." New York: Harper and Row.

Plehn-Dujowich, J. M. (2009). "Endogenous Growth and Adverse Selection in Entrepreneurship." Journal of Economic Dynamics and Control, 33(7), 1419-1436.

Prusa, T. J., and Schmitz, J. A. (1991). "Are New Firms an Important Source of Innovation? : Evidence from the PC Software Industry." Economics Letters, 35(3), 339-342.

Robbins, D. K., Pantuosco, L. J., Parker, D. F., and Fuller, B. K. (2000). "An Empirical Assessment of the Contribution of Small Business Employment to U.S. State Economic Performance." Small Business Economics, 15(4), 293-302. 
Romer, P.M. (1986). "Increasing Returns and Long-run Growth.” Journal of Political Economy 94(5), 1002-37.

Romer, P. M. (1990). "Endogenous Technological Change." The Journal of Political Economy, 98(5), 71-102.

Schmitz, J. A., Jr. (1989). "Imitation, Entrepreneurship, and Long-Run Growth." The Journal of Political Economy, 97(3), 721-739.

Schultz, T. W. (1975). "The Value of the Ability to Deal with Disequilibria." Journal of Economic Literature, 13(3), 827-846.

Schumpeter, J. (1934). The Theory of Economic Development. Cambridge, MA: Harvard University Press.

Seyfried, W. (2005). "Examining the Relationship between Employment and Economic Growth in the Ten Largest States." Southwestern Economic Review 32, 13-24.

Shane, S. (2001). "Technology Regimes and New Firm Formation.” Management Science, 47(9), $1173-1190$.

Shane, S. (2006). "Introduction to the Focused Issue on Entrepreneurship." Management Science: Institute for Operations Research.

Solow, R. M. (1956). "A Contribution to the Theory of Economic Growth." The Quarterly Journal of Economics, 70(1), 65-94.

Spulber, D. F. (2008). "Entrepreneurs in the Theory of the Firm." Prepared for presentation at the 2008 AEA Annual Meetings in New Orleans in the Session titled "Entrepreneurship: Toward Useful Micro theory.

Steinnes, D. N. (1982). "Do People Follow Jobs or Do Jobs Follow People ? A Causality Issue in Urban Economics." Urban Studies, 19(2), 187 - 192.

Sweezy, P. M. (1943). "Professor Schumpeter's Theory of Innovation." The Review of Economics and Statistics, 25 (1), 93-96.

US Census Bureau, Census 2000 Summary File 1 (SF 1) 100-Percent Data, available at http://factfinder.census.gov/servlet/DatasetMainPageServlet? program=DEC\& submenuld=pop ulation_0\&_lang=en\& ts. Accessed date August, 2010.

USDA-ERS County Typology (2004), County Topology Codes, available at http://www.ers.usda.gov/catalog/CatalobByTitle.asp?PDT=1\&SON=TRUE\&LET=C\&PTD=\&A $\underline{\mathrm{RC}=\mathrm{C}}$ 
Van Stel, A., Carree, M., and Thurik, R. (2005). "The Effect of Entrepreneurial Activity on National Economic Growth.” Small Business Economics, 24(3), 311-321.

Venesaar, U. (2006). "Regional New Firms Formation and Entrepreneurship Policy in Estonia." Tallinn University of Technology and Estonian Science Fund.

Walzer, N. (1994). "Economic Development Issues." University of Wisconsin-Madison.

Wennekers, S., and Thurik, R. (1999). "Linking Entrepreneurship and Economic Growth." Small Business Economics, 13(1), 27.

Wood, G. (2003). "Staying Secure, Staying Poor: The "Faustian Bargain." World Development, $31(3), 455-471$.

Wong, P. K., Ho, Y. P., and Autio, E. (2005). "Entrepreneurship, Innovation and Economic Growth: Evidence from GEM Data." Small Business Economics, 24(3), 335-350.

Yang, T. C., and Snyder, A. R. (2007). "Population Change in the Northeast, 2000-2005." The Northeast Regional Center for Rural Development, RDP No. 39

Yenerall, J. (2008). "What Entrepreneurs Mean for Your Community, and How Entrepreneurship Can Be Fostered." Rural Development Paper No. 40: The Northeast Regional Center for Rural Development.

Yu, T. F. L. (1998). "Adaptive Entrepreneurship and the Economic Development of Hong Kong." World Development, 26(5), 897-911. 


\section{Appendix}

Table 5.2.2.1: The SDM Results of Population Density Growth Equation

\begin{tabular}{|c|c|c|c|}
\hline Variable & Direct Effect & Indirect Effect & Total Effect \\
\hline GREMP & -0.000461 & -0.201315 & -0.201776 \\
\hline POPBASE & -0.038225 & $-0.146867^{*}$ & $-0.185092 * *$ \\
\hline EMPBASE & 0.026486 & 0.807550 & 0.834037 \\
\hline PCIBASE & $-0.274653 * * *$ & -0.125564 & $-0.400217 * *$ \\
\hline ENTBASE & 0.005599 & -0.799176 & -0.793577 \\
\hline POVERTY & $-0.002668 * * *$ & $-0.005503 * * *$ & $-0.008171 * * *$ \\
\hline START & $0.078932 * * *$ & $0.243973 * * *$ & $0.322905 * * *$ \\
\hline EGOV & $-0.008838^{*}$ & -0.001103 & -0.009940 \\
\hline NFIRM & -0.086760 & -0.134692 & $-0.221452 *$ \\
\hline CMHV & $0.190793 * * *$ & $-0.179605 * * *$ & 0.011188 \\
\hline ROADDEN & -0.008045 & 0.067994 & 0.059949 \\
\hline NONWTE & 0.000197 & 0.000606 & 0.000804 \\
\hline OPERATIVE & 0.184252 & 0.603949 & 0.788201 \\
\hline METRO & 0.007479 & $0.037316^{*}$ & $0.044796 * *$ \\
\hline RHO & $0.413986^{* * *}$ & & \\
\hline SIGMA $^{2}$ & 0.0010 & & \\
\hline $\mathrm{R}^{2}$ & 0.5959 & & \\
\hline
\end{tabular}


Table 5.2.2.2: The SDM Results of Employment Growth Equation

\begin{tabular}{|l|l|l|l|}
\hline Variable & Direct Effect & Indirect Effect & Total Effect \\
\hline GRPCI & 0.008534 & 0.094923 & 0.103457 \\
\hline GRENT & -0.006923 & -0.019957 & -0.026880 \\
\hline EMPBASE & -0.023875 & -0.046881 & -0.070756 \\
\hline PCIBASE & $-0.176598 * * *$ & 0.160649 & -0.015949 \\
\hline PCITAX & -0.001030 & -0.037276 & $-0.038306 *$ \\
\hline EGOV & -0.001159 & 0.037929 & 0.036771 \\
\hline NFIRM & -0.004820 & -0.044048 & -0.048868 \\
\hline CMHV & $0.262006 * * *$ & 0.075952 & $0.337959 * * *$ \\
\hline ROADDEN & -0.022260 & 0.029751 & 0.007491 \\
\hline METRO & $0.011513 * *$ & $0.055798 * *$ & $0.067311 * * *$ \\
\hline \multicolumn{4}{|l}{} \\
\hline RHO & $0.543980 * * *$ & \\
\hline SIGMA & 0.0010 & & \\
\hline$R^{2}$ & 0.5136 & & \\
\hline Note: $* * * *$ and $*$ represent $1,5,10 \%$ significance, respectively \\
\hline
\end{tabular}


Table 5.2.2.3: The SDM Results of Per Capita Income Growth Equation

\begin{tabular}{|l|l|l|l|}
\hline Variable & Direct Effect & Indirect Effect & Total Effect \\
\hline GREMP & 0.039911 & 0.033666 & 0.073577 \\
\hline GRENT & $-0.007937 *$ & -0.005418 & -0.013354 \\
\hline PCIBASE & 0.036745 & 0.310914 & 0.347659 \\
\hline ENTBASE & $0.251214 * * *$ & $-0.425191 *$ & -0.173976 \\
\hline PCITAX & 0.010296 & -0.017203 & -0.006907 \\
\hline NFIRM & $-0.296058 * * *$ & 0.357135 & 0.061077 \\
\hline ROADDEN & -0.007892 & $0.092578 *$ & 0.084686 \\
\hline OPERATIVE & -0.070477 & 0.601855 & 0.531378 \\
\hline COLLD & 0.000697 & -0.001560 & -0.000863 \\
\hline UNEMP & $-0.003609 * * *$ & -0.005720 & $-0.009329 * *$ \\
\hline RETIRE & $-0.151861 * * *$ & 0.070410 & -0.081451 \\
\hline METRO & 0.005001 & 0.033088 & 0.038089 \\
\hline Constant & & & \\
\hline RHO & $0.589942 * * *$ & & \\
\hline SIGMA & & \\
\hline R $^{2}$ & 0.0011 & & \\
\hline Note: $* * * * *$, and & $*$ represent $1,5,10 \%$ significance, respectively \\
\hline
\end{tabular}

